DIEGO PATRICIO CALERO ARELLANO

\title{
AVALIAÇÃO NUMÉRICA E EXPERIMENTAL DE SOLUÇÕES PASSIVA E ATIVA PARA REDUÇÃO DE CHATTER EM PROCESSOS DE TORNEAMENTO USANDO MATERIAL PIEZELÉTRICO
}


DIEGO PATRICIO CALERO ARELANO

\author{
AVALIAÇÃO NUMÉRICA E EXPERIMENTAL \\ DE SOLUÇÕES PASSIVA E ATIVA \\ PARA REDUÇÃO DE CHATTER \\ EM PROCESSOS DE TORNEAMENTO USANDO \\ MATERIAL PIEZELÉTRICO
}

\author{
Dissertação apresentada à Escola de Engenharia \\ de São Carlos da Universidade de São Paulo, \\ como parte dos requisitos para a obtenção do \\ Título de Mestre em Ciências obtido \\ no programa de Engenharia Mecânica
}

Área de Concentração:

Dinâmica das Máquinas e Sistemas

Orientadora: Profa. Dra. Maíra Martins Da Silva

São Carlos
2014
ESTE EXEMPLAR TRATA-SE DA VERSÃO CORRIGIDA. A VERSÃO ORIGINAL ENCONTRA-SE DISPONIVEL JUNTO AO DEPARTAMENTO DE ENGENHARIA MECÃNICA DA


AUTORIZO A REPRODUÇÃO TOTAL OU PARCIAL DESTE TRABALHO, POR QUALQUER MEIO CONVENCIONAL OU ELETRÔNICO, PARA FINS DE ESTUDO E PESQUISA, DESDE QUE CITADA A FONTE.

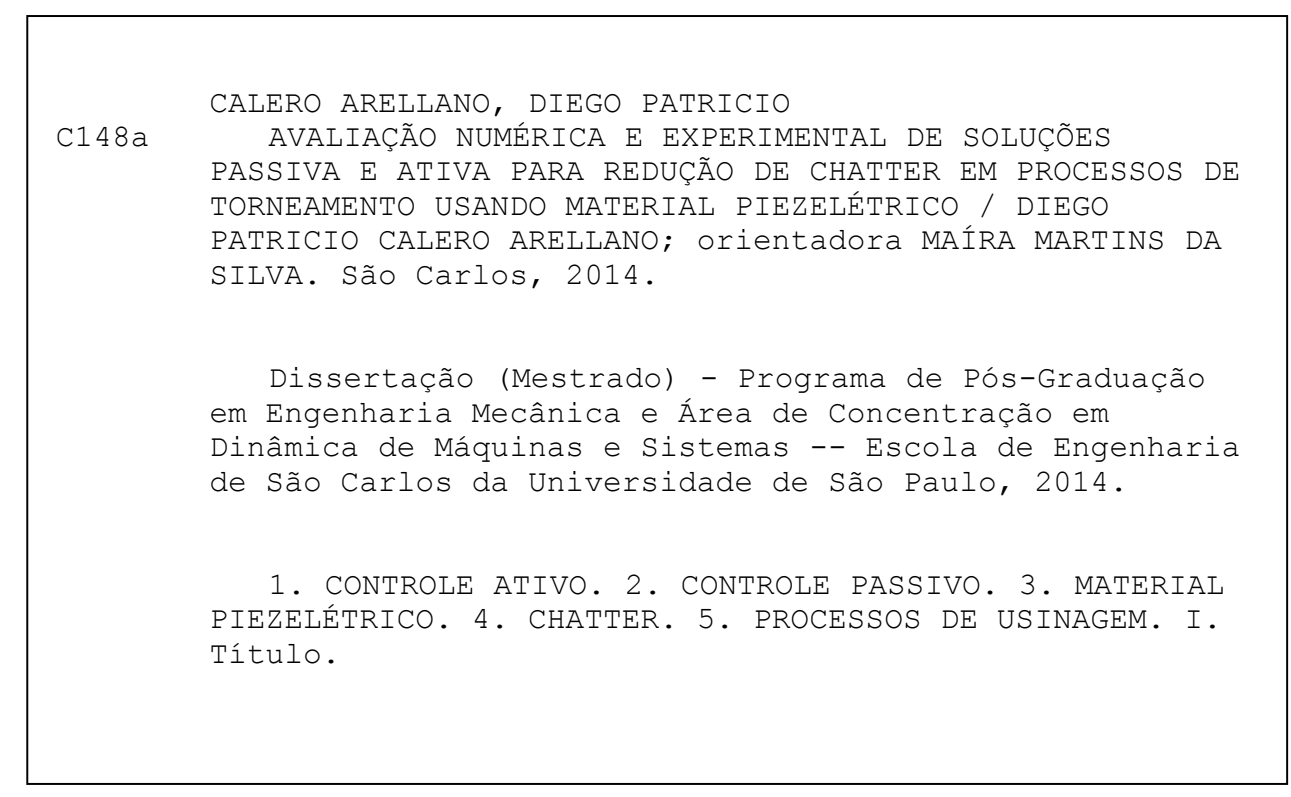




\section{FOLHA DE JULGAMENTO}

Candidato: Engenheiro DIEGO PATRICIO CALERO ARELLANO.

Título da dissertação: "Avaliação numérica e experimental de soluções passiva e ativa para redução de chatter em processos de torneamento usando material piezelétrico".

Data da defesa: $11 / 03 / 2014$

Comissão Julgadora:

Resultado:

Profa. Dra. Maíra Martins da Silva (orientadora)

APRQVAPO

(Escola de Engenharia de São Carlos/EESC)

Prof. Dr. Luiz Eduardo de Ângelo Sanchez

$\triangle P B O V A D O$

(Universidade Estadual Paulista "Júlio de Mesquita Filho"/UNESP-Bauru)

Prof. Dr. Paulo José Paupitz Gonçalves

Aprovado

(Universidade Estadual Paulista "Júlio de Mesquita Filho"/UNESP-Bauru)

Coordenador do Programa de Pós-Graduação em Engenheira Mecânica:

Prof. Associado Marcelo Areias Trindade

Presidente da Comissão de Pós-Graduação:

Prof. Titular Denis Vinicius Coury 
Dedico esse trabalho aos meus pais Rodrigo e Natalia (in memoriam), sem cujo sacrifício, dedicação e apoio, tivesse sido impossível chegar até aqui 
"Todos devem deixar algo para trás quando morrem, dizia meu avô. Um filho, um livro, um quadro, uma casa ou parede construída, um par de sapatos. Ou um jardim. [...] A diferença entre o homem que apenas apara gramados e um verdadeiro jardineiro está no toque, dizia ele. O aparador de grama podia muito bem não ter estado ali; o jardineiro estará lá durante uma vida inteira"Fragmento do livro Fahrenheit 451 de Ray Bradbury 


\section{Agradecimentos}

À Profa. Dra. Maíra Martins Da Silva pela oportunidade de trabalhar nesse projeto, pela paciência no seu trabalho de orientação, pelos conhecimento e conselhos compartilhados no mestrado, congressos e reuniões, e pela confiança e incentivo depositados na minha pessoa para a conclusão desse trabalho.

À Coordenação de Aperfeiçoamento de Nível Superior CAPES, pelo apoio financeiro brindado a través do processo DS00011/07-0.

Aos professores e funcionários do programa da Pós-Graduação em Engenharia Mecânica, pelos conhecimentos necessários para desenvolver minha pesquisa, e a ajuda brindada durante o tempo do mestrado.

Ao José Eduardo Cervelin, colega do Laboratório de Otimização de Processos de Manufatura OPF, pelas sugestões para melhorar meu trabalho e principalmente pela ajuda na parte experimental.

Aos meus amigos equatorianos que moram (ou moraram) em São Carlos: Ricardo, Juan e Irina, por compartilhar comigo esse tempo fora de casa, pelo apoio em todo momento, e pelas boas experiências vividas.

Aos colegas do Laboratório de Dinâmica, pelos comentários e sugestões no desenvolvimento do projeto, e pelo companheirismo com o qual fizeram do laboratório um bom lugar pra trabalhar.

À Carolina, pela companhia, apoio, confiança e carinho brindados durante toda esta nova experiência de vida.

À minha mãe Natalia, e ao meu pai Rodrigo pelo exemplo de entrega, sacrifício, e responsabilidade, também pelo apoio, compreensão e incentivo de superação pessoal. À minha madrasta Tatiana e aos meus irmãos Carlos, Melissa e Irina, pelo carinho, entusiasmo e confiança.

A todas aquelas pessoas que me deram sua amizade e conselhos, e que de alguma maneira motivaram meu desenvolvimento profissional neste programa de mestrado. 


\section{Resumo}

\section{CALERO AREllanO, D. P. Avaliação Numérica e Experimental de Soluções Passiva e}

Ativa para Redução de Chatter em Processos de Torneamento usando Material Piezelétrico. 2014. 113 f. Dissertação (Mestrado) - Departamento de Engenharia Mecânica, Escola de Engenharia de São Carlos, Universidade de São Paulo, São Carlos, 2014.

O chatter é o principal problema de instabilidade nos processos de usinagem, e é causado pelas ondulações deixadas na superfície durante cortes sucessivos, ou chamado processo de regeneração, e é caracterizado pelo ruído e qualidade superficial ruim nas superfícies usinadas. Portanto, a comunidade científica tem se preocupado em desenvolver ações, tanto para a predição do fenômeno, como para desenvolver estratégias para sua redução. Neste trabalho avalia-se numérica e experimentalmente, a utilização de pastilhas piezelétricas acopladas no suporte da ferramenta, e aplicando estratégias de controle passivo e ativo, procurando a redução do chatter em processos de torneamento. A solução passiva consiste em conectar os terminais das pastilhas piezelétricas a um circuito elétrico dissipador de energia. A solução ativa propõe usar uma das pastilhas como sensor e a outra como atuador para aplicar leis de controle de realimentação. $\mathrm{Na}$ avaliação numérica foi considerado um modelo eletromecânico de parâmetros distribuídos usando a teoria de viga engastada de Euler-Bernoulli, e as equações constitutivas elétricas e mecânicas do material piezelétrico. A comparação das funções de resposta em frequência (FRFs) do sistema, obtidas numericamente, mostra uma adição de amortecimento ao sistema quando é usado um circuito de dissipação com uma resistência e uma indutância como solução passiva. A avaliação numérica da solução ativa indica que o controle de realimentação de velocidade adiciona amortecimento do sistema. A melhora da estabilidade no processo de torneamento destas duas estratégias é comprovada num diagrama de lóbulos de estabilidade. Na parte experimental foram obtidas as funções de resposta em frequência do sistema suporte da ferramenta, usando um sistema de aquisição de dados, com o fim de comparar as magnitudes da resposta, e foram feitos testes de torneamento com o fim de comparar qualitativamente as qualidades superficiais obtidas nas peças usinadas. A medição das FRFs com circuitos de dissipação indicou uma atenuação da resposta para um sistema com circuito em série, estratégia que foi avaliada em testes de torneamento, e mostrando uma melhora no acabamento superficial.

Palavras-chave: controle ativo e passivo, material piezelétrico, chatter, processos de usinagem. 


\section{Abstract}

CALERO ARELlANO, D. P. Numeric and Experimental Evaluation of Passive and Active Solutions for Chatter Reduction in Turning Process using Piezoelectric Material. 2014. 113p. Dissertation (Master Degree) - Department of Mechanical Engineering, São Carlos School of Engineering, University of São Paulo, São Carlos, 2014.

Chatter is the main problem of instability in machining processes, caused by the modulations left on the surface during the successive cuts, called regeneration process, and is characterized by violent vibrations, noise and poor surface quality on machined surfaces. Thus, the scientific community has been concerned with developing actions for both the phenomenom prediction, and developing strategies to reduce them. This work evaluates numerically and experimentally the use of piezoelectric layers embedded to the tool-holder, and applying active and passive strategies trying to reduce the chatter in turning processes. For the passive case, the conductive electrode pairs of the piezoelectric layers are connected to a shunt circuit which modifies the system dynamics. The active solution proposes to use one of the piezoelectric layers as sensor an the other one as actuator, in order to apply feedback control laws. A numerical evaluation considers an electromechanical distributed parameter model based on Euler- Bernoulli cantilever beam theory, and the electrical and mechanical constitutive equations of the piezoelectric material. A comparison of the system frequency response functions (FRFs), numerically obtained, shows an increase of system damping when a resistive-inductive shunt circuit is used as a passive solution. The numerical evaluation of the active solution shows that the velocity feedback control increases the system damping. The turning process stability improvement using both strategies, is shown in a stability lobe diagram. Frequency response functions of the tool-holder system were obtained experimentally using a data acquisition system, in order to compare the response amplitudes. Turning tests were performed in order to compare surface qualities obtained of machined parts. Measurement of FRFs using series resistive-inductive shunt circuits shows a system response attenuation, later this strategy was evaluated in turning tests, showing an improvement in surface finish.

Keywords: active and passive control, piezoelectric material, chatter, turning. 


\section{Sumário}

Lista de Figuras $\quad$ ix

Lista de Tabelas $\quad$ xiii

$\begin{array}{ll}\text { Lista de símbolos } & \text { xv }\end{array}$

1 Introdução 1

1.1 Identificação do problema . . . . . . . . . . . . . . . . . . 1

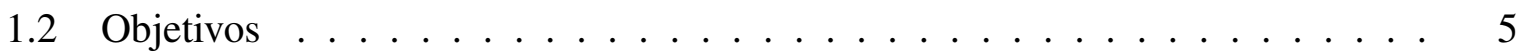

1.3 Estrutura da Dissertação . . . . . . . . . . . . . . . 6

2 Revisão Bibliográfica 9

2.1 Chatter em processos de torneamento . . . . . . . . . . . . . 9

2.1.1 O processo de regeneração . . . . . . . . . . . . . . . . . . . . . 10

2.1.2 Modelo dinâmico do suporte da ferramenta . . . . . . . . . . . . . . 11

2.1.3 Diagrama de lóbulos de estabilidade . . . . . . . . . . . . . . . . 14

2.2 Estratégias para redução do chatter . . . . . . . . . . . . . . . . . . 17

2.2.1 Estratégias passivas . . . . . . . . . . . . . . . . . . . . . . . . . . .

2.2 .2 Estratégias ativas . . . . . . . . . . . . . 20

3 Metodologia para avaliação numérica $\quad 27$

3.1 Modelo eletromecânico . . . . . . . . . . . . . . . . . . . . . 27

3.2 Solução passiva . . . . . . . . . . . . . . . . . . . . 30

3.2.1 Seleção do circuito de dissipação . . . . . . . . . . . . . . . 36

Circuito de dissipação resistivo-indutivo em série . . . . . . . . . . . . 37

Circuito de dissipação resistivo-indutivo em paralelo . . . . . . . . . . 40

3.2 .2 Indutores sintéticos . . . . . . . . . . . . . . . . . 42

3.3 Solução Ativa . . . . . . . . . . . . . . . . . . . . . . . . . 44

3.3.1 Análise do controle ativo . . . . . . . . . . . . . . . . 48

4 Metodologia para avaliação experimental $\quad 51$

4.1 Materiais e equipamentos . . . . . . . . . . . . . . . . 51

4.1.1 Máquina e materiais para usinagem . . . . . . . . . . . 51 
4.1 .2 Equipamento de medição . . . . . . . . . . . . . . . . 52

4.1.3 Características da placa de aquisição . . . . . . . . . . . . . 52

4.2 Descrição do experimento . . . . . . . . . . . . . . . . . 53

4.2.1 Circuito de condicionamento . . . . . . . . . . . . . . . 54

4.2.2 Medição da FRF . . . . . . . . . . . . . . . . . . . . . 55

4.3 Aquisição de dados solução passiva . . . . . . . . . . . . . . . . 58

4.4 Aquisição de dados solução ativa . . . . . . . . . . . . . . . . . . . . . . . 59

5 Análise de Resultados

5.1 Resultados Simulação Numérica . . . . . . . . . . . . . . . . . 61

5.1.1 Propriedades do suporte da ferramenta com camadas piezelétricas . . . 61

5.1 .2 Avaliação da solução passiva . . . . . . . . . . . . . . . . . . . 62

Circuito resistivo . . . . . . . . . . . . . . 62

Circuito capacitivo . . . . . . . . . . . . . . . 63

Circuito indutivo . . . . . . . . . . . . . . . . . . 64

Circuito resistivo-indutivo . . . . . . . . . . . . . 64

Análise do indutor sintético . . . . . . . . . . . . . . 66

Análise da estabilidade das estrategias passivas . . . . . . . . . . . . . 69

5.1 .3 Avaliação da solução ativa . . . . . . . . . . . . . . . . . . . 70

Controle de deslocamento . . . . . . . . . . . . . . . 70

Controle de velocidade . . . . . . . . . . . . . . . . 72

Análise da solução ativa pelo lugar das raízes . . . . . . . . . . . . 72

Análise da estabilidade das estrategias ativas . . . . . . . . . . 76

Comparação da estabilidade das estratégias passivas e ativas . . . . . . 77

5.2 Resultados experimentais . . . . . . . . . . . . . . . . . . . 79

5.2.1 Resultados medição FRFs ． . . . . . . . . . . . . . . . . . . 79

5.2.2 Resultados torneamento . . . . . . . . . . . . . . . 80

6 Conclusões e Sugestões para Trabalhos Futuros 83

6.1 Conclusões . . . . . . . . . . . . . . . . . . . . 83

6.2 Sugestões para trabalhos futuros $\ldots \ldots \ldots \ldots$. . . . . . . . 85

$\begin{array}{ll}\text { Referências Bibliográficas } & 87\end{array}$ 


\section{Lista de Figuras}

1.1 (a) Esquema da peça de trabalho e suporte da ferramenta (b) Processo de regeneração com corte prévio e atual durante o torneamento . . . . . . . . . . 2

1.2 Esquema da peça de trabalho, suporte da ferramenta e camadas piezelétricas . . 4

1.3 Disposição da camada piezelétrica para solução: (a) passiva e (b) ativa . . . . . 5

2.1 Processo de regeneração (modificado do Ganguli et al. (2007)) . . . . . . . . . 10

2.2 Diagrama de lóbulos de estabilidade . . . . . . . . . . . . . . . . 16

2.3 Suporte da ferramenta Silent Tools ${ }^{T M}$ A) corpo ajustável B) buchas de borracha C) liquido oleoso (retirado de Sandvik-Coromant ()) . . . . . . . . . . . . . . . 18

2.4 Modelo do suporte de ferramenta com o absorbedor dinâmico (retirado de Miguélez et al. (2010)) . . . . . . . . . . . . . . . . . . . . . . . 19

2.5 Modelo de viga engastada com material piezelétrico acoplado (retirado de Erturk e Inman (2009)) . . . . . . . . . . . . . . . . . . . . 21

2.6 Esquema do protótipo com amortecedor de massa ativo (retirado de Ganguli

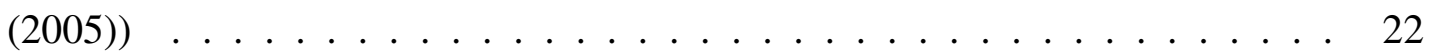

2.7 Porta-ferramenta ativo (retirado de Radecki et al. (2009)) . . . . . . . . . . . . 24

2.8 Esquema do suporte da ferramenta com fluido magneto-reológico (retirado de Mei et al. (2009)) . . . . . . . . . . . . . . . . . . . . . . . . 25

3.1 (a) Esquema do suporte da ferramenta com as camadas piezelétricas acopladas (b) Seção transversal do suporte da ferramenta . . . . . . . . . . . . . . . . . 28

3.2 Convenção dos eixos numa placa de material piezelétrico (modificada de Viana e Steffen (2006)) . . . . . . . . . . . . . . . . . . . . . 28

3.3 Esquema de viga engastada (modificada de Smirnova (2008)) . . . . . . . . . . 29

3.4 Esquema do sistema com o dispositivo piezelétrico (modificado de Hagood e Von Flotow (1991)) . . . . . . . . . . . . . . . . . . . 37

3.5 Circuito de dissipação resistivo-indutivo em série (modificado de Viana e Stef-

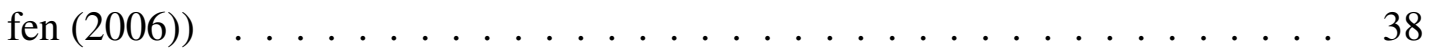

3.6 Funçao de transferência $H_{\text {ser }}(g)$ do sistema com circuito em série (retirado de Viana e Steffen (2006)) . . . . . . . . . . . . . . . . . . . . . . . 40

3.7 Circuito de dissipação resistivo-indutivo em paralelo (modificado de Viana e Steffen (2006)) . . . . . . . . . . . . . . . . . . . . . 
3.8 Funçao de transferência $H_{\text {par }}(g)$ do sistema com circuito em paralelo (retirado de Viana e Steffen (2006)) . . . . . . . . . . . . . . . . . . . 42

3.9 Circuito para um indutor sintético (modificado de Viana e Steffen (2006)) . . . 43

3.10 Controle de realimentação . . . . . . . . . . . . . . . . . . . . 48

4.1 Torno INDEX GU 600 CNC: (a) Vista geral da máquina (b) Vista do eixo de aço no fuso principal e do suporte de ferramenta com as pastilhas piezelétricas coladas ........................... 51

4.2 Equipamento para medição da FRF . . . . . . . . . . . . . . . . . 53

4.3 Placa de aquisição DS1103 . . . . . . . . . . . . . . . . . 53

4.4 Osciloscópio usado para a medição das tensões de saída durante a usinagem . . 55

4.5 Medição de tensões de saída com o circuito de condicionamento de sinal . . . . 55

4.6 Medição da FRF usando uma pastilha piezelétrica como sensor e o martelo modal como atuador . . . . . . . . . . . . . . . . . . 56

4.7 Esquema do software ControlDesk ${ }^{\circledR} 3.7 .1$ para aquisição de dados na placa

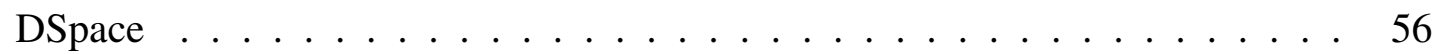

4.8 Medição da FRF usando um acelerômetro como sensor e o martelo modal como atuador ............................. 57

4.9 Software CutPro ${ }^{\circledR}$ para medição de FRF em equipamentos de usinagem . . . . 57

4.10 Circuitos de dissipação: (a) Com indutores de bobina (b) Com indutores sintéticos 58

4.11 Aquisição de dados na solução passiva . . . . . . . . . . . . . . . . . . 59

4.12 Aquisição de dados na solução ativa . . . . . . . . . . . . . . . . . 59

4.13 Aquisição de dados na solução ativo . . . . . . . . . . . . . . . . . 60

5.1 Formas modais solução passiva . . . . . . . . . . . . . . 63

5.2 FRF com circuito de dissipação resistivo . . . . . . . . . . . . . . 63

5.3 FRF com circuito de dissipação capacitivo . . . . . . . . . . . . . . . . . . . 64

5.4 FRF com circuito de dissipação indutivo . . . . . . . . . . . . . . 65

5.5 FRF com circuito resistivo-indutivo em série . . . . . . . . . . . . 65

5.6 FRF com circuito resistivo-indutivo em paralelo . . . . . . . . . . . . 66

5.7 Comparação de FRFs com circuitos resistivo-indutivos ótimos . . . . . . . . . 67

5.8 Esquema dos circuitos RL simulados no software NI Multisim ${ }^{\mathrm{TM}} 11.0$ (a) com indutor sintético $(\mathrm{b})$ com indutor ideal . . . . . . . . . . . . 68

5.9 Diagrama de bode circuito RL com indutores sintéticos e ideal . . . . . . . . 68

5.10 Comparação de impedâncias do indutor real e do indutor sintético em função da frequência . . . . . . . . . . . . . . . . . . 69

5.11 Comparação entre diagramas de lóbulos de estabilidade solução passiva . . . . 71

5.12 FRF com controle de deslocamento . . . . . . . . . . . . . . 71

5.13 FRF com controle de velocidade . . . . . . . . . . . . . . . 72 
5.14 FRF com controle de deslocamento e velocidade . . . . . . . . . . . 73

5.15 Arquitetura básica de controle considerada pela ferramenta SISOTOOL de Matlab ${ }^{\circledR} 73$

5.16 Diagrama do lugar das raízes $G_{t}(s)$ (a) Completo para os três primeiros modos (b) Detalhe para o primeiro modo . . . . . . . . . . . . . . . 74

5.17 Diagrama do lugar das raízes $G_{t}(s)$ com controle de realimentação de velocidade (a) Completo para os três primeiros modos (b) Detalhe para o primeiro modo . . . . . . . . . . . . . . . . . 75

5.18 Diagrama do lugar das raízes $G_{t}(s)$ com controle de realimentação de deslocamento e velocidade (a) Completo para os três primeiros modos (b) Detalhe para o primeiro modo . . . . . . . . . . . . . . . . 75

5.19 Diagrama de bode $G_{t}(s)$ com estrategias de controle ativo $\ldots \ldots \ldots$

5.20 Resposta ao impulso unitário para as estratégias de controle ativo . . . . . . . . 77

5.21 Comparação entre diagramas de lóbulos de estabilidade solução ativa . . . . . 78

5.22 Comparação entre diagramas de lóbulos de estabilidade soluções passiva e ativa 78

5.23 Comparação FRF circuitos em série . . . . . . . . . . . . . . . . . 80

5.24 Comparação FRF circuitos em paralelo . . . . . . . . . . . . . . . 81

5.25 Comparação FRF circuitos em série e paralelo . . . . . . . . . . . . . . 81

5.26 Comparação visual acabamento superficial peça usinada $\ldots$. . . . . . . . . . 82 


\section{Lista de Tabelas}

5.1 Dimensões e propriedades do suporte de ferramenta . . . . . . . . . . . 61

5.2 Propriedades do PZT-5A (modificado de Sinocera ()) . . . . . . . . . . 62

5.3 Valores $\lambda$ solução passiva . . . . . . . . . . . . . . . . 62

5.4 Valores de resistência e capacitância usados no indutor sintético . . . . . . . 67

5.5 Características dinâmicas soluções passivas . . . . . . . . . . . . . . 70

5.6 Características dinâmicas soluções ativas . . . . . . . . . . . . . . . 77

5.7 Valores de indutância e resistência dos circuitos de dissipação usados no expe-

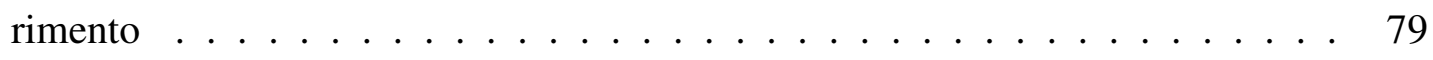




\section{Lista de símbolos}

$a$ largura de corte

$A$ área transversal

$A_{1}, A_{2}$ ganhos dos amplificadores operacionais

$b$ largura do suporte da ferramenta

$c$ coeficiente de amortecimento modal

$C$ capacitância do circuito de dissipação

$C_{p}^{S}, C_{p}^{S}$ capacitância da camada piezelétrica com deformação constante e tensão constante

$d_{31}$ constante piezelétrica

$D$ deslocamento elétrico

E campo elétrico

$F_{c}$ força de corte

$f(t)$ força aplicada no extremo livre da ferramenta

$F(s)$ força aplicada no extremo livre da ferramenta no domínio da frequência

$F R F$ função de resposta em frequência

$G(s)$ função de transferência do sistema

$G_{d}$ ganho de realimentação de deslocamento

$G_{v}$ ganho de realimentação de velocidade

$G_{t}(s)$ função de transferência que relaciona as tensões do sensor e atuador

$G_{m f}(s)$ função de transferência em malha fechada

$G_{x y}, G_{y y}$ densidades espectrais de força entre entrada e saída, e da saída

$h(t)$ profundidade de corte instantânea 
$H_{2}(\omega)$ estimador de função de resposta em frequência

$H(s)$ profundidade de corte no domínio da frequência

$H_{\text {ser }}(\gamma)$ função de resposta em frequência adimensional

$H_{r}(s)$ coordenadas normais no domínio da frequência

$h_{0}$ profundidade de corte nominal

$h_{31}$ constante piezelétrica do sensor

$h_{s}$ espessura da estrutura metálica do suporte de ferramenta

$h_{t}$ espessura total do suporte de ferramenta

$k$ rigidez

$k_{31}$ coeficiente de acoplamento eletromecânico

$K_{r}$ rigidez modal do sistema

$K_{11}^{E}$ rigidez da camada piezelétrica

$K_{31}$ coeficiente de acoplamento elétrico generalizado

$K_{f}$ pressão específica de corte

$K_{\text {lim }}$ limite de estabilidade

$L$ indutância do circuito de dissipação

$L_{e q}$ indutância equivalente do indutor sintético

$L_{o t}^{s e r}, L_{o t}^{p a r}$ indutância ótima em série e paralelo

$L_{b}$ Posição do extremo livre do suporte da ferramenta

$m$ massa

$m_{R}, m_{I}, n_{R}, n_{I}$ valores obtidos do ajuste de curvas para identificação modal

$M^{a}(x, t)$ momento do atuador

$M_{r}$ massa modal

$M(x, t)$ momento fletor

$q(t)$ carga elétrica 
$R$ resistência elétrica do circuito de dissipação

$R_{o t}^{s e r}, R_{o t}^{p a r}$ resistência ótima em série e paralelo

$S$ deformação do material

$s^{E}$ inversa do módulo de Young em campo elétrico constante

$T$ tensão mecânica

$v(t)$ tensão elétrica no domínio do tempo

$V(s)$ tensão elétrica no domínio da frequência

$v^{a c}(t)$ tensão do atuador

$v^{s e}(t)$ tensão do sensor

$w(x, t)$ deslocamento transversal no ponto $x$

$W(s)$ deslocamento transversal no domínio da frequência

$Y I$ rigidez da viga engastada

$Y$ módulo de Young

$z(t)$ impedância elétrica do circuito de dissipação no domínio do tempo

$Z(s)$ impedância elétrica do circuito de dissipação no domínio da frequência

$Z^{M E C}$ impedância mecânica do componente piezelétrico acoplado

$\alpha_{r}$ soluções da equação transcendental (solução ativa)

$\beta$ termo relacionado com os autovalores e as soluções

$\delta$ relação de ajuste adimensional

$\delta_{r s}$ função delta de Kronecker

$\delta_{o t}^{s e r}, \delta_{o t}^{p a r}$ relação de frequências ótima em série e paralelo

$\epsilon$ fator de amortecimento elétrico

$\epsilon_{o t}^{s e r}, \epsilon_{o t}^{p a r}$ fator de amortecimento ótimo em série e paralelo

$\epsilon^{T}$ constante dielétrica do material com tensão mecânica constante

$\epsilon_{33}^{S}, \epsilon_{33}^{T}$ permissividade a deformação constante e a tensão constante 
$\phi_{r}(x), \phi_{s}(x)$ formas modais

$\gamma$ frequência adimensional

$\lambda_{r}$ números adimensionais de frequência (autovalores)

$\lambda_{r e}$ parte real do autovalor complexo

$\lambda_{i m}$ parte imaginária do autovalor complexo

$\Lambda_{R}$ parte real

$\Lambda_{I}$ parte imaginária

$\omega_{c}$ frequência de chatter

$\omega_{r}$ frequência natural do sistema

$\omega_{r}^{E}$ frequência de ressonância do sistema mecânico

$\omega_{0}$ frequência de ressonância elétrica

$\Omega_{r}$ matriz de frequências naturais

$\Psi$ matriz de formas modais

$\vartheta$ termo de acoplamento

$\rho$ densidade

$\eta_{r}(t)$ coordenadas normais

$\zeta_{r}$ amortecimento modal

$\xi_{d}$ termo relacionado com o ganho de deslocamento

$\xi_{v}$ termo relacionado com o ganho de velocidade

$\chi_{r}$ termo de acoplamento modal 


\section{Capítulo 1}

\section{Introdução}

\subsection{Identificação do problema}

Os processos de usinagem envolvem variáveis físicas, tais como forças, velocidades e deslocamentos, que são o resultado da remoção do material e da energia necessária para a transformação da peça de trabalho. Estas variáveis podem ser relacionadas com o processo do ponto de vista dinâmico, devido as características flexíveis dos elementos de um sistema máquinaferramenta como o porta-ferramenta, a ferramenta ou a peça de trabalho. Por essa razão, a máquina-ferramenta apresenta vibrações que afetam direta ou indiretamente o processo de usinagem. Estas vibrações podem ser geradas por fontes externas, como o movimento do motor das máquinas ou produto da flexibilidade do conjunto da máquina-ferramenta, e que na maioria das vezes são controladas através de isolação, consideradas inicialmente no projeto da máquinaferramenta (HUO; CHENG, 2009).

Existem também vibrações geradas pelo próprio processo de usinagem. Os trabalhos de Tobias e Fishwick (1958), Tlusty e Polacek (1963) e Merrit (1965), estabeleceram as causas do chatter regenerativo e os principais critérios teóricos de estabilidade relacionados com os parâmetros de usinagem.

O chatter é o principal problema de instabilidade nos processos de usinagem, e é caracterizado por vibrações violentas, ruído e qualidade superficial ruim nas superfícies usinadas (GANGULI, 2005). Também existe desgaste excessivo da ferramenta, diminuindo as taxas de remoção de material e a vida operativa da máquina (QUINTANA; CIURANA, 2011). Todos estes problemas afetam a produtividade e o ambiente do trabalho devido à alteração do desempenho normal da máquina-ferramenta. Portanto, a comunidade científica e a industrial tem se preocupado em desenvolver ações, tanto para a predição do fenômeno do chatter durante o processo de usinagem, como para desenvolver estratégias para sua redução. Trabalhos recentes de revisão bibliográfica como aqueles do Quintana e Ciurana (2011) e do Siddhpura e Paroubally (2012) recolhem e analisam algumas estratégias de predição, redução e controle do chatter, indicando que este problema ainda é motivo da intensa pesquisa.

Quintana e Ciurana (2011) classificam o chatter em primário e secundário. O chatter primário é causado pelos efeitos do processo de corte, como o atrito entre a ferramenta e peça de 
trabalho, os efeitos termo-mecânicos na formação do cavaco ou acoplamento de modos (quando a vibração na direção de avanço gera vibrações na direção de corte). $\mathrm{O}$ chatter secundário pode ser causado pelo processo de regeneração o qual é a causa mais comum para aparição de chatter. A Fig. 1.1 (a) ilustra a ferramenta de corte, a peça de trabalho e o eixo de coordenadas utilizados no trabalho. Em cortes sucessivos, as vibrações são causadas pelo passo da ferramenta na superfície ondulada deixada pelo passo prévio como mostra o esquema da Fig. 1.1 (b). Este fenômeno ocorre para determinadas combinações de parâmetros de usinagem (profundidade de corte e velocidade de rotação da peça de trabalho).

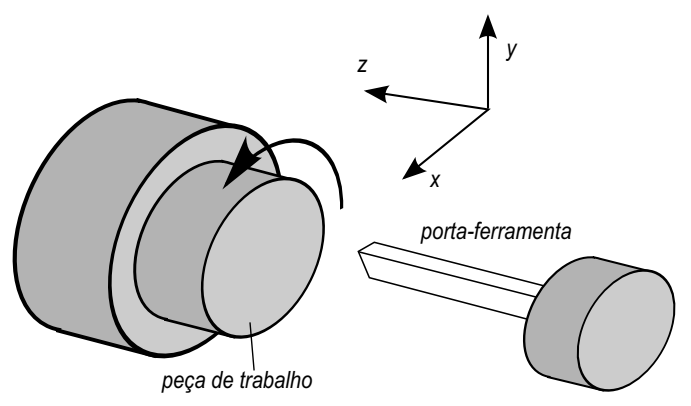

(a)

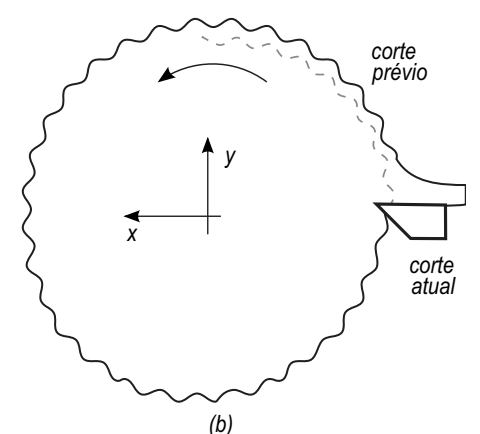

Figura 1.1: (a) Esquema da peça de trabalho e suporte da ferramenta (b) Processo de regeneração com corte prévio e atual durante o torneamento

Os procedimentos de medição, predição e análise do chatter para os diferentes processos de usinagem como torneamento, fresamento e perfuração, precisam ser estudados de maneira separada (SIDDHPURA; PAROUBALLY, 2012), assim como as estratégias selecionadas para seu controle ou redução.

O estudo do chatter num processo de usinagem tem como parte importante o desenho dos lóbulos de estabilidade, que permite aos usuários uma escolha aproximada dos principais parâmetros de corte, sendo estes: a profundidade de corte, o avanço e a velocidade de rotação (GANGULI, 2005).

Os métodos de predição e redução do chatter requerem o conhecimento do comportamento dinâmico da máquina-ferramenta, principalmente do porta-ferramenta o qual é uma parte crítica dentro do aspecto dinâmico do processo de torneamento (SMIRNOVA, 2008). Um modelo teórico pode ser obtido considerando o suporte da ferramenta como um sistema de parâmetros distribuídos e usando a teoria de vigas de Euler-Bernoulli (RAO, 1995) foi considerado por Erturk e Inman (2009). Além de usar este modelo, Smirnova (2008) fez uma comparação entre os modelos teóricos de viga de Timoshenko, um modelo de elementos finitos (FEM) e um modelo experimental de análise modal (EMA).

Também é possível obter as características dinâmicas do sistema través da medição da função da resposta em frequência (FRF), e usando técnicas de identificação modal é possível obter os principais parâmetros modais do sistema (frequências naturais e amortecimento). Smirnova (2008) colocou vários acelerômetros em posições definidas de um suporte de ferramenta para 
torneamento interno, obtendo a FRF com um equipamento de aquisição de dados. Da Silva et al. (2010) obteve experimentalmente a FRF medido no extremo livre do suporte para obter as características dinâmicas do sistema e fazer comparações de diferentes estratégias de dissipação de energia com o objetivo de reduzir o chatter.

Em ferramentas muito pequenas (por exemplo para micro-usinagem), o uso do acelerômetros e excitadores comuns não é factível pelo tamanho e a influência do equipamento usado nas medições. Sims et al. (2005) desenvolveu um sistema de medição baseado em sensores e atuadores piezelétricos colocados no suporte da ferramenta, na qual através de uma força de excitação no atuador, e um processamento de sinais, é possível obter a FRF. Park e Rahnama (2010) usaram o método de acoplamento de receptância (RC) no qual combina a medição experimental (EMA) e uma análise de elementos finitos (FEM) para obter as principais características do sistema.

Devido à dependência do chatter da velocidade de rotação da peça, este fenômeno é um dos maiores limitantes em processos onde ser requerem altas taxas de remoção de material com altas velocidades, tais como HSM (High Speed Milling). De Souza e Coelho (2007) comprovaram experimentalmente que as vibrações produzidas nas altas velocidades requeridas para usinagem de precisão (aproximadamente $21000 \mathrm{rev} / \mathrm{min}$ ), limitam o avanço da ferramenta e prejudicam o acabamento superficial.

Para processos de micro-usinagem, as altas velocidades também são um fator limitante. Park e Rahnama (2010) estudaram o efeito do chatter em processos de micro-fresamento (velocidades maiores a $30000 \mathrm{rev} / \mathrm{min}$ ) e comprovou experimentalmente a mudança dos coeficientes de corte (considerados constantes em estudos de macro-usinagem) devido as propriedades elastoplásticas da peça a usinar com certos parâmetros.

Outro fator limitante do chatter são as dimensões do suporte da ferramenta, principalmente nos processos de torneamento interno, devido à sua estrutura esbelta (SMIRNOVA, 2008). O manual do Sandvik-Coromant () ${ }^{\circledR}$ indica que os suportes com relações comprimento-diâmetro maiores a 4 vezes apresentam problemas de vibração, e propõe o uso de ferramentas silenciosas, nas quais a rigidez foi modificada reforçando o material do suporte. Nagano et al. (1997) usou barras reforçadas com fibras de carbono, modificando a rigidez do sistema e atingindo estabilidade no processo, com relações comprimento-diâmetro da ferramenta de até 7 vezes. Lee et al. (2003) desenvolveu uma barra composta para fresamento de alta velocidade onde pode se obter relações de até 10 vezes.

Existem muitas variáveis que podem ser controladas dentro do processo de usinagem, gerando assim alguns métodos para a redução do chatter, segundo Huo e Cheng (2009) esses métodos podem ser baseados na seleção de parâmetros de corte ou geometria da ferramenta ótimos, no uso de isoladores de vibrações, na modificação da rigidez e amortecimento do sistema analisado, na alteração da velocidade de corte durante o processo, ou no uso de um liquido refrigerante diferente. Esta última estrategia é usada no trabalho do Maksoud e Makbel (2012), aumentando o amortecimento na zona de contato da ferramenta-peça em processos de retifica- 
ção com um liquido refrigerante de alta viscosidade.

Segundo o trabalho do Siddhpura e Paroubally (2012), as estratégias de controle, redução e supressão do chatter podem ser classificadas em soluções ativas e passivas. As soluções passivas modificam as características do sistema, melhorando o projeto das partes da máquinaferramenta, por exemplo usando materiais compostos para o suporte da ferramenta (NAGANO $e t$ al., 1997), ou adicionando dispositivos adicionais, como no trabalho de Yang et al. (2010) onde se colocaram massas adicionais ao sistema. As soluções ativas precisam de energia adicional e o chatter é eliminado ou controlado durante o processo, alguns exemplos são o controle de velocidade de rotação durante o processo (BEDIAGA et al., 2009), ou o uso de materiais inteligentes como fluidos magneto reológicos no suporte da ferramenta (MEI et al., 2009). Os materiais piezelétricos tem sido usados ultimamente tanto para solução passiva ou ativa, sendo implementados no sistema como sensores ou atuadores (PARK et al., 2007).

Dentro das estratégias que usam materiais piezelétricos, Erturk e Inman (2009) desenvolveram um modelo eletromecânico do suporte da ferramenta para torneamento com pastilhas piezelétricas montadas na estrutura, comparando numericamente vários circuitos elétricos de dissipação (circuitos shunt) e a influência deles no amortecimento do sistema. Da Silva et al. (2010) usaram o mesmo modelo para mostrar a melhora da estabilidade do sistema no diagrama de lóbulos usando o circuito resistivo-indutivo. Baseado nos lóbulos de estabilidade, e a teoria do lugar das raízes, Ganguli (2005) fez simulações numéricas da introdução de amortecimento de forma ativa com sensores e atuadores piezelétricos para processos de torneamento e fresamento. Ast et al. (2007) também usou um atuador piezelétrico, para controle ativo de amortecimento comparando algumas técnicas de controle, aplicada a máquinas com cinemática paralela. Radecki et al. (2010) usou materiais piezelétricos no suporte da ferramenta, implementando um controle ativo no processo de usinagem, demonstrando uma melhora no acabamento superficial em experimentos de usinagem.

O presente estudo propõe avaliar numericamente e experimentalmente a utilização de pastilhas piezelétricas acopladas no suporte da ferramenta como mostra a Fig. 1.2 aplicando controle passivo e ativo para a redução do chatter em processos de torneamento .

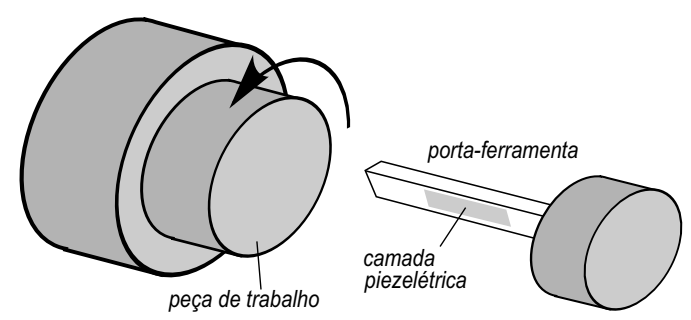

Figura 1.2: Esquema da peça de trabalho, suporte da ferramenta e camadas piezelétricas

No controle passivo, os eletrodos da camada piezelétrica são conectados a um circuito de dissipação de energia (resistivo, indutivos, ou a combinação em série ou paralelo) de impedância $Z$ ilustrado na Fig. 1.3 (a). No controle ativo uma camada piezelétrica é usada como sensor 
e a outra como atuador como mostra a fig. 1.3 (b), onde serão aplicadas leis de controle de realimentação (de deslocamento e velocidade).

(a)

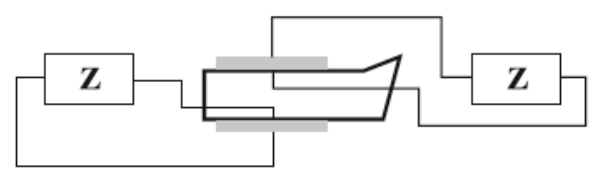

(b)

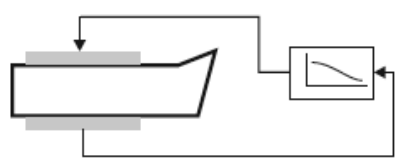

Figura 1.3: Disposição da camada piezelétrica para solução: (a) passiva e (b) ativa

O modelo eletromecânico do suporte da ferramenta para a simulação numérica é baseado no trabalho de Erturk e Inman (2008a) e Erturk e Inman (2009) para o controle passivo. O modelo para a solução ativa é baseado no trabalho de Kayacik et al. (2008). Os dois modelos são baseados na teoria de vigas de Euler-Bernoulli (RAO, 1995). A estabilidade do processo é verificada através de diagrama de lóbulos de estabilidade. Para diversas condições, o aumento de estabilidade permite uma escolha mais flexível de parâmetros de corte, como maior velocidade e profundidade de corte, tornando os processos mais produtivos e eficientes. A parte experimental propõe implementar o controle passivo e ativo usando pastilhas piezelétricas coladas no suporte de ferramenta, e comparando as respostas do sistema com ajuda de um sistema de aquisição de dados durante o processo de torneamento.

Esse estudo permite avaliar a aplicação das soluções propostas na indústria. Entre as aplicações estão o processo de torneamento interno de peças longas, no qual se aumentaria a taxa de remoção de material com melhor acabamento superficial. Estas peças são usadas em várias aplicações industriais, por exemplo componentes da indústria petroleira, canais internos em carcaças de turbinas na indústria de geração energética, êmbolos e cilindros hidráulicos, maquinaria pesada agrícola e civil, entre outras, como propõe Sandvik-Coromant () ${ }^{\circledR}$. Outra aplicação direta onde os efeitos do chatter no acabamento superficial são inaceitáveis, é a usinagem de assentamento de válvulas (BAMBERGER et al., 2011), devido ao vazamento no processo de combustão nos motores. Radecki et al. (2009) justifica o estudo do chatter na usinagem de peças feitas com materiais de alto custo (nesse caso plutônio) onde é necessária uma alta qualidade superficial.

\subsection{Objetivos}

O objetivo principal deste trabalho é avaliar numericamente e experimentalmente a utilização de pastilhas piezelétricas acopladas no suporte da ferramenta, conectando-as a um circuito de dissipação de energia como solução passiva, e usando-as como sensores e atuadores para aplicar leis de controle de realimentação como solução ativa, procurando a redução do chatter em processos de torneamento. Como objetivos específicos se tem:

- Obter modelos eletro-mecânicos com pastilhas piezelétricas acopladas que descrevam o 
comportamento dinâmico do suporte da ferramenta na solução passiva e na solução ativa.

- Avaliar numericamente o uso de material piezelétrico acoplado no suporte da ferramenta, conectado-o a um circuito elétrico dissipador de energia, e obtendo a função de resposta em frequência (FRF) do extremo livre do suporte da ferramenta.

- Avaliar numericamente o uso de material piezelétrico acoplado no suporte da ferramenta como sensor e atuador para a aplicação de leis de controle de realimentação, obtendo a FRF do extremo livre do suporte da ferramenta.

- Avaliar experimentalmente as soluções de controle passivo, usando pastilhas piezelétricas coladas no porta-ferramenta, obtendo a FRF do sistema durante o processo de torneamento de peças.

- Comparar os resultados numéricos obtidos da implementação de diversos circuitos dissipadores de energia (resistivo, indutivo, em série ou paralelo), e da aplicação de leis de controle de realimentação (deslocamento e velocidade) com diagramas de lóbulos de estabilidade.

- Comparar os resultados experimentais obtidos da implementação das soluções passivas durante a usinagem, e analisar sua efetividade como soluções de redução do chatter em processos de torneamento.

- Baseado na análise de resultados, propor metodologias para o aumento dos limites de estabilidade nos processos de torneamento, com o fim de tornar os processos mais produtivos.

\subsection{Estrutura da Dissertação}

O trabalho está organizado da seguinte maneira:

- Capítulo 2 - Revisão Bibliográfica: Encontram-se os conceitos teóricos do fenômeno chatter, a revisão de algumas estratégias de controle ativo e passivo para o aumento da estabilidade em processos de usinagem (principalmente o torneamento), e conceitos teóricos relacionados com uso de materiais piezelétricos.

- Capítulo 3 - Metodologia para avaliação numérica: Descreve-se a metodologia para obtenção de modelos matemáticos do suporte da ferramenta com as camadas de material piezelétrico acopladas, incluindo os circuitos dissipadores de energia na solução passiva, e as leis de controle de realimentação para a solução ativa.

- Capítulo 4 - Metodologia para avaliação experimental: Detalham-se os materiais, equipamentos e procedimentos de montagem necessários no desenvolvimento dos experimentos de torneamento, também o tratamento dos resultados obtidos. 
- Capítulo 5 - Análise de Resultados: Comparam-se os resultados da simulação numérica e os obtidos dos experimentos de usinagem, aplicando as diferentes estrategias de controle, assim como a discussão da efetividade das soluções passivas e ativas.

- Capítulo 6 - Conclusões e Trabalhos Futuros: Encontram-se as conclusões finais do trabalho desenvolvido e sugestões para novos projetos de pesquisa. 


\section{Capítulo 2}

\section{Revisão Bibliográfica}

Esta seção apresenta os aspectos teóricos do chatter em processos de torneamento, onde se descreve o modelo matemático do processo de corte e do fenômeno de regeneração, as diferentes formas de obter um modelo dinâmico do suporte da ferramenta e como caracterizar um processo de usinagem de acordo com os parâmetros de corte (velocidade de rotação da peça e profundidade de corte) plotando o diagrama de lóbulos de estabilidade. Também são detalhadas algumas estratégias passivas e ativas para redução e controle do chatter usadas ultimamente, principalmente aquelas que usam materiais piezelétricos.

\subsection{Chatter em processos de torneamento}

Nos processos de usinagem, onde está incluído o torneamento, aparecem vibrações devido a flexibilidade dos elementos do processo: a máquina-ferramenta, o suporte, a ferramenta de corte e a peça de trabalho. Esses vibrações podem ser livres, forçadas ou auto-excitadas (SIDDHPURA; PAROUBALLY, 2012). As vibrações livres aparecem quando existe uma carga de impacto produto de uma montagem incorreta da ferramenta em relação a peça de trabalho. As vibrações forçadas aparecem como produto de um desbalançamento das diferentes peças da máquina-ferramenta como eixos ou rolamentos. Esse dois tipos de vibrações podem ser controlados ou eliminados quando a fonte da vibração é identificada (QUINTANA; CIURANA, 2011).

As vibrações auto-excitadas são produto do processo de usinagem principalmente na interação da ferramenta com a peça de trabalho, portanto são mais complexas de controlar ou eliminar. Dependendo da fase entre dois cortes sucessivos, a espessura máxima do cavaco pode aumentar com uma frequência de chatter a qual é próxima, mas não é igual, a frequência fundamental do sistema (ALTINTAS, 2000). Segundo os trabalhos de Quintana e Ciurana (2011) e Siddhpura e Paroubally (2012) as vibrações auto-excitadas podem ser classificadas como chatter primário e chatter secundário. O chatter primário é causado pelo atrito entre a ferramenta e a peça, pelos efeitos termo-mecânicos na formação de cavaco ou pelo acoplamento de modos, o acoplamento de modos aparece quando existem vibrações em duas direções do plano de corte (ALTINTAS, 2000). O chatter secundário é causado pelo efeito do processo de regeneração que cria ondulações na superfície da peça usinada, sendo a principal causa do chatter e na qual estão focados a maioria dos estudos para seu controle, redução ou eliminação. 
O fenômeno chatter é um dos maiores problemas de instabilidade em processos de usinagem, sendo uma limitante para a qualidade e a produtividade dos processos, esta última é afetada devido a escolha de parâmetros conservativos, principalmente velocidade de rotação e profundidade de corte (DA SILVA et al., 2010). Além dos problemas mencionados, existem uma série de problemas produto do chatter como são acabamento superficial ruim, peças fora de tolerância, desgaste excessivo da ferramenta, ruído excessivo, peças da máquina-ferramenta danificadas, desperdício de energia e materiais (QUINTANA; CIURANA, 2011).

\subsubsection{O processo de regeneração}

Embora nos processos de usinagem existam forças e geometrias complexas em três dimensões, para explicar os modelos do processo de corte é usado o modelo simples em duas dimensões do corte ortogonal (ALTINTAS, 2000). Além de se trabalhar num único plano, a direção da força de corte, as características dinâmicas e a espessura do cavaco não variam com o tempo (SIDDHPURA; PAROUBALLY, 2012). Combinando certos parâmetros de usinagem (profundidade de corte e velocidade de rotação da peça) podem aparecer variações na espessura final do cavaco. Estas variações geram ondulações na superfície da peça, causando vibração do sistema no passo da ferramenta e gerando ruído. Este fenômeno é chamado de chatter regenerativo.

Baseado nos modelos de torneamento encontrados na teoria de Ganguli (2005), assume-se o porta-ferramenta como um sistema de um grau de liberdade e flexível na direção de corte como é mostrado na Fig. 2.1 segundo o sistema de coordenadas da Fig. 1.1 (a). Se $T$ é a velocidade de giro da peça, $w(t)$ e $w(t-T)$ são os deslocamentos de dois cortes sucessivos da ferramenta, $h_{0}$ é a profundidade de corte nominal (estática), também conhecida como espessura de cavaco não deformada. A profundidade de corte instantânea (dinâmica) é definida por:

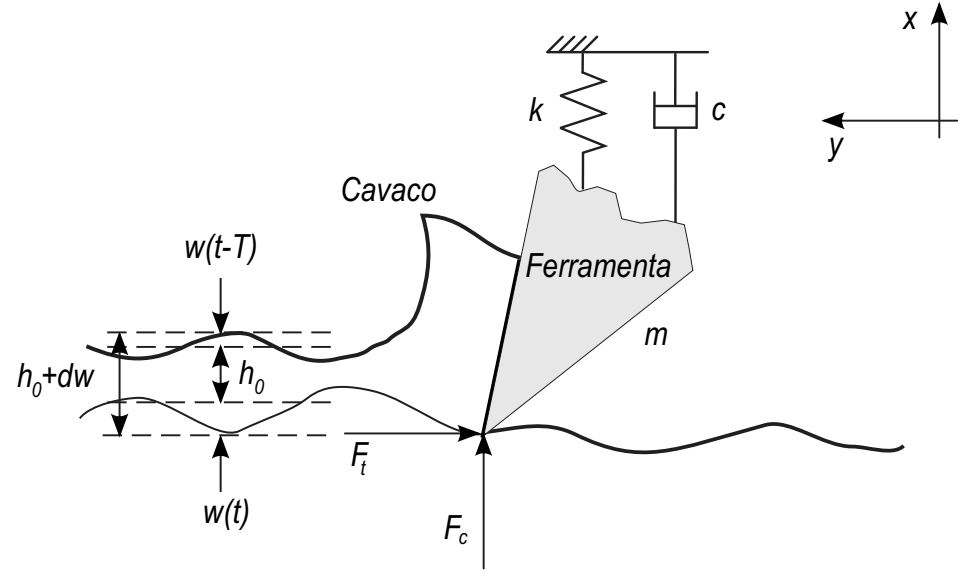

Figura 2.1: Processo de regeneração (modificado do Ganguli et al. (2007))

$$
h(t)=h_{0}+w(t-T)-w(t)
$$

Como hipótese podemos assumir que a força de corte $F_{c}$ é proporcional à área frontal do cavaco, que pode ser calculada conhecendo a largura de corte $a$, e a profundidade de corte 
instantânea $h(t)$. Obtendo assim:

$$
F_{c}(t)=K_{f} a\left(h_{0}+w(t-T)-w(t)\right)
$$

onde $K_{f}$ é o coeficiente de corte (ou pressão específica de corte), que pode ser obtida experimentalmente e que para o caso de análise é considerado constante. Este coeficiente também pode mudar dependendo da variação na espessura do cavaco e da orientação da ferramenta ou da peça de trabalho.

Os efeitos da velocidade de rotação da peça (giroscópicos e de atrito) e da geometria da ferramenta nos coeficientes de corte são considerados no trabalho de Park e Qin (2007), onde são obtidos coeficientes de corte dinâmicos usados para dar mais exatidão na modelagem dinâmica do processo de fresamento. Taylor et al. (2010) analisaram a importância da geometria da ferramenta e o mecanismo de formação de cavaco em certos materiais, comparando o acabamento superficial em ligas de titânio.

Quando existe interferência entre a face de ataque da ferramenta e a superfície ondulada deixada pelo passo prévio da ferramenta, é adicionado o amortecimento do processo, o qual reduz as vibrações do chatter (ALTINTAS, 2000). Esse fenômeno aparece comumente quando são aplicadas velocidades baixas que afetam a geometria das ondas. Eynian e Altintas (2009) consideraram uma geometria da ferramenta para gerar um modelo de três dimensões do processo dinâmico de torneamento, obtendo mudanças na área de cavaco para certos parâmetros de corte comprovando experimentalmente a influência do amortecimento de processo. O desgaste da ferramenta também pode aumentar o amortecimento de processo, como foi comprovado no trabalho de Altintas et al. (2008), no qual se fizeram experimentos de torneamento em aço inoxidável.

Considerando um sistema de um grau de liberdade mostrado na Fig. 2.1 (a), a relação entre a força de corte $F_{c}$ e o deslocamento do extremo livre do suporte da ferramenta $w$ pode ser descrito, no domínio de Laplace, pela função de transferência:

$$
G(s)=\frac{W}{F_{c}}(s)=\frac{1}{m s^{2}+c s+k},
$$

onde $m, c$, e $k$ são a massa, o coeficiente de amortecimento, e a rigidez do suporte da ferramenta respectivamente.

\subsubsection{Modelo dinâmico do suporte da ferramenta}

Para poder determinar os parâmetros ótimos para um processo de usinagem estável, ou adotar qualquer estratégia de redução ou eliminação do chatter, é necessário ter um modelo dinâmico do sistema máquina-ferramenta. A modelagem do sistema é um assunto complexo devido à quantidade de graus de liberdade, a presença de forças de corte variáveis, o comportamento não linear do mecanismo de formação de cavaco que complicam o cálculo (QUINTANA; CIURANA, 2011). Por essa razão o modelo obtido é específico para uma operação, ferramenta, 
variando unicamente a velocidade de rotação e a profundidade de corte.

Para modelar o comportamento dinâmico das máquinas-ferramenta é necessário assumir algumas hipóteses, com o fim de simplificar a análise (SIMS, 2009). A primeira é assumir um comportamento não variável no tempo, desconsiderando as mudanças nas características da dinâmica do sistema (por exemplo orientação da ferramenta ou quantidade do material) durante a usinagem. A segunda condição implica assumir que o comportamento não linear pode ser linearizado, o qual pode afetar a obtenção de modelos a partir da parte experimental. Finalmente, pode se assumir que a resposta do porta-ferramenta pode ser descrita com suficiente precisão usando um número finito de graus de liberdade, embora seja um sistema contínuo.

As propriedades dinâmicas do porta-ferramenta podem ser obtidas usando alguns métodos. Nesse trabalho o suporte da ferramenta será considerado como uma viga engastada, usando um modelo de parâmetros distribuídos. Um sistema modelado com parâmetros distribuídos considera um número infinito de graus de liberdade. A teoria de viga engastada de Euler-Bernoulli é usada por por Erturk e Inman (2009) e Da Silva et al. (2010) para obter um modelo eletromecânico do porta-ferramenta com pastilhas piezelétricas num processo de torneamento, como será visto posteriormente. O modelo também é usado por Miguélez et al. (2010) para modelar o suporte da ferramenta e observar a influência de absorvedores dinâmicos no comportamento do sistema.

O modelo de Euler-Bernoulli ignora a deformação de cisalhamento e os efeitos da inércia rotacional (RAO, 1995). Segundo Smirnova (2008), esse modelo pode ser usado para estimar as frequências fundamentais baixas e quando a geometria do porta-ferramenta é esbelta, como no caso de torneamento interno. Para o caso de vigas não esbeltas Smirnova (2008) propõe usar o modelo de vigas contínuas de Timoshenko, onde se incluem os efeitos da deformação de cisalhamento e a inércia rotacional na equação diferencial de movimento.

Os modelos de parâmetros distribuídos não consideram a influência da fixação do suporte da ferramenta com outras partes da máquina-ferramenta, que podem contribuir com a resposta não linear do sistema. Smirnova (2008) fez uma comparação com um modelo de elementos finitos do porta-ferramenta considerando estas condições de fronteira e comprovando que as frequências naturais obtidas com os modelos de viga engastada tendem a sobrestimar as frequências naturais. Nagano et al. (1997) trabalharam num modelo de elementos finitos do porta-ferramenta para obter as características dinâmicas de um porta-ferramenta feito de material composto. Mei et al. (2009) modelaram um absorvedor usando a teoria de vigas de Euler-Bernoulli para a parte dinâmica (massa e rigidez), e o modelo de elementos finitos para projetar a parte magnética do absorvedor com líquido magneto reológico.

A função da resposta em frequência (FRF) do suporte da ferramenta também pode ser obtida experimentalmente. A análise modal experimental é uma técnica que pode ser usada para verificar a exatidão dos modelos teóricos e identificar as características dinâmicas do sistema (incluindo o amortecimento). No sistema de medição existem três mecanismos básicos (MAIA; SILVA, 1998): 
- O mecanismo de excitação onde estão incluídos os excitadores eletromagnéticos ou eletro hidráulicos, conhecidos como shakers, ou martelo modal que é o mais comumente usado, entre outros. Os componentes devem ser selecionados de acordo ao material, a massa, a rigidez da estrutura a medir e a faixa de frequência. As cargas de trabalho sobre uma estrutura também podem ser consideradas como um mecanismo de excitação, como por exemplo as forças de usinagem sobre o suporte da ferramenta para a medição durante o processo. Neste caso seriam as respostas em condições operacionais.

- O mecanismo de sensoriamento onde se encontram os sensores de deslocamento, velocidade ou aceleração. O uso de acelerômetros é comum em medição de vibrações, e de igual maneira é importante selecionar a massa e a faixa de frequência dos dispositivos (ALTINTAS, 2000). Recentemente Shetty et al. (2011) desenvolveu um sistema de instrumentação láser para medição e monitoramento de máquinas-ferramenta pois os acelerômetros podem afetar as frequências naturais medidas em estruturas leves como por exemplo ferramentas pequenas de fresamento. Smirnova (2008) indica que a posição dos sensores é importante e colocou vários acelerômetros afastados dos nós das formas modais de um porta-ferramenta. Igualmente podem ser usados sensores para medição durante um processo de usinagem como transdutores piezelétricos, dinamômetros ou microfones.

- O mecanismo de aquisição e processamento de dados. Os analisadores de sinais modernos podem ser manipulados num computador. Os sinais de saída passam por filtros e são transformados de analógicos a digitais. Os analisadores mais comuns são baseados na transformada rápida de Fourier (FFT) que combinados com técnicas de janelamento e número de promédios, convertem os sinais no domínio do tempo à informação no domínio da frequência. As quantidades obtidas são usadas para construir a matriz de FRFs. A qualidade dos sinais obtidos é comprovada obtendo as funções de coerência.

Com os dados obtidos experimentalmente, podem se definir os valores das frequências e formas modais, informação sobre amortecimento para obter modelos dinâmicos mais exatos, fazer uma correlação com os modelos teóricos ou simplesmente uma comparação de magnitudes de resposta. Zhang e Sims (2005) usaram a análise modal experimental para obter as frequências modais necessárias para ajustar um controlador de vibrações piezelétrico no processo de fresamento. Radecki et al. (2009) fizeram o mesmo procedimento para um controlador num processo de torneamento.

Devido a complexidade em número de peças, geometria ou tamanho de algumas estruturas da máquina-ferramenta, tem se utilizado técnicas de acoplamento de FRFs para obter modelos dinâmicos das ferramentas. A análise de acoplamento de FRFs usa modelos de subsistemas da estrutura total obtidos com dados experimentais ou modelos teóricos (MAIA; SILVA, 1998). Park e Rahnama (2010) usou o método de acoplamento de receptância (RC) para obter características dinâmicas de ferramentas de micro-usinagem, combinando o modelo de elementos finitos e 
análise modal. Houck et al. (2011) usa também esse método para acoplar o modelo teórico do porta-ferramenta com os dados experimentais do suporte e ajustar as frequências naturais. Sims et al. (2005) desenvolveu uma alternativa com pastilhas piezelétricas colocadas na ferramenta de fresamento, usando uma delas como sensor e outra recebendo um sinal como atuador.

\subsubsection{Diagrama de lóbulos de estabilidade}

Uma técnica usada para caracterizar um processo estável ou instável baseado nos parâmetros de corte (velocidade de rotação e profundidade de corte), é a plotagem do diagrama de lóbulos de estabilidade. Usando as equações da profundidade de corte instantânea 2.1 e da força de corte 2.2 que definem o processo de regeneração, como a função de transferência da Eq. 2.3, pode se explicar a estabilidade de um processo de usinagem de comportamento linear. A espessura de cavaco, no domínio de Laplace, está definida como (ALTINTAS, 2000):

$$
H(s)=H_{0}-W(s)+e^{-s T} W(s)=H_{0}+\left(e^{-s T}-1\right) W(s)
$$

A força de corte excita a estrutura produzindo as vibrações:

$$
W(s)=F_{c}(s) G(s)=K_{f} a H(s) G(s)
$$

Usando as relações $H(s) / W(s)$ e $W(s) / H_{0}$, a relação entre as profundidades de corte dinâmica e nominal podem ser descritas como:

$$
\frac{H(s)}{H_{0}}=\frac{1}{1+K_{c u t}(s) G(s)\left(1-e^{-s T}\right)},
$$

onde $K_{c u t}(s)=K_{f} a$. A estabilidade da função de transferência do sistema em malha fechada da Eq. 2.6 depende da equação característica:

$$
1+K_{\text {cut }}(s) G(s)\left(1-e^{-s T}\right)=0
$$

Se a parte real da raiz da equação característica for positiva as vibrações do chatter aumentarão indefinidamente e o sistema será instável. Se for negativa as vibrações diminuirão com o tempo e o sistema será estável. Quando a parte real é zero $s=i \omega_{c}$ o sistema é criticamente estável, e o sistema oscila harmonicamente com uma amplitude constante à frequência de chatter $\omega_{c}$. Embora a frequência de chatter seja muito próxima da frequência natural da estrutura, não é igual desde que a função de transferência do processo de corte tem termos adicionais à função de transferência da estrutura (ALTINTAS, 2000).

Substituindo $s=i \omega_{c}$ na função de transferência da Eq. 2.3 se tem:

$$
G\left(i \omega_{c}\right)=\frac{1}{\left(k-m \omega_{c}^{2}\right)+c \omega_{c} i}=\frac{k-m \omega_{c}^{2}}{\left(k-m \omega_{c}^{2}\right)^{2}+\left(c \omega_{c} i\right)^{2}}-\frac{c \omega_{c}}{\left(k-m \omega_{c}^{2}\right)^{2}+\left(c \omega_{c} i\right)^{2}} i
$$


Assumindo uma análise de estabilidade crítica, substituindo $s=i \omega_{c}$ na equação característica da Eq. 2.7, e usando a identidade de Euler se tem (DA SILVA et al., 2010):

$$
\begin{aligned}
K_{\text {lim }}=K_{c u t}\left(i \omega_{c}\right)= & \frac{\Lambda_{R}\left(1-\cos \left(\omega_{c} T\right)\right)-\Lambda_{I} \sin \left(\omega_{c} T\right)}{2\left(\Lambda_{R}^{2}+\Lambda_{I}^{2}\right)\left(1-\cos \left(\omega_{c} T\right)\right)}- \\
& -\frac{\Lambda_{I}\left(1-\cos \left(\omega_{c} T\right)\right)+\Lambda_{R} \sin \left(\omega_{c} T\right)}{2\left(\Lambda_{R}^{2}+\Lambda_{I}^{2}\right)\left(1-\cos \left(\omega_{c} T\right)\right)} i
\end{aligned}
$$

onde $\Lambda_{R}=\operatorname{Re}\left(G\left(i \omega_{c}\right)\right)$ e $\Lambda_{I}=\operatorname{Im}\left(G\left(i \omega_{c}\right)\right)$ da Eq. 2.8. Como o valor de $K_{\text {lim }}=K_{\text {cut }}\left(i \omega_{c}\right)$ é uma propriedade física do sistema, a parte imaginária é nula. Com este conceito, pode-se obter $\omega_{c}$ e $K_{l i m}$ :

$$
\begin{gathered}
\omega_{c} T=2 p \pi-2 \tan ^{-1}\left(\frac{\Lambda_{R}}{\Lambda_{I}}\right) \quad p=1,2,3 \ldots \\
K_{\text {lim }}=-\frac{1}{2 \Lambda_{R}}
\end{gathered}
$$

Da Eq. 2.11 pode se concluir o seguinte:

- O limite de estabilidade $K_{\text {lim }}$ deve ser um valor real e positivo, portanto:

$$
\Lambda_{R}=\frac{k-m \omega_{c}^{2}}{\left(k-m \omega_{c}^{2}\right)^{2}+\left(c \omega_{c} i\right)^{2}}<0,
$$

e obtendo assim:

$$
\omega_{c}>\sqrt{\frac{k}{m}}
$$

o que significa que a frequência de chatter $\omega_{c}$ é maior que a frequência natural do sistema.

- Para aumentar o limite de estabilidade $K_{\text {lim }}$, o valor de $\Lambda_{R}$ tem que ser mais negativo. Isso pode ser realizando aumentando o amortecimento $c$ do sistema.

- Aumentando a rigidez $k$, também é possível obter um maior limite de estabilidade do processo.

Os diagramas de lóbulos de estabilidade podem ser gerados selecionando uma frequência de chatter $\omega_{c}$ na parte real negativa da função de transferência, calculando $K_{\text {lim }}$ da Eq. 2.11, e plotando esse valor em função da velocidade de rotação da peça, que pode ser calculada com o período de revolução $T$ para cada lóbulo de estabilidade $p=1,2,3 \ldots$ Um exemplo de diagrama de lóbulos é mostrado na Fig. 2.2.

Os diagramas de lóbulos de estabilidade separam regiões, onde dependendo da combinação de parâmetros de corte (velocidade da rotação da peça e profundidade de corte), o processo de usinagem é estável ou instável. Na revisão de Quintana e Ciurana (2011), os diagramas de lóbulo de estabilidade são usados na classificação das estratégias que permitem garantir um 


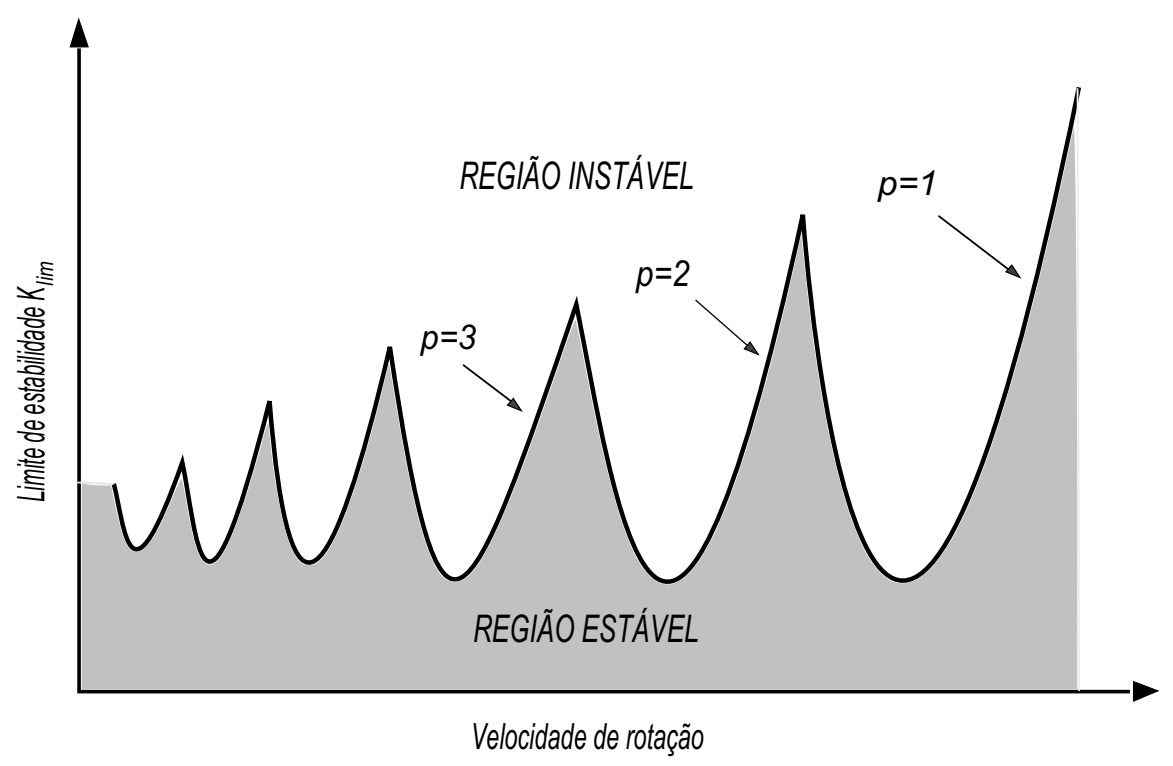

Figura 2.2: Diagrama de lóbulos de estabilidade

processo estável. Num subgrupo estão as estratégias baseadas na seleção de parâmetros fora do processo as quais são baseadas na seleção ótima de parâmetros antes de começar o processo de usinagem (predição do chatter). Isto pode ser feito usando o diagrama de lóbulos ou em cartas de estabilidade. Um exemplo é encontrado no trabalho de Lu et al. (2011) onde são elaboradas cartas de estabilidade onde o usuário possa escolher parâmetros de usinagem em processos de torneamento e fresamento. O outro subgrupo inclui as estrategias baseadas na mudança de parâmetros durante o processo. O desempenho da máquina ferramenta é medido com sensores que permitem a mudança de parâmetros automaticamente, Sims (2009), Siddhpura e Paroubally (2012) e Shetty et al. (2011) detalham alguns exemplos como dinamômetros montados na ferramenta ou na peça, também medições acústicas ou elétricas. Dentro dessas estrategias Bediaga et al. (2009) desenvolveram um assistente digital portátil que usa microfones para medir as condições de usinagem em alta velocidade, e que tem um algoritmo de detecção e diagnóstico que pode se adaptar as mudanças na velocidade de rotação da ferramenta.

A estabilidade também é analisada em outros processos de usinagem com modelos diferentes do torneamento. No processo de fresamento as forças de corte rotacionais e os períodos de corte intermitentes complicam a aplicação da teoria ortogonal. Também são encontrados efeitos giroscópicos e térmicos que reduzem o desempenho da ferramenta. No entanto, são considerados dois graus de liberdade ortogonais e a ferramenta tem ângulo de hélice zero (ALTINTAS, 2000). Novakov e Jackson (2010) estudaram o efeito do chatter em operações de furação, onde a modelagem é mais complexa devido ao aparecimento de vibrações torcionais, além das vibrações axiais. Também esclarecem as diferenças dos modelos em macro e micro usinagem, neste último caso existem problemas de exatidão devido ao modelo que não considera o efeito das propriedades elasto-plásticas e que o material não pode ser considerado homogêneo desde que existem diferenças no tamanho de grão. Os trabalhos de Park e Qin (2007) e Park e Rah- 
nama (2010) desenvolvem um critério de estabilidade robusto, no qual são considerados estes parâmetros variáveis, principalmente em operações de micro usinagem.

Os efeitos do chatter depois do processo de usinagem também tem sido estudados. $\mathrm{Na}$ indústria a detecção do chatter é necessária para dar mais objetividade ao diagnóstico do chatter e evitar aferições do usuário da máquina baseadas no som produzido ou no acabamento superficial da peça. Sims (2009) propõe uma classificação das técnicas de detecção, entre as quais estão o processamento de sinais no domínio do tempo e da frequência. Siddhpura e Paroubally (2012) detalha algumas estratégias baseadas na análise do cavaco produzido. Kelly et al. (1999) relacionaram o comportamento dinâmico do porta-ferramenta com a topografia da superfície da peça usinada. Bamberger et al. (2011) identifica as marcas do chatter na usinagem de assentamento de válvulas com o processamento e comparação geométrica de imagens das superfícies para evitar erros humanos durante a inspeção.

\subsection{Estratégias para redução do chatter}

Além das técnicas de predição onde é necessário encontrar uma zona de estabilidade no diagrama de lóbulos, existem outras estrategias para redução, controle ou eliminação do chatter. Estas estratégias procuram a modificação das características dinâmicas do sistema, (massa, amortecimento ou rigidez) e aumentar o limite de estabilidade do processo de usinagem. Segundo as revisões de Siddhpura e Paroubally (2012) e Quintana e Ciurana (2011) as estratégias podem ser classificadas em ativas ou passivas.

\subsubsection{Estratégias passivas}

As estratégias passivas mudam o comportamento dinâmico do sistema melhorando o projeto da máquina-ferramenta ou usando dispositivos adicionais para dissipar a energia produzida pelo processo de regeneração (SIDDHPURA; PAROUBALLY, 2012).

Uma das estratégias que modificam as características dinâmicas do sistema se encontra no trabalho de Nagano et al. (1997), os quais desenvolveram um suporte da ferramenta feito com material composto (plástico reforçado com fibras de carbono) para melhorar a rigidez e o amortecimento em processos de torneamento interno. Neste processo, a relação entre o comprimento e o diâmetro $(L / D)$ é crítica quando é maior que 6 , condição em que o chatter aparece. Foram feitos experimentos com vários tipos de fabricação das barras, dependendo da posição das fibras, obtendo uma maior estabilidade com relações $L / D$ maiores a 6 . Nesta mesma linha, Lee et al. (2003) experimentaram com barras de torneamento interno feitas com resina de carbono, mudando a rigidez e o amortecimento para melhorar o desempenho em relação as barras de aço (onde o chatter aparece quando $L / D=5$ ) e de carbeto de tungstênio (quando $L / D=6$ ). Experimentos de usinagem comprovaram uma melhoria no desempenho do suporte da ferramenta desde que o sistema apresentou instabilidade somente em condições superiores a $L / D=10.7$.

Modificar a geometria da ferramenta de usinagem também pode mudar as características dinâmicas do sistema da máquina-ferramenta. Yusoff e Sims (2011) obtiveram coeficientes de 
corte dinâmicos que dependem da geometria da ferramenta em processos de fresamento, usando uma análise de sistemas dinâmicos lineares retardados. A parte experimental demonstrou o aumento da estabilidade do processo variando o ângulo de hélice e o passo da ferramenta.

Entre os elementos que podem mudar a estabilidade de um processo de usinagem, está o fluido refrigerante. Maksoud e Makbel (2012) trabalharam num modelo numérico e comprovaram experimentalmente a influencia do fluido refrigerante em processos de retificação. Analisando a área de contato entre o rebolo e a peça de trabalho, a condição de estabilidade no processo está dada pela variação na pressão hidrodinâmica, a qual é criada a partir dos gradientes de velocidade do fluido refrigerante.

Para aplicações industriais, o manual de Sandvik-Coromant () ${ }^{\circledR}$ propõe algumas técnicas práticas para evitar a vibração no processo de torneamento interno, como a seleção da geometria do inserto da ferramenta (escolher o rádio de aresta segundo a profundidade de corte), a mudança do material do suporte (aço ou carbeto de tungstênio para relações $L / D$ entre 4 e 6 ), o aumento da vazão do fluido refrigerante, redução de velocidade de rotação, mudança no método de suporte (parafusos ou suportes hidráulicos). Para aplicações especiais, especificamente quando a relação $L / D$ e maior a 14 (torneamento de tubos longos) é proposta o solução de Silent Tools ${ }^{T M}$ mostrado na figura 2.3, a qual usa um dispositivo com uma massa suspensa em duas buchas de borracha, e o corpo ajustável, segundo valores em tabelas, está rodeado por um líquido oleoso.

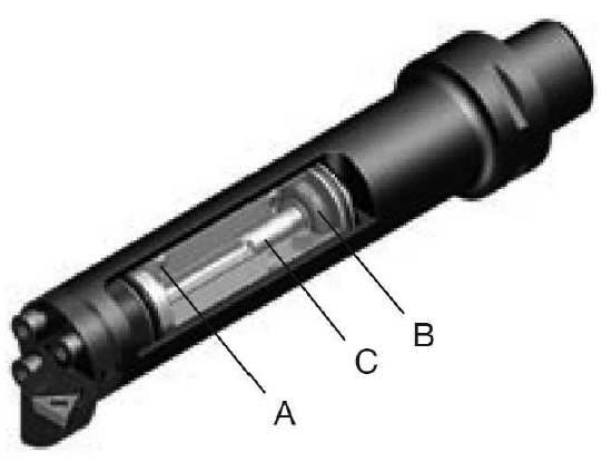

Figura 2.3: Suporte da ferramenta Silent Tools ${ }^{T M}$ A) corpo ajustável B) buchas de borracha C) liquido oleoso (retirado de Sandvik-Coromant ())

Outra técnica para obter um melhor desempenho em ferramentas de torneamento interno está descrita no trabalho de Houck et al. (2011), onde são usadas buchas de bronze para mudar a massa e a rigidez do suporte durante a usinagem de barras de alumínio, para ajustar a frequência natural do suporte com aquela do porta-ferramenta, o qual tem uma rigidez alta. A vantagem do método é que podem se usar os suportes de aço usados comumente.

Entre os dispositivos dissipadores de energia mais comumente usados estão os absorvedores dinâmicos, e os amortecedores de massa ajustáveis (TMD pelas siglas em inglês). Yang et 
al. (2010) usa um método numérico de otimização para montar os amortecedores, ajustados na direção principal de corte em operações de fresamento. $\mathrm{O}$ aumento da estabilidade é conseguido pela maximização da parte real negativa da FRF, conseguindo também uma redução na magnitude na frequência de ressonância. Miguélez et al. (2010) modelaram o suporte da ferramenta com os absorvedores para operações de torneamento interno como mostra a figura 2.4. Tarng et al. (2000) adicionaram um grau de liberdade na modelagem do absorvedor dinâmico, procurando uma relação de amortecimento maior à do suporte. Os resultados experimentais mostraram um aumento do limite de estabilidade de até seis vezes. Wang et al. (2010) combinaram o absorvedor dinâmico linear, baseado na variação da massa, com um suporte elástico e um amortecedor não linear baseado no atrito em placas de aço, comprovando experimentalmente um aumento do limite de estabilidade.
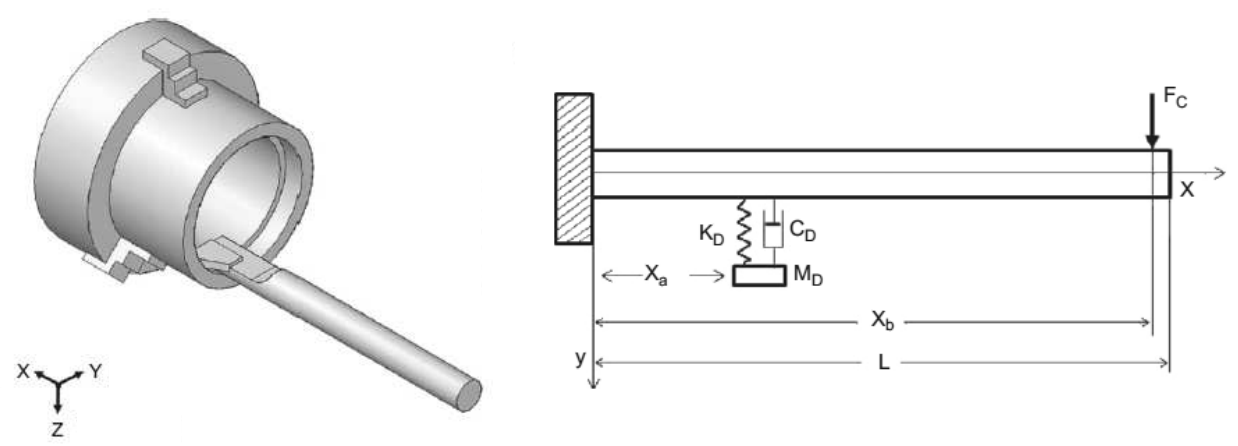

Figura 2.4: Modelo do suporte de ferramenta com o absorbedor dinâmico (retirado de Miguélez et al. (2010))

Os dispositivos adicionais usados para dissipar energia de forma passiva também podem ser eletromecânicos. Os mais conhecidos são aqueles que usam materiais piezelétricos devido à capacidade de transformar vibrações mecânicas em energia elétrica. $\mathrm{O}$ efeito piezelétrico direto consiste na capacidade de certos materiais de gerar uma carga elétrica proporcional à uma força aplicada, este efeito é usado em transdutores. No efeito piezelétrico inverso, um campo elétrico paralelo à direção de polarização gera uma expansão do material (PREUMONT, 2006). Os materiais piezelétricos mais usados são o titano-zirconato de chumbo (PZT) que é uma cerâmica, e o polifluoreto de vinilideno (PVDF) que é um plástico. O trabalho de Kim et al. (2011) revisa algumas técnicas e aplicações nas quais os materiais piezelétricos trabalham como coletores de energia baseadas no efeito piezelétrico. Erturk e Inman (2008a) desenvolveram um modelo eletromecânico de parâmetros distribuídos de uma viga engastada com material piezelétrico acoplado para geração de energia. Este modelo definiu as saídas elétricas assumindo uma excitação na base da viga.

Para dissipação da energia mecânica é necessário conectar a saída dos eletrodos do material piezelétrico a um circuito dissipador de energia ou circuito shunt. Hagood e Von Flotow (1991) estudaram a possibilidade e comprovaram experimentalmente a possibilidade de dissipar 
a energia gerada de um material piezelétrico com circuitos resistivos e indutivos. Devido a que esses circuitos geram una ressonância elétrica, é necessário ajusta-la com a frequência de ressonância da estrutura onde estiver montado o material piezelétrico, obtendo os valores ótimos das resistências e indutâncias de acordo com as constantes piezelétricas. Granier et al. (2002) conectaram circuitos indutivos, resistivos e capacitivos numa viga engastada com material piezelétrico , comprovando experimentalmente que a seleção dos elementos para os circuitos não é um método robusto, devido a que precisam valores mais exatos das frequências naturais medidas no experimento. Viana e Steffen (2006) obtiveram valores de resistências e indutâncias ótimos para circuitos dissipadores, adicionando amortecimento em vários modos de vibração de uma estrutura. Devido aos altos valores de indutância requeridos nos circuitos, foram usados indutores sintéticos, os quais usam amplificadores operacionais para obter indutâncias equivalentes.

O uso de circuitos dissipadores para redução de vibrações em processos de usinagem foi estudado recentemente por Erturk e Inman (2009). Nesse trabalho foi revisada numericamente a influência de alguns circuitos resistivos, indutivos e capacitivos no comportamento dinâmico de um suporte da ferramenta modelado com a teoria de vigas de Euler Bernoulli como mostra a figura 2.5. O circuito resistivo indutivo (em série ou paralelo) poderia ser uma solução devido a que se comporta como um absorvedor dinâmico amortecido. Também se observou a influencia da constante de acoplamento electromecânico na atenuação das vibrações comparando dois materiais piezelétricos diferentes. Entre as vantagens deste método estão o custo baixo dos elementos elétricos (os quais não precisam de energia elétrica externa), as camadas piezelétricas podem ser usadas como sensores de medição (enquanto não estiverem conectadas a um circuito dissipador) e não afetam a carga de massa do sistema como os outros absorvedores dinâmicos de massa ajustável (no entanto afetam a capacitância no circuito dissipador). Nessa mesma linha de pesquisa, Da Silva et al. (2010) usaram o mesmo modelo eletromecânico e realizaram simulações numéricas com os circuitos resistivo e indutivo para várias espessuras de camada piezelétrica, obtendo um maior amortecimento com o circuito resistivo-indutivo. A melhora da proposta foi comprovada no diagramas de lóbulos de estabilidade comparando o sistema sem camada piezelétrica e o sistema com a camada piezelétrica conectada ao circuito dissipador, com o qual é obtido um aumento do limite de estabilidade.

As soluções passivas em geral tem como vantagens a montagem simples, o custo baixo e que não precisam de energia externa para seu funcionamento. No entanto, para seu correto funcionamento é necessário um ajuste baseado na dinâmica do sistema, o qual as vezes é inexato, devido as incertezas na estrutura da máquina ferramenta e o processo de corte (SIDDHPURA; PAROUBALLY, 2012).

\subsubsection{Estratégias ativas}

As estratégias ativas tem como objetivo monitorar o comportamento dinâmico do sistema durante o processo de usinagem, fazer o diagnóstico do estado do processo (estável ou instá- 
vel) e levar a cabo as ações necessárias para mudar ou controlar os parâmetros de corte ou as características dinâmicas do sistema. Para este objetivo, precisam de energia externa para o funcionamento dos dispositivos de controle (atuadores e dispositivos responsáveis pela lógica de controle).

Uma das estratégias mais usadas é o controle da velocidade da rotação da peça ou da ferramenta, conhecida como SSV pelas siglas em inglês, e que consiste em controlar a velocidade do eixo para reduzir os efeitos de regeneração do processo de usinagem. As primeiras simulações numéricas deste método são encontrada no trabalho de Jemielniak e Widota (1984). Al-Regib et al. (2003) desenvolveram um método de variação senoidal da velocidade, cujos valores de amplitude e frequência ótimos foram obtidos de uma análise de balanço de energia entre o trabalho feito pela força regenerativa e a energia absorbida pelo amortecimento estrutural da máquina. Também foram obtidos resultados experimentais satisfatórios em processos de torneamento. Albertelli et al. (2012) estudou as aplicações do método de variação da velocidade da industria, avaliando sua efetividade e estabelecendo limites de velocidade onde o desempenho não é afetado pela carga térmica do motor da máquina-ferramenta.

A modificação dos parâmetros de corte também pode incluir a mudança da posição da ferramenta. Mei et al. (1994) comprovou teórica e experimentalmente a melhora da estabilidade aumentando o ângulo de entrada e diminuindo o ângulo de saída da ferramenta de torneamento, o qual influi na não linearidade da força de corte em função da formação do cavaco. No trabalho de Chen e Knospe (2007), é aplicado controle proporcional integral derivativo (PID) em atuadores magnéticos posicionados nos rolamentos da máquina-ferramenta, os quais aplicam força na ferramenta durante a usinagem, modificando a estabilidade do processo.

O uso de absorvedores ajustáveis de vibrações (TVA pelas siglas em inglês) também está incluído nas estratégias ativas, no entanto, Moradi et al. (2008) consideraram este tipo de absorvedores como uma estratégia semi-ativa. Os dispositivos de controle semi-ativo são essencialmente dispositivos passivos onde as características dinâmicas (rigidez, amortecimento) podem ser ajustadas em tempo real, mas eles não podem adicionar energia diretamente no sistema que

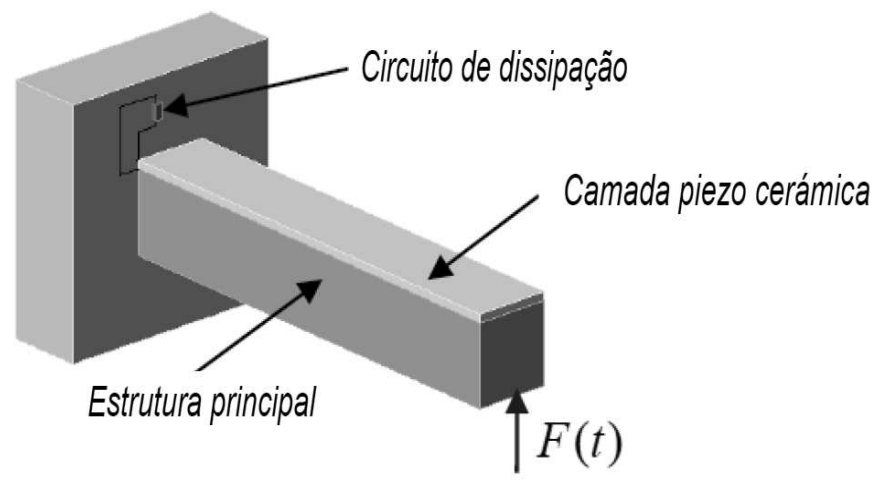

Figura 2.5: Modelo de viga engastada com material piezelétrico acoplado (retirado de Erturk e Inman (2009)) 
está sendo controlado (PREUMONT, 2002). Olgac e Holm-Hansen (1994) usaram um absorvedor simples de massa-mola-amortecedor aplicando um controle de realimentação de posição onde o atraso pode ser ajustado durante o processo. Por essa razão recebe o nome de ressonador com atraso. Moradi et al. (2008) usam um algoritmo de soma de modos para determinar as posições da massa e mola do absorvedor no suporte da ferramenta.

$\mathrm{O}$ ajuste de um controlador com a frequência natural do modo dominante pode ter efeito nos demais modos da estrutura. Este efeito é chamado de spillover e é um dos maiores problemas de instabilidade nas soluções ativas. Este problema aparece devido ao baixo amortecimento das estruturas flexíveis, onde existe o perigo de que o controle de realimentação baseado num modelo reduzido, desestabilize os modos residuais que não estão contidos no modelo. Por essa razão, o spillover pode ser controlado minimizando a energia alimentada aos modos residuais pela estratégia de controle (PREUMONT, 2002). Mei (2005) projetou um controlador para processos de torneamento interno, baseado numa ampla banda de frequência, reduzindo a amplitude das vibrações em todos os modos da estrutura.

O controle de realimentação de velocidade aplicado a processos de torneamento e fresamento foi estudado por Ganguli (2005), quem fez uma análise de estabilidade com o método do lugar das raízes para encontrar os ganhos ótimos do controlador. O dispositivo escolhido foi um amortecedor de massa ativo com o qual foram feitas simulações numéricas num modelo de porta-ferramenta. Também foi desenvolvido um protótipo que simula condições de usinagem mostrado na Fig. 2.6, onde foi aplicado o controle ativo, aumentando o limite de estabilidade. Ganguli et al. (2007) adotou o amortecimento ativo com o controle de realimentação de velocidade afetando o amortecimento da estrutura e a fase entre os passos da ferramenta.

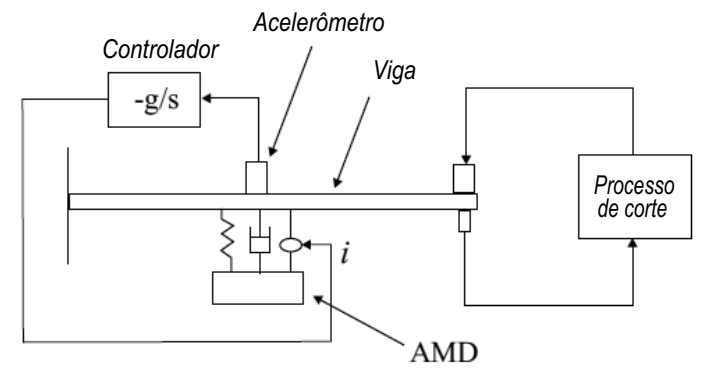

Figura 2.6: Esquema do protótipo com amortecedor de massa ativo (retirado de Ganguli (2005))

A utilização de materiais ativos em processos de usinagem é revisada no trabalho de Park et al. (2007), onde detalham algumas vantagens dos materiais ativos (ou inteligentes) tais como o peso leve, o tamanho compacto, a operabilidade com sinais elétricos e a grande faixa de frequência de operação. Embora esses materiais apresentem vantagens eles ainda não tem sido utilizados na industria pois requerem técnicas de projeto mais avançadas baseadas em modelagem e otimização.

No estudo dos materiais inteligentes, Park et al. (2007) indica que os materiais piezelétricos 
são amplamente usados dentro das estratégias ativas, apresentando algumas vantagens (PARK et al., 2007):

- A capacidade de ser usados como sensores e atuadores e propriedades de acoplamento eletromecânico

- O tamanho compacto que facilita sua utilização onde existe restrição de espaço

- Grande faixa de frequência de operação sem apresentar batimento ou atrito.

- Podem atingir rigidezes altas e produzir forças de resposta elevadas

- Tem uma alta resolução para seu posicionamento

As desvantagens do uso dos materiais também são descritas:

- Comportamento linear histerético

- Seu desempenho depende da temperatura. Existe a propriedade de temperatura de Curie, acima da qual as propriedades de acoplamento eletromecânico mudam.

- Tendem a gerar calor quando funcionam a frequências altas de vibração o que requer sistemas externos de refrigeração

- Deslocamentos de resposta relativamente pequenos

- Requerem amplificadores especialmente projetados para seu uso

Devido ao seu desempenho em frequências altas, os dispositivos piezelétricos são usados para controle de vibrações em usinagem ultrassônica, onde se requere qualidades superficiais elevadas. Kim e Nam (1997) usaram controladores PI de realimentação com atuadores piezelétricos para usinagem de micro-precisão, usado na indústria aeroespacial. Ma et al. (2011) melhoraram o acabamento superficial aplicando um sinal de tensão elétrica senoidal de alta frequência a duas pastilhas piezelétricas coladas no porta-ferramenta, obtendo uma vibração elíptica ultrassônica que reduz os efeitos do chatter. Para usinagem de maior exatidão Ast et al. (2007) usaram técnicas de controle de realimentação como $H_{2}$ e $H_{\infty}$ em máquinas ferramenta de cinemática paralela, as quais tem estruturas leves para atingir altas velocidades de processamento. Algumas outras técnicas de controle de realimentação em estruturas com materiais piezelétricos podem ser encontradas em Preumont (2006) e Leo (2007).

Os atuadores piezelétricos também podem ser montados na peça de trabalho como foi realizado por Zhang e Sims (2005). A flexibilidade da peça de trabalho em processos de fresamento foi estudada, e o controlador foi ajustado com a frequência natural. Uma das pastilhas piezelétricas foi usada como sensor para observar a resposta do sistema, e também foi usada uma identificação visual das marcas do chatter, obtendo um aumento da estabilidade. Também foi 
possível observar alguns detalhes experimentais interessantes como problemas de contaminação do líquido refrigerante, problemas de colamento dos dispositivos nas peças a altas velocidades, saturamento dos sensores e a falta de exatidão na modelação da peça de trabalho de geometria variável.

Um exemplo de atuadores piezelétricos montados no suporte da ferramenta foi encontrado no trabalho de Radecki et al. (2010). O dispositivo piezelétrico tem o sensor e o atuador na mesma peça acoplada no porta-ferramenta como mostra a figura 2.7 , onde foi aplicado um controle de realimentação de posição positivo (PPF pelas siglas em inglês). O controlador foi ajustado com os valores de frequência natural obtidos do modelo de elementos finitos e medição com martelo modal. Numa primeira parte experimental, os dispositivos foram montados numa viga engastada, onde foi testado o algoritmo de controle. Aplicando um sinal aleatório se observou o efeito de spillover, reduzindo a magnitude no primeiro modo, mas aumentando nos modos seguintes. Para evitar o problema foi colocado um filtro Butterworth de passa baixa sem afetar o desempenho. Na segunda parte experimental foram feitos experimentos de torneamento, montando o atuador piezelétrico com amplificadores piezelétricos de $200 \mathrm{~V}$ e $1000 \mathrm{~V}$. Se observou uma redução na magnitude da resposta e uma melhora significativa no acabamento superficial da peça. Radecki et al. (2009) definiram anteriormente que o requisito de acabamento superficial é importante para materiais com custo alto como o plutônio, comprovando a efetividade do controlador em processos de faceamento.
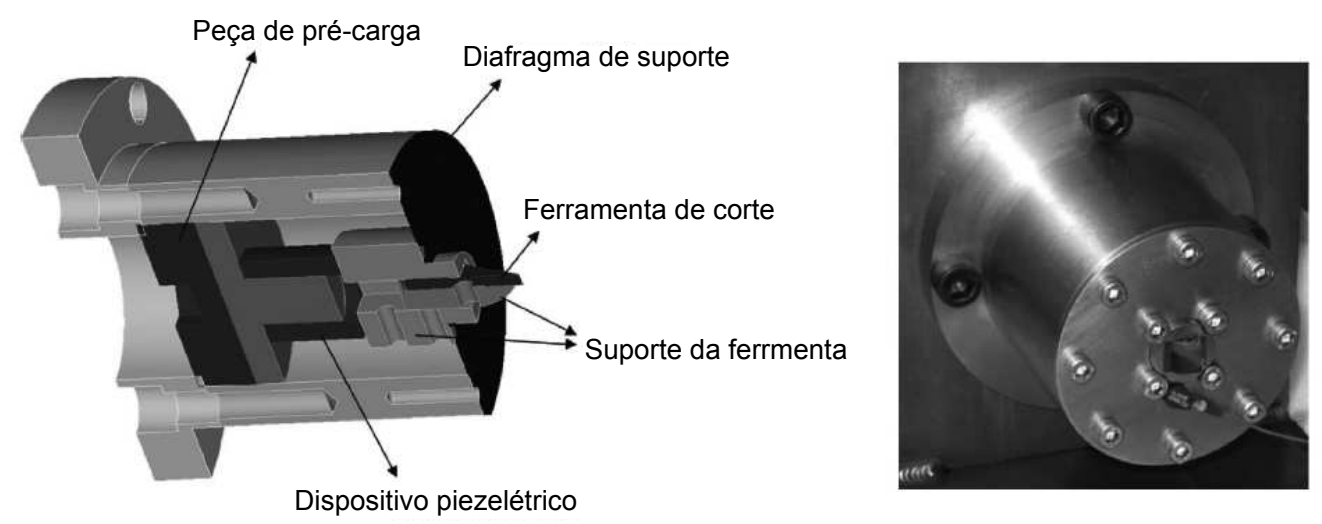

Figura 2.7: Porta-ferramenta ativo (retirado de Radecki et al. (2009))

Entre os materiais ativos detalhados em Park et al. (2007) estão os materiais magnetoresistivos, os quais respondem com deformação do material ao campo magnético (conhecido como efeito Joule), e cujos efeitos são reversíveis. Este tipo de materiais geram uma maior deformação que os dispositivos piezelétricos, são resistentes a fadiga, precisam de baixas tensões de funcionamento e tem uma maior rigidez. Entre as desvantagens estão seu custo alto e a geração de calor em altas frequências. Outros tipos de dispositivos que usam o efeito magnético com efeitos similares são aquelas que usam fluidos magneto-reológicos (MR) ou eletro- reológicos (ER), os quais contem partículas magnetizáveis ou ferrosas, e mudam suas propriedades reoló- 
gicas (como a viscosidade) com a aplicação de um campo magnético ou elétrico (PREUMONT, 2002). Estes dispositivos operam em grandes faixas de frequência e a altas temperaturas, mas tem como desvantagem que depois de um longo tempo de uso aparecem sedimentos no fluido e é necessária uma manutenção do dispositivo, incluindo reposição de peças. Mei et al. (2009) considera o dispositivo com fluido magneto-reológico com uma solução semi-ativa já que é possível mudar as características de rigidez e amortecimento durante o processo. Neste trabalho, foram feitos experimentos de torneamento com o suporte da ferramenta mostrado na figura 2.8, onde a medição da rugosidade da peça usinada mostrou uma melhora no processo. No entanto, é necessário um modelo dinâmico mais complexo e exato para medir o desempenho a altas velocidades. Mei et al. (2010) analisou a estabilidade do processo de torneamento com dispositivos magneto-reológicos usando o método do balanço de energias, otimizando as características dinâmicas do dispositivo, e definindo que a frequência de excitação do fluido não pode ser maior à velocidade de rotação da peça.

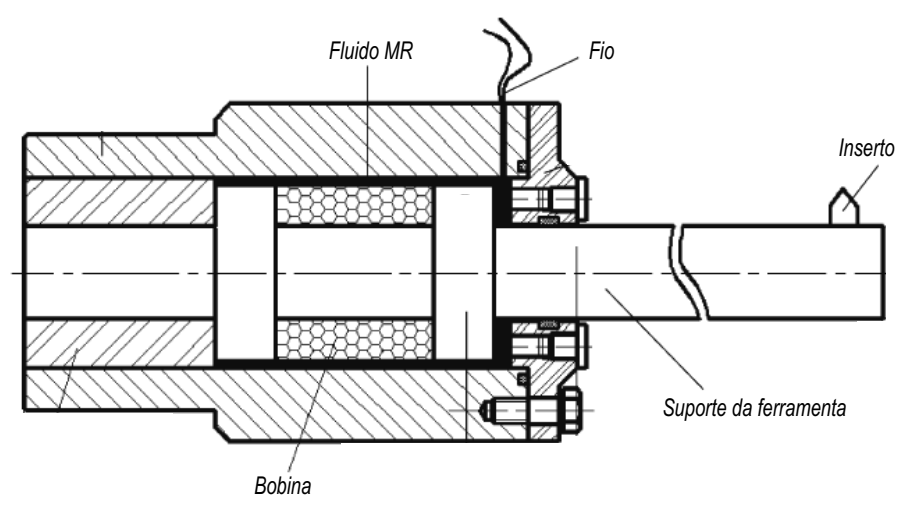

Figura 2.8: Esquema do suporte da ferramenta com fluido magneto-reológico (retirado de Mei et al. (2009)) 


\section{Capítulo 3}

\section{Metodologia para avaliação numérica}

O presente capítulo descreve a metodologia usada para avaliar numericamente o uso de material piezelétrico acoplado ao suporte da ferramenta, no qual serão aplicadas soluções de controle passivo e ativo. A seção 3.1 detalha a obtenção do modelo eletromecânico do suporte de ferramenta com as camadas piezelétricas acopladas. Depois a resposta do sistema quando os eletrodos da camada piezelétrica são conetados a um circuito dissipador de energia como solução de controle passivo é analisada na seção 3.2. Finalmente, a resposta do sistema quando uma camada piezelétrica é utilizada como sensor e outra como atuador, onde são aplicadas leis de controle de realimentação de deslocamento e velocidade, como solução de controle ativo, é obtida na seção 3.3 .

\subsection{Modelo eletromecânico}

Com o fim de mudar de maneira ativa ou passiva o amortecimento do sistema, duas camadas piezelétricas são acopladas ao sistema do suporte da ferramenta, como foi mostrado na Fig.1.3. Um modelo eletromecânico de parâmetros distribuídos é usado para avaliar as estratégias para redução do chatter. Neste caso, o suporte da ferramenta com as camadas piezelétricas, é modelado como uma viga engastada.

Embora a geometria do suporte da ferramenta seja complexa, com curvaturas e mudanças de seção, é assumida uma geometria retangular para simplificar a análise. Na Fig. 3.1 (a) é mostrado um esquema de um suporte da ferramenta de aço com as camadas piezelétricas, e as dimensões respetivas da estrutura a ser consideradas na análise.

Na figura 3.1 (a) também estão ilustradas as saídas dos eletrodos do material piezelétrico, as quais serão conectadas a um circuito dissipador de energia na solução passiva, e funcionarão como sensor e atuador na solução ativa. Para um material piezelétrico, as equações constitutivas elétricas e mecânicas que descrevem os efeitos piezelétricos direto e inverso segundo a norma de piezoelectricidade de IEEE (1988) são:

$$
\begin{aligned}
& S=d E+s^{E} T, \\
& D=\epsilon^{T} E+d T,
\end{aligned}
$$




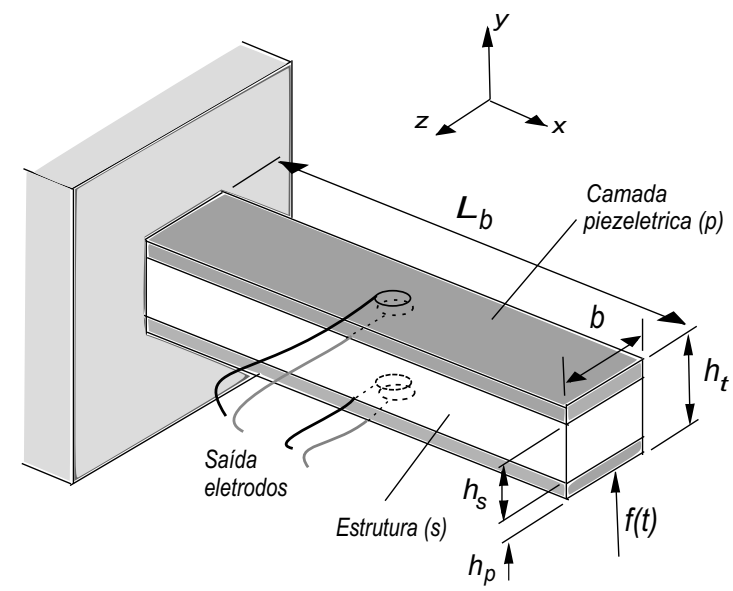

(a)

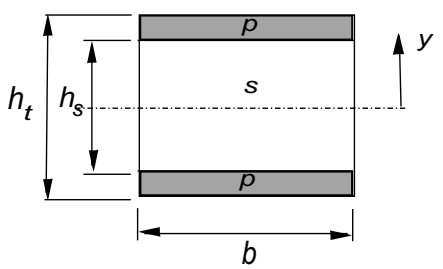

(b)

Figura 3.1: (a) Esquema do suporte da ferramenta com as camadas piezelétricas acopladas (b) Seção transversal do suporte da ferramenta

onde $S$ é a deformação do material, $T$ é a tensão, $D$ é o deslocamento elétrico (carga por unidade de área), $E$ é o campo elétrico, $s^{E}$ é a inversa do módulo de Young quando o campo elétrico é constante, $\epsilon^{T}$ é a constante dielétrica do material quando a tensão mecânica é constante. A constante piezelétrica $d$ relaciona a deformação e o campo elétrico na ausência de tensão mecânica, e geralmente indica a direção de expansão com respeito à direção do campo elétrico. A convenção dos eixos para uma placa piezelétrica é mostrada na figura 3.2 onde 1 é a direção de deformação e 3 a direção de polarização do eletrodo. O material é fabricado de forma que um dos coeficientes numa direção domina a outra direção (PREUMONT, 2002).

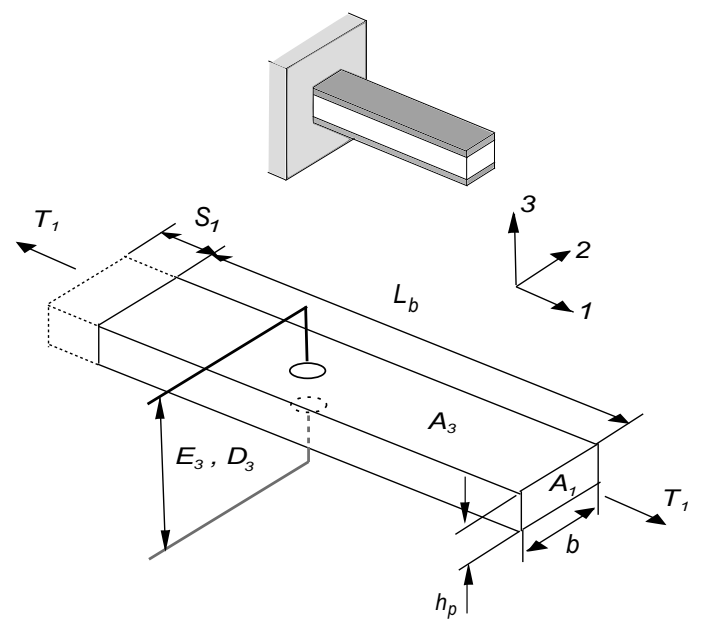

Figura 3.2: Convenção dos eixos numa placa de material piezelétrico (modificada de Viana e Steffen (2006))

Para a obtenção dos modelos eletromecânicos é aplicada a teoria de viga engastada de EulerBernoulli. Este é um modelo de parâmetros distribuídos, conhecido também como modelo con- 
tínuo, tem um infinito número de graus de liberdade. A teoria desconsidera a rotação da seção transversal e a deformação cortante, comparados com o deslocamento e a deformação por flexão, respectivamente. A figura 3.3 mostra um esquema de uma viga engastada, onde um extremo é livre é o outro fixo.

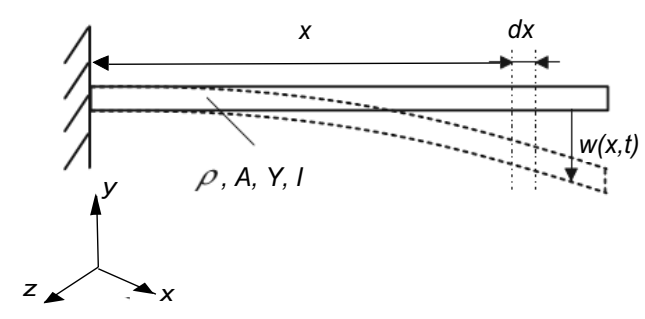

Figura 3.3: Esquema de viga engastada (modificada de Smirnova (2008))

Usando a segunda lei de Newton para um elemento da viga $d x$, de seção e propriedades constantes ao longo da viga, é possível obter a equação diferencial parcial de movimento de uma viga (RAO, 1995):

$$
\frac{\partial^{2} M(x, t)}{\partial x^{2}}+\rho A \frac{\partial^{2} w(x, t)}{\partial t^{2}}=f(x, t)
$$

onde $M(x, t)$ é o momento fletor, $w(x, t)$ é o deslocamento transversal no ponto $x, f(x, t)$ é a força externa por unidade de comprimento, $\rho$ é a densidade e $A$ é a área transversal da viga.

A resposta da estrutura para vibração forçada pode ser determinada usando o método de superposição de modos (RAO, 1995). Este análise usa a separação de variáveis e a transformação das coordenadas de deslocamento $w(x, t)$ em coordenadas normais $\eta_{r}(t)$, as quais estão associadas às formas modais $\phi_{r}(x)$ que dependem da geometria e das condições de contorno da viga. Desta maneira, qualquer deslocamento pode ser calculado através da superposição das amplitudes e modos de vibração respectivos:

$$
w(x, t)=\sum_{r=1}^{\infty} \phi_{r}(x) \eta_{r}(t)
$$

As condições de contorno para a solução da equação diferencial de movimento descrita na equação 3.3 mudarão dependendo da estratégia adotada. Considerando um sistema discreto de $N$ graus de liberdade, amortecido, a resposta do sistema à vibração livre pode ser descrita com o seguinte modelo modal de duas matrizes, as quais contêm uma descrição completa das características dinâmicas do sistema (MAIA; SILVA, 1998):

$$
\left[\Omega_{r}^{2}\right]=\left[\begin{array}{cccc}
\omega_{1}^{2} & 0 & \ldots & 0 \\
0 & \omega_{2}^{2} & \ldots & 0 \\
\vdots & \ldots & \ddots & \vdots \\
0 & 0 & \ldots & \omega_{N}^{2}
\end{array}\right]
$$




$$
[\Psi]=\left[\begin{array}{llll}
\left\{\psi_{1}\right\} & \left\{\psi_{2}\right\} & \ldots & \left\{\psi_{N}\right\}
\end{array}\right]
$$

para $r=1 \ldots N$. As frequências naturais $\omega_{r}$ formam parte da diagonal da matriz $\Omega$, e $\psi_{r}$ são as formas modais coletadas na matriz modal $\Psi$. É comum normalizar as formas modais, para que possam ser usadas sem um fator de escala determinado:

$$
\left\{\phi_{r}\right\}=\frac{\left\{\psi_{r}\right\}}{\sqrt{M_{r}}}
$$

onde $M_{r}$ é a massa modal do modo $r$ que para o caso da viga contínua da figura 3.1 está dada por $\rho A L_{b}$. Assim a resposta modal do sistema com amortecimento viscoso, considerando $\zeta_{r}$ como o fator de amortecimento modal (RAO, 1995), e vibração forçada, pode ser escrita no domínio de Laplace:

$$
\alpha_{i j}(s)=\sum_{r=1}^{N} \frac{\phi_{i r}(x) \phi_{j r}(x)}{s^{2}+2 \zeta_{r} \omega_{r} s+\omega_{r}^{2}}
$$

onde $\alpha_{i j}$ é a relação entre o deslocamento da resposta medida na posição $i$, e a força de excitação medida em $j$, conhecida como receptância do sistema. Substituindo o termo $s=i \omega$ obtemos a função de resposta em frequência (FRF) correspondente.

A função de transferência do suporte da ferramenta $G(s)$ definida na equação 2.3 para um único grau de liberdade, pode ser descrita para um número infinito de graus de liberdade usando a equação 3.8, assumindo que a força $f(x, t)$ é aplicada no extremo livre do suporte, e a resposta $w(x, t)$ é medida no mesmo ponto:

$$
G(s)=\frac{W}{F}(s)=\sum_{r=1}^{\infty} \phi_{r}\left(L_{b}\right) \frac{H_{r}}{F}(s)=\sum_{r=1}^{\infty} \frac{\phi_{r}^{2}\left(L_{b}\right)}{s^{2}+2 \zeta_{r} \omega_{r} s+\omega_{r}^{2}}
$$

\subsection{Solução passiva}

Para aumentar o amortecimento de maneira passiva os eletrodos das camadas piezelétricas estão conectadas a um circuito de dissipação de energia de impedância $Z$ como ilustra a fig. 1.3 (a). Para uma subestrutura de aço denominada como $s$, com camadas piezelétricas acopladas, denominadas $p$, como mostrado na figura 3.1, a relação entre a tensão $T_{1}$ e a deformação $S_{1}$ (mostrados no esquema da Fig. 3.2) para a subestrutura é dada por (PREUMONT, 2006):

$$
T_{1}^{s}=Y_{s} S_{1}^{s}
$$

onde $Y_{s}$ é o módulo de Young da subestrutura. Para as camadas piezelétricas é necessário considerar a relação constitutiva piezelétrica da equação 3.1:

$$
S_{1}^{p}=s_{11}^{E} T_{1}^{p}+d_{31} E_{3}
$$


onde $E_{3}$ é o campo elétrico na direção vertical, $d_{31}$ é a constante piezelétrica para uma deformação axial na direção horizontal quando é polarizado na direção vertical, e $s_{11}^{E}$ é o acoplamento elástico no campo elétrico constante (sendo o inverso do módulo de Young do piezelétrico $\left.Y_{p}=1 / s_{11}^{E}\right)$. Assim a relação de tensão e deformação para o material piezelétrico é descrita por (ERTURK; INMAN, 2008a):

$$
T_{1}^{p}=\frac{S_{1}^{p}-d_{31} E_{3}}{s_{11}^{E}}=Y_{p}\left(S_{1}^{p}-d_{31} E_{3}\right)
$$

O momento fletor $M(x, t)$ no ponto $x$ pode ser obtido integrando o primeiro momento da distribuição das tensões das equações 3.10 e 3.12, na seção da figura 3.1 (b), onde a linha neutra está no centro da seção simétrica:

$$
M(x, t)=-\int_{-h_{t} / 2}^{-h_{s} / 2} T_{1}^{p} b y d y-\int_{-h_{s} / 2}^{h_{s} / 2} T_{1}^{s} b y d y-\int_{h_{s} / 2}^{h_{t} / 2} T_{1}^{p} b y d y
$$

Expressando a deformação a flexão em termos do raio de curvatura $S_{1}=y \partial^{2} w(x, t) / \partial x^{2}$ (onde $y$ é a distância desde a linha neutra da seção), e o campo elétrico em termos da tensão elétrica $v(t)$ através da camada piezelétrica $E_{3}(t)=-v(t) / h_{p}$ (onde $h_{p}$ é a espessura da camada piezelétrica $\left.\left(h_{t}-h_{s}\right) / 2\right)$, a eq. 3.13 pode ser escrita como:

$$
\begin{array}{r}
M(x, t)=Y_{p} b \frac{\partial^{2} w(x, t)}{\partial x^{2}} \int_{-h_{t} / 2}^{-h_{s} / 2} y^{2} d y-2 Y_{p} b d_{31} \frac{v(t)}{h_{t}-h_{s}} \int_{-h_{t} / 2}^{-h_{s} / 2} y d y+ \\
+Y_{s} b \frac{\partial^{2} w(x, t)}{\partial x^{2}} \int_{-h_{s} / 2}^{h_{s} / 2} y^{2} d y+Y_{p} b \frac{\partial^{2} w(x, t)}{\partial x^{2}} \int_{h_{s} / 2}^{h_{t} / 2} y^{2} d y- \\
2 Y_{p} b d_{31} \frac{v(t)}{h_{t}-h_{s}} \int_{h_{s} / 2}^{h_{t} / 2} y d y
\end{array}
$$

A equação 3.14 pode ser reduzida a:

$$
M(x, t)=Y I \frac{\partial^{2} w(x, t)}{\partial x^{2}}+\vartheta v(t)
$$

onde a rigidez está dada pela equação:

$$
Y I=b\left[\frac{Y_{s} h_{s}^{3}}{12}+\frac{Y_{p}\left(h_{t}^{3}-h_{s}^{3}\right)}{12}\right]
$$

e o termo de acoplamento $\vartheta$ :

$$
\vartheta=\frac{Y_{p} b d_{31}}{2}\left(h_{t}+h_{s}\right)
$$

Incluindo uma força pontual $f(t) \delta\left(x-L_{b}\right)$ no extremo livre do suporte da ferramenta (ERTURK; INMAN, 2009), e substituindo a expressão do momento fletor da eq. 3.15 na equação diferencial parcial de movimento da eq. 3.3 tem-se: 


$$
Y I \frac{\partial^{4} w(x, t)}{\partial x^{4}}+\rho A \frac{\partial^{2} w(x, t)}{\partial t^{2}}+\vartheta v(t)=f(t) \delta\left(x-L_{b}\right)
$$

Devido a equação 3.18 possuir uma derivada parcial de segunda ordem com respeito ao tempo e uma de quarta ordem com respeito a $x$, são necessárias duas condições iniciais e quatro condições de contorno para solucionar a equação diferencial (RAO, 1995). As condições de contorno da viga engastada-livre podem ser descritas como:

$$
\begin{gathered}
w(0, t)=0 \\
\frac{\partial w(0, t)}{\partial x}=0 \\
Y I \frac{\partial^{2} w\left(L_{b}, t\right)}{\partial x^{2}}=0 \\
Y I \frac{\partial^{3} w\left(L_{b}, t\right)}{\partial x^{3}}=0
\end{gathered}
$$

As condições de contorno das equações 3.19 e 3.20 indicam que, no extremo fixo da viga engastada, o deslocamento e a rotação da viga são nulas, enquanto as Eqs. 3.21 e 3.22 indicam que, no extremo livre da viga, o momento fletor e a força cortante são nulas.

De acordo com Erturk e Inman (2008a), as formas modais normalizadas de uma viga engastada que satisfazem as condições de ortogonalidade $\left(\int_{0}^{L_{b}} \phi_{s}(x) \phi_{r}(x) d x=0\right)$ da transformação da eq. 3.4 são calculadas por:

$$
\phi_{r}(x)=\sqrt{\frac{1}{\rho A L_{b}}}\left[\cosh \frac{\lambda_{r}}{L_{b}} x-\cos \frac{\lambda_{r}}{L_{b}} x-\frac{\sinh \lambda_{r}-\sin \lambda_{r}}{\cosh \lambda_{r}+\cos \lambda_{r}}\left(\sinh \frac{\lambda_{r}}{L_{b}} x-\sin \frac{\lambda_{r}}{L_{b}} x\right)\right],
$$

onde os números adimensionais de frequência $\lambda_{r}$ podem ser calculados com a equação transcendental para uma viga engastada-livre:

$$
\cos \lambda_{r} \cosh \lambda_{r}=-1
$$

As frequências naturais não amortecidas, relacionadas ás raízes $\lambda_{r}$, podem ser calculadas com a equação:

$$
\omega_{r}=\lambda_{r}^{2} \sqrt{\frac{Y I}{\rho A L_{b}^{4}}}
$$

Usando o método de separação de variáveis e substituindo a transformação de coordenadas da eq. 3.4 na equação diferencial de movimento da eq. 3.18, multiplicando por a função normal $\phi_{s}(x)$ e integrando nos limites de 0 a $L_{b}$ obtem-se: 


$$
\begin{array}{r}
\eta_{r}(t) \sum_{r=1}^{\infty} \int_{0}^{L_{b}} Y I \frac{d^{4} \phi_{r}(x)}{d x^{4}} \phi_{s}(x) d x+\frac{d^{2} \eta_{r}(t)}{d t^{2}} \sum_{r=1}^{\infty} \int_{0}^{L_{b}} \rho A \phi_{r}(x) \phi_{s}(x) d x+ \\
+\vartheta v(t) \int_{0}^{L_{b}} \phi_{s}(x) d x=f(t) \int_{0}^{L_{b}} \phi_{s}(x) \delta\left(x-L_{b}\right) d x
\end{array}
$$

Para reduzir a eq. 3.26 são usadas as condições de ortogonalidade descritas no modelo de Erturk e Inman (2008a):

$$
\begin{gathered}
\int_{x=0}^{L_{b}} \rho A \phi_{s}(x) \phi_{r}(x) d x=\delta_{r s} \\
\int_{x=0}^{L_{b}} Y I \phi_{s}(x) \frac{d^{4} \phi_{r}(x)}{d x^{4}} d x=\omega_{r}^{2} \delta_{r s}
\end{gathered}
$$

onde $\delta_{r s}$ é o delta de Kronecker, definido como 1 quando $r=s$, e 0 quando $r \neq s$. Incluindo o termo de amortecimento modal $\zeta_{r}$, a equação diferencial ordinária de movimento pode ser descrita como:

$$
\frac{d^{2} \eta_{r}(t)}{d t^{2}}+2 \zeta_{r} \omega_{r} \frac{d \eta_{r}(t)}{d t}+\omega_{r}^{2} \eta_{r}(t)+\chi_{r} v(t)=f(t) \phi_{r}\left(L_{b}\right)
$$

onde o termo de acoplamento modal $\chi_{r}$ está definido como como:

$$
\chi_{r}=\left.\vartheta \frac{d \phi_{r}(x)}{d x}\right|_{x=L_{b}}
$$

Considerando que tanto a excitação como a resposta eletromecânica são de carácter harmônico $\eta_{r}(t)=H_{r} e^{i \omega t}$ e $v(t)=V e^{i \omega t}$, a equação de movimento da viga engastada com acoplamento eletromecânico e uma força pontual aplicada no extremo livre da viga, no domínio de Laplace, está definida por:

$$
\left(s^{2}+2 \zeta_{r} \omega_{r} s+\omega_{r}^{2}\right) H_{r}(s)+\chi_{r} V(s)=F(s) \phi_{r}\left(L_{b}\right)
$$

Para obter a relação do circuito elétrico com acoplamento mecânico, se considera as seguinte equação constitutiva relacionada com a eq. 3.35 (ERTURK; INMAN, 2008a):

$$
D_{3}=d_{31} T_{1}+e_{33}^{T} E_{3}
$$

e a relação entre constantes piezelétricas:

$$
\epsilon_{33}^{S}=\epsilon_{33}^{T}-d_{31}^{2} Y_{p}
$$

onde $D_{3}$ é o deslocamento elétrico, $\epsilon_{33}^{S}$ e $\epsilon_{33}^{T}$ são as permissividades a deformação e tensão 
constante, respectivamente. Se $T_{1}$ for expressado em termos da deformação à flexão $S_{1}$ e do módulo de Young do material piezelétrico, e o campo elétrico em termos da tensão se obtêm (ERTURK; INMAN, 2008a):

$$
D_{3}=d_{31} Y_{p} S_{1}-2 \epsilon_{33}^{S} \frac{v(t)}{h_{t}-h_{s}}
$$

A deformação na posição $x$ no tempo $t$ na camada piezoelétrica pode ser expressa como função da distância desde o centro da seção da viga ao centro da seção da camada piezelétrica $\left(h_{t}+h_{s}\right) / 2$, e a curvatura da viga na posição $x$ no tempo $t$ :

$$
S_{1}(x, t)=\frac{h_{t}+h_{s}}{2} \frac{\partial^{2} w(x, t)}{\partial x^{2}}
$$

Então a Eq. 3.34 pode ser escrita como:

$$
D_{3}(x, t)=d_{31} Y_{p} \frac{h_{t}+h_{s}}{2} \frac{\partial^{2} w(x, t)}{\partial x^{2}}-2 \epsilon_{33}^{S} \frac{v(t)}{h_{t}-h_{s}}
$$

A carga elétrica $q(t)$ desenvolvida no material piezelétrico pode ser obtida integrando o deslocamento elétrico sobre a área do eletrodo $A_{3}$ da figura 3.2:

$$
q(t)=\int_{A} D \cdot n d A=\int_{A_{3}} D_{3} d A=\int_{0}^{L_{b}} D_{3} b d x
$$

onde $D$ é o vetor de deslocamentos elétricos e $n$ é o vetor normal unitário. Substituindo a eq. 3.36 na eq. 3.37 a carga elétrica é definida por:

$$
q(t)=\int_{x=0}^{L_{b}}\left(d_{31} Y_{p} \frac{h_{t}+h_{s}}{2} \frac{\partial^{2} w(x, t)}{\partial x^{2}}-2 \epsilon_{33}^{S} \frac{v(t)}{h_{t}-h_{s}}\right) b d x
$$

A corrente $i(t)$ gerada pelo material piezelétrico é:

$$
i(t)=\frac{d q(t)}{d t}=\int_{x=0}^{L_{b}} d_{31} Y_{p} \frac{h_{t}+h_{s}}{2} b \frac{\partial^{3} w(x, t)}{\partial x^{2} \partial t} d x-\frac{2 \epsilon_{33}^{S} b L_{b}}{h_{t}-h_{s}} \frac{d v(t)}{d t}
$$

Pode-se definir como capacitância da camada piezelétrica (DA SILVA et al., 2010) a relação obtida no segundo termo da 3.39 com deformação constante:

$$
C_{p}^{S}=\frac{2 \epsilon_{33}^{S} b L_{b}}{h_{t}-h_{s}}
$$

O cálculo da capacitância equivalente da camada piezelétrica depende da conexão dos eletrodos das camadas e da direção de polarização (ERTURK; INMAN, 2008b). Neste caso as duas camadas de material piezelétrico estão conectadas em paralelo. As saídas dos electrodos da camada piezelétrica são conectadas num circuito de dissipação de energia com impedância $z(t)$ como mostra a figura 1.3 , a tensão e a corrente estão relacionadas por: 


$$
v(t)=z(t) i(t)
$$

Isolando o termo $i(t)$ da eq. 3.41, e substituindo junto com a transformação modal (eq. 3.4) na Eq. 3.39 obtêm-se:

$$
\frac{v(t)}{z(t)}=\sum_{r=1}^{\infty} \frac{d \eta_{r}}{d t} \int_{x=0}^{L_{b}} Y_{p} b d_{31} \frac{h_{t}+h_{s}}{2} \frac{d^{2} \phi_{r}(x)}{d x^{2}} d x-C_{p}^{S} \frac{d v(t)}{d t}
$$

Rearranjando os termos e resolvendo a integral:

$$
C_{p}^{S} \frac{d v(t)}{d t}+\frac{v(t)}{z(t)}=\left.\sum_{r=1}^{\infty} \frac{d \eta_{r}}{d t} \frac{Y_{p} b d_{31}}{2}\left(h_{t}+h_{s}\right) \frac{d \phi_{r}(x)}{d x}\right|_{x=L_{b}}
$$

Substituindo os termos das equações 3.17 e 3.30 na equação 3.43:

$$
C_{p}^{S} \frac{d v(t)}{d t}+\frac{v(t)}{z(t)}=\left.\sum_{r=1}^{\infty} \frac{d \eta_{r}}{d t} \vartheta \frac{d \phi_{r}(x)}{d x}\right|_{x=L_{b}}=\sum_{r=1}^{\infty} \chi_{r} \frac{d \eta_{r}}{d t}
$$

Transformando a eq. 3.43 ao domínio de Laplace e substituindo o termo de acoplamento da eq. 3.30:

$$
V(s)\left(s C_{p}^{S}+\frac{1}{Z(s)}\right)=s \sum_{r=1}^{\infty} \chi_{r} H_{r}
$$

O termo da tensão isolado:

$$
V(s)=\frac{s \sum_{r=1}^{\infty} \chi_{r} H_{r}}{s C_{p}^{S}+\frac{1}{Z(s)}}
$$

A relação $H_{r}(s) / F(s)$ pode ser obtida substituindo a eq. 3.46 na eq. 3.31. Denominando $G_{H}(s)=s^{2}+2 \zeta_{r} \omega_{r} s+\omega_{r}^{2}$ (DA SILVA et al., 2010) pode se obter:

$$
G_{H}(s) H_{r}(s)+\chi_{r} \frac{s \sum_{r=1}^{\infty} \chi_{r} H_{r}}{s C_{p}+\frac{1}{Z(s)}}=F(s) \phi_{r}\left(L_{b}\right)
$$

Isolando o termo $H_{r}(s) / F(s)$ da eq. 3.47:

$$
\frac{H_{r}}{F}(s)=\frac{\phi_{r}\left(L_{b}\right)-\chi_{r} \frac{s \sum_{r=1}^{\infty} \frac{\phi_{r}\left(L_{b}\right) \chi_{r}}{G_{H}(s)}}{s C_{p}^{S}+\frac{1}{Z(s)}+s \sum_{r=1}^{\infty} \frac{\chi_{r}^{2}}{G_{H}(s)}}}{G_{H}(s)}
$$

Finalmente, a função de transferência $G(s)$, definida na eq. 3.9, pode ser calculada com a relação $H_{r}(s) / F(s)$ eq. 3.48 e as formas modais $\phi_{r}(x)$ no extremo livre da viga $L_{b}$ calculadas com a equação 3.23: 


$$
G(s)=\sum_{r=1}^{\infty} \phi_{r}\left(L_{b}\right) \frac{H_{r}}{F}(s)
$$

\subsubsection{Seleção do circuito de dissipação}

A função de transferência da equação 3.49 pode ser modificada dependendo da impedância $Z(s)$ resultante do circuito de dissipação conectado aos eletrodos da camada piezelétrica. No trabalho de Erturk e Inman (2009) estão descritos os principais circuitos dissipadores de energia e seus efeitos na estrutura.

Um circuito resistivo com impedância resultante $Z=R$ modifica a rigidez e o amortecimento e seu desempenho depende da constante piezelétrica de acoplamento. Um circuito indutivo com impedância $Z(s)=L s$ se comporta como um absorvedor dinâmico não amortecido, devido ao cancelamento da capacitância interna da camada piezelétrica $C_{p}$. Assim a indutância do absorvedor que atinge a frequência de ressonância pode se aproximar pela expressão (ERTURK; INMAN, 2009):

$$
L=\frac{1}{\omega_{r}^{2} C_{p}^{S}}
$$

Para obter o efeito de um absorvedor dinâmico amortecido, o circuito de dissipação pode ser resistivo-indutivo. Isto permite a dissipação de energia numa grande faixa de frequência perto da ressonância. A energia de deformação (associada com a vibração) é convertida em energia elétrica e dissipada em forma de calor através do efeito Joule (VIANA; STEFFEN, 2006). A transformação de energia é devida as propriedades eletromecânicas da camada piezelétrica. Hagood e Von Flotow (1991) define a constante de acoplamento eletromecânico como a relação entre a energia máxima armazenada no capacitor e a energia máxima armazenada na deformação do material considerando que os eletrodos da camada piezelétrica estão em circuito aberto. Matematicamente, o coeficiente de acoplamento eletromecânico está definido como (VIANA; STEFFEN, 2006):

$$
k_{31}=\frac{d_{31}}{\sqrt{s_{11}^{E} \epsilon_{33}^{T}}}
$$

Este valor também pode ser obtido diretamente da tabela de propriedades do material piezelétrico.

Hagood e Von Flotow (1991) modelou o sistema com a configuração mostrada na Fig. 3.4, como um sistema de um grau de liberdade com o componente piezelétrico, conectado ao circuito de dissipação de impedância elétrica $Z^{E L E}$, colocado em paralelo com a rigidez do sistema, representada na Fig. 3.4 com uma mola.

Sabendo que os eletrodos da camada piezelétrica estão conectados em série ao circuito de dissipação, com impedância $Z^{C I R}$, a impedância elétrica $Z^{E L E}$ pode se expressar como (VIANA; STEFFEN, 2006): 


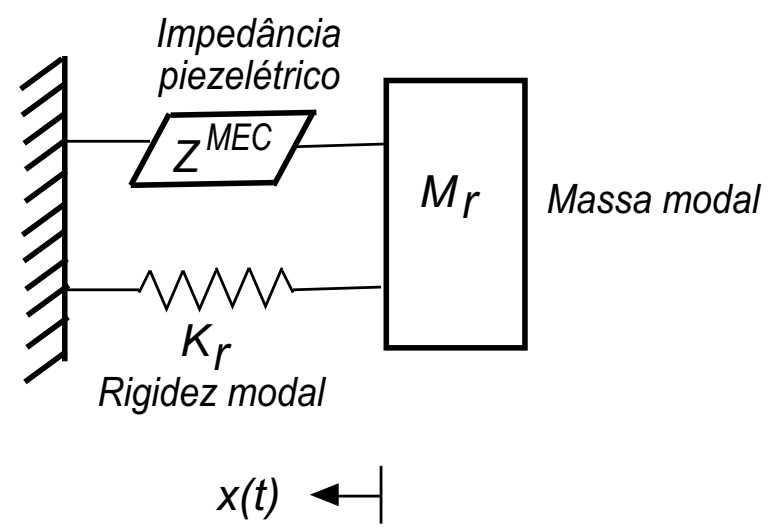

Figura 3.4: Esquema do sistema com o dispositivo piezelétrico (modificado de Hagood e Von Flotow (1991))

$$
\begin{gathered}
\frac{1}{Z^{E L E}(s)}=\frac{1}{Z_{p}}+\frac{1}{Z^{C I R}} \\
Z^{E L E}(s)=\frac{Z_{p} Z^{C I R}}{Z_{p}+Z^{C I R}}=\frac{Z^{C I R}}{1+Z^{C I R} C_{p}^{T} s}
\end{gathered}
$$

Onde $C_{p}^{T}$ é a capacitância da camada piezelétrica em condição de esforço constante (livre) e está relacionada com a capacitância de deformação constante $C_{p}^{S}$ da eq. 3.40 (HOLLKAMP, 1994):

$$
C_{p}^{S}=C_{p}^{T}\left(1-k_{31}^{2}\right)
$$

A impedância mecânica $Z^{M E C}(s)$ do componente piezelétrico acoplado pode ser expressa de forma adimensional dividindo pela impedância da camada piezelétrica em circuito aberto $Z_{p}=1 / C_{p}^{S} s$, e é calculada com a equação (HAGOOD; VON FLOTOW, 1991):

$$
\bar{Z}^{M E C}(s)=\frac{Z^{M E C}}{Z_{p}}=\frac{1-k_{31}^{2}}{1-k_{31}^{2} \bar{Z}^{E L E}(s)}
$$

Para avaliar o efeito do circuito dissipador no sistema mecânico da Fig. 3.4, é necessário definir a FRF que relaciona a aceleração da saída do sistema mecânico, e a força externa aplicada. No domínio de Laplace, essa relação é definida como (VIANA; STEFFEN, 2006):

$$
H(s)=\frac{s^{2}}{M_{r} s^{2}+Z^{M E C}(s) s+K_{r}}
$$

\section{Circuito de dissipação resistivo-indutivo em série}

O circuito de dissipação resistivo-indutivo em série foi proposto por Hagood e Von Flotow (1991), e está representado na figura 3.5:

A impedância obtida deste circuito está definida por: 


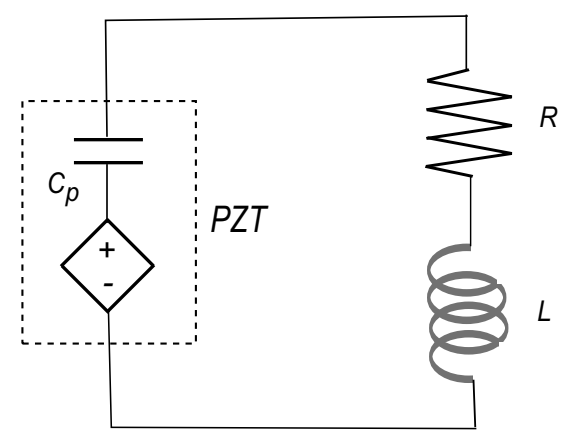

Figura 3.5: Circuito de dissipação resistivo-indutivo em série (modificado de Viana e Steffen (2006))

$$
Z_{\text {ser }}^{C I R}(s)=R+L s
$$

Substituindo a eq. 3.57 nas equações 3.52 e 3.55, pode se obter a impedância mecânica adimensional do componente piezelétrico conectado a um circuito de dissipação em série:

$$
\bar{Z}_{s e r}^{M E C}(s)=1-k_{31}^{2}\left(\frac{1}{L C_{p}^{S} s^{2}+R C p_{s}^{S}+1}\right)
$$

Com o fim de obter os valores ótimos de $L$ e $R$ para o circuito de dissipação, Viana e Steffen (2006) definem os seguintes termos:

- Frequência adimensional

$$
\gamma=\frac{s}{\omega_{r}^{E}}
$$

- Relação de ajuste adimensional

$$
\delta=\frac{\omega_{0}}{\omega_{r}}
$$

- Fator de amortecimento

$$
\epsilon=R C_{p}^{S} \omega_{r}^{E}
$$

onde $\omega_{0}$ é a frequência de ressonância elétrica:

$$
\omega_{0}=\frac{1}{\sqrt{L C_{p}^{S}}}
$$

$\omega_{r}^{E}$ é a frequência de ressonância do sistema mecânico correspondente ao circuito aberto:

$$
\omega_{r}^{E}=\sqrt{\frac{K_{r}+K_{11}^{E}}{M_{r}}},
$$

e $K_{11}^{E}$ é a rigidez da camada piezelétrica correspondente ao caso de circuito aberto $K_{11}^{E}$ definida como:

$$
K_{11}^{E}=\frac{A_{1}}{s_{11}^{E} L_{b}}
$$


onde $A_{1}$ é a área transversal da camada piezelétrica $b h_{p}$ como é mostrado na fig. 3.2. O termo da rigidez do sistema $K_{r}$ pode ser isolado da equação da frequência natural do sistema mecânico $\omega_{r}=\sqrt{K_{r} / M_{r}}$, obtendo assim:

$$
K_{r}=\omega_{r}^{2} \rho A L_{b}
$$

A equação 3.58 pode ser rescrita considerando os termos adimensionais das equações 3.59 , 3.60 e 3.61 :

$$
\bar{Z}_{\text {ser }}^{M E C}(\gamma)=1-k_{31}^{2}\left(\frac{\delta^{2}}{\gamma^{2}+\delta^{2} \epsilon \gamma+\delta^{2}}\right)
$$

O coeficiente de acoplamento eletromecânico generalizado relaciona as rigidezes da camada piezelétrica e da estrutura, através do coeficiente definido na eq. 3.51 e pode ser escrito como:

$$
K_{31}^{2}=\left(\frac{K_{11}^{E}}{K_{r}+K_{11}^{E}}\right)\left(\frac{k_{31}^{2}}{1-k_{31}^{2}}\right)
$$

Uma outra aproximação deste coeficiente pode ser calculada com valores experimentais. Hagood e Von Flotow (1991) usam a seguinte expressão:

$$
K_{31}^{2}=\frac{\left(\omega_{r}^{D}\right)^{2}+\left(\omega_{r}^{E}\right)^{2}}{\left(\omega_{r}^{E}\right)^{2}}
$$

onde $\omega_{r}^{D}$ e $\omega_{r}^{E}$ são as frequências naturais da estrutura quando os terminais das camadas piezelétricas estão em circuito aberto e fechado respectivamente.

Assim a FRF da eq. 3.56 para um sistema com circuito em série também pode ser rescrita considerando os termos adimensionais:

$$
H_{\text {ser }}(\gamma)=\frac{\left(\delta^{2}+\gamma^{2}\right)+\delta^{2} \epsilon \gamma}{\left(1+\gamma^{2}\right)\left(\delta^{2}+\gamma^{2}+\delta^{2} \epsilon \gamma\right)+K_{31}^{2}\left(\gamma^{2}+\delta^{2} \epsilon \gamma\right)}
$$

A FRF da eq. 3.69 é comparada com uma FRF de um absorvedor dinâmico de vibrações (DVA pelas siglas em inglês). Enquanto o DVA absorbe energia cinética e sua localização ótima está num ponto de deslocamento máximo, o circuito dissipa uma porção da energia de deformação que é convertida em energia elétrica e porém sua localização ótima está num ponto de deformação máxima (VIANA; STEFFEN, 2006).

Hagood e Von Flotow (1991) usaram a análise da equação 3.69 para obter os valores ótimos de $\delta$ e de $\epsilon$, de maneira similar à qual são obtidos estes valores para um DVA. A Fig. 3.6 ilustra a influência dos distintos valores de $\epsilon$ na função de transferência de um sistema com circuito em série, usando $K_{31}^{2}=0.05$, Uma relação de ajuste ótima $\delta=\delta_{o t}$, e usando a frequência adimensional $g=\omega / \omega_{r}$. Pode se observar que para todos os valores de $\epsilon$, as curvas da função de transferência passam pelos pontos invariantes $P$ e $Q$. O processo de otimização usa os valores das magnitudes da FRF da eq. 3.69 quando $\epsilon$ é 0 e $\infty$ para definir os pontos invariantes $P$ e $Q$.

Nos trabalhos de Hollkamp (1994), Caruso (2001), Granier et al. (2002) e Viana e Steffen (2006) é usado este processo de otimização para obter os valores ótimos e testar o desempenho 


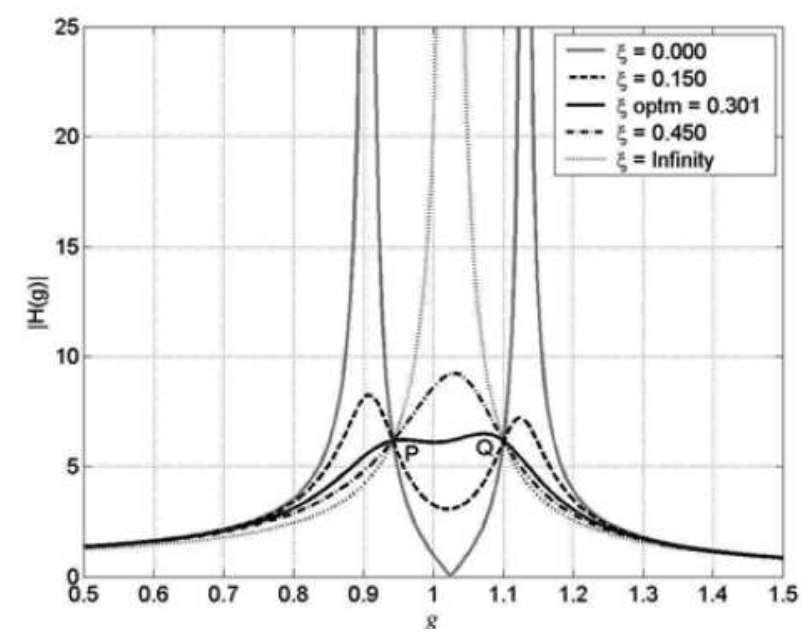

Figura 3.6: Funçao de transferência $H_{s e r}(g)$ do sistema com circuito em série (retirado de Viana e Steffen (2006))

do circuito experimentalmente. Assim a relação de frequências ótima é definida como:

$$
\delta_{o t}^{s e r}=\sqrt{1+K_{31}^{2}}
$$

Um método usado para obter o amortecimento ótimo é selecionar uma frequência ou relação de frequências, a qual pode ser $\delta_{\text {ot }}$, e ajustar a magnitude nessa frequência com a magnitude dos pontos invariantes $P$ e $Q$ (HAGOOD; VON FLOTOW, 1991), assim o amortecimento ótimo é definido como:

$$
\epsilon_{o t}^{s e r}=\frac{\sqrt{2} K_{31}}{1+K_{31}^{2}}
$$

Usando o coeficiente de acoplamento eletromecânico $K_{31}$ da eq. 3.67 (ou de um ponto de vista prático o coeficiente da eq. 3.93), a capacitância da camada piezelétrica $C_{p}^{S}$ da eq. $3.40 \mathrm{e}$ a frequência de ressonância $\omega_{r}$ da eq. 3.25, pode se obter os valor ótimo da indutância para o circuito de dissipação resistivo-indutivo em série (VIANA; STEFFEN, 2006):

$$
L_{o t}^{s e r}=\frac{1}{C_{p}^{S} \omega_{0}^{2}}=\frac{1}{C_{p}^{S}\left(\omega_{r} \delta_{o t}^{s e r}\right)^{2}}=\frac{1}{C_{p}^{S}\left(1+K_{31}^{2}\right) \omega_{r}^{2}}
$$

O valor da resistência está definido por:

$$
R_{o t}^{s e r}=\frac{\epsilon_{o t}^{s e r}}{C_{p}^{S} \omega_{r}}=\frac{\sqrt{2} K_{31}}{C_{p}^{S} \omega_{r}\left(1+K_{31}^{2}\right)}
$$

\section{Circuito de dissipação resistivo-indutivo em paralelo}

O circuito de dissipação resistivo-indutivo em paralelo foi proposto por Wu (1996), como alternativa ao circuito em série, obtendo o mesmo efeito do absorvedor dinâmico de vibrações. A configuração do circuito é mostrada na Fig. 3.7: 


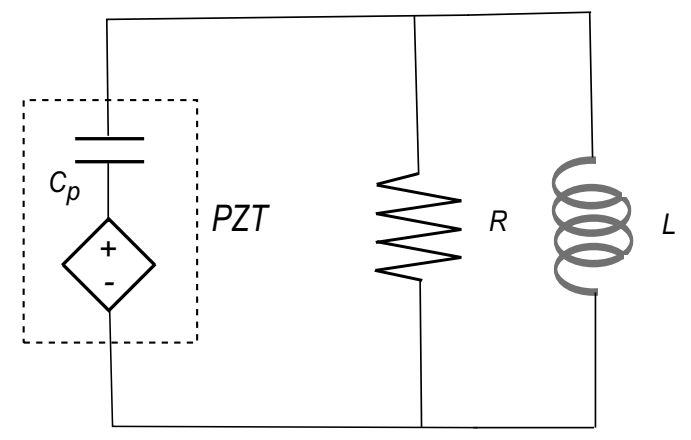

Figura 3.7: Circuito de dissipação resistivo-indutivo em paralelo (modificado de Viana e Steffen (2006))

A impedância obtida da análise do circuito é:

$$
Z_{\text {par }}^{C I R}(s)=\frac{R L s}{R+L s}
$$

Usando a equações 3.52 e 3.55 pode se obter a impedância mecânica do componente piezelétrico conectado a um circuito de dissipação em paralelo:

$$
\bar{Z}_{p a r}^{M E C}(s)=1-k_{31}^{2}\left(\frac{L s^{2}+R}{R L C_{p} s^{2}+L s+R}\right)
$$

Expressando a eq. 3.75 em termos adimensionais:

$$
\bar{Z}_{p a r}^{M E C}(s)=1-k_{31}^{2}\left(\frac{\gamma+\epsilon \delta^{2}}{\epsilon \gamma^{2}+\gamma+\epsilon \delta^{2}}\right)
$$

Substituindo na FRF da eq. 3.56 obtém-se:

$$
H_{p a r}(\gamma)=\frac{\delta^{2} \epsilon+\gamma^{2} \epsilon+\gamma}{\left(\delta^{2} \epsilon+\gamma^{2} \epsilon+\gamma\right)\left(1+\gamma^{2}\right)+K_{31}^{2} \gamma^{2} \epsilon}
$$

De maneira similar ao procedimento proposto por Hagood e Von Flotow (1991) para o circuito em série, Wu (1996) usou a analise da função de transferência para obter os valores ótimos da frequência adimensional:

$$
\delta_{o t}^{p a r}=\sqrt{1+\frac{K_{31}^{2}}{2}}
$$

e o fator de amortecimento:

$$
\epsilon_{o t}^{p a r}=\frac{1}{\sqrt{2} K_{31}}
$$

De igual maneira do que no circuito em série, pode se plotar a função de transferência de um sistema com circuito em paralelo, como mostrado na Figura 3.8. Observa-se a influência dos valores de $\epsilon$, usando $K_{31}^{2}=0.05, \delta=\delta_{\text {ot }}$ e usando a frequência adimensional $g=\omega / \omega_{r}$. São observados os pontos invariantes $P$ e $Q$.

O valor ótimo de indutância do circuito de dissipação em paralelo está definido por (VIANA; STEFFEN, 2006): 


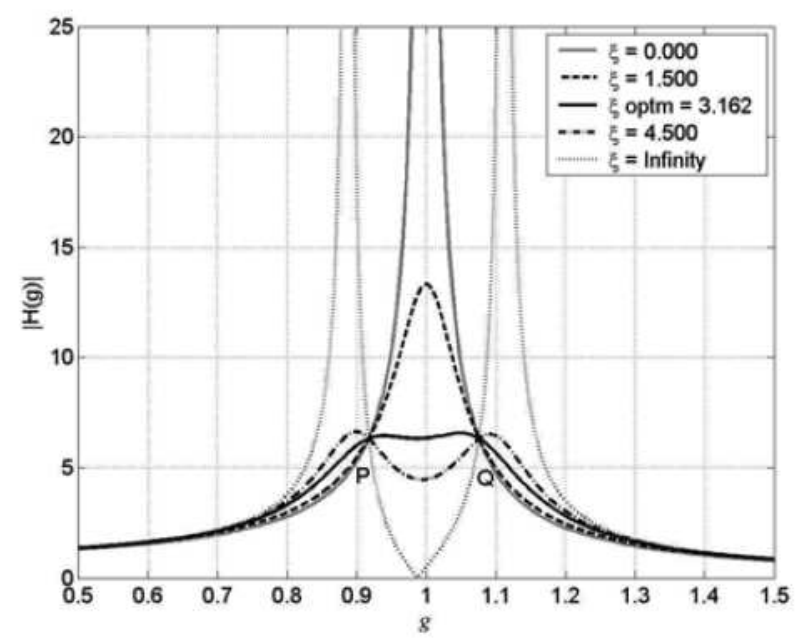

Figura 3.8: Funçao de transferência $H_{\text {par }}(g)$ do sistema com circuito em paralelo (retirado de Viana e Steffen (2006))

$$
L_{o t}^{p a r}=\frac{1}{C_{p}^{S} \omega_{0}^{2}}=\frac{1}{C_{p}^{S}\left(\omega_{r} \delta_{o t}^{p a r}\right)^{2}}=\frac{1}{C_{p}^{S}\left(1-\frac{K_{31}^{2}}{2}\right) \omega_{r}^{2}}
$$

E o valor ótimo de resistência seria:

$$
R_{o t}^{p a r}=\frac{\epsilon_{o t}^{p a r}}{C_{p}^{S} \omega_{r}}=\frac{1}{\sqrt{2} K_{31} C_{p}^{S} \omega_{r}}
$$

\subsubsection{Indutores sintéticos}

As indutâncias ótimas dos circuitos resistivo-indutivos, calculadas nas eqs. 3.72 e 3.80, são inversamente proporcionais às frequências naturais, que para elementos esbeltos como o suporte da ferramenta são relativamente baixas, assim como aos valores da capacitância da camada piezelétrica. Dessa maneira os valores requeridos de indutância podem chegar a ser relativamente altos para ser encontrados comercialmente, devido ao tamanho e capacidade que deveriam ter (VIANA; STEFFEN, 2006). Por esta razão tem sido desenvolvidos indutores sintéticos usando amplificadores operacionais, obtendo assim indutâncias equivalentes relativamente altas. Um circuito sintético desenvolvido por Antoniou (1969) é mostrado na Fig. 3.9.

As tensões de saída dos amplificadores operacionais estão definidas como:

$$
V_{d}=A_{1}\left(V_{a}-V_{c}\right), \quad V_{b}=A_{2}\left(V_{e}-V_{c}\right)
$$

Considerando amplificadores operacionais ideais, as correntes nas entradas são nulas, e os ganhos dos amplificadores são infinitos $\left(A_{1}=A_{2}=\infty\right)$, assim as tensões de entrada das equações 3.82 seriam iguais $\left(V_{a}=V_{c}=V_{e}=V_{i}\right)$.

Aplicando a lei de Ohm para obter a corrente que passa pela impedância $Z_{5}$ (a tensão de saída $V_{o}=0$ ), e a lei de Kirchhoff de soma de correntes no nó $e$ (a corrente na entrada positiva 


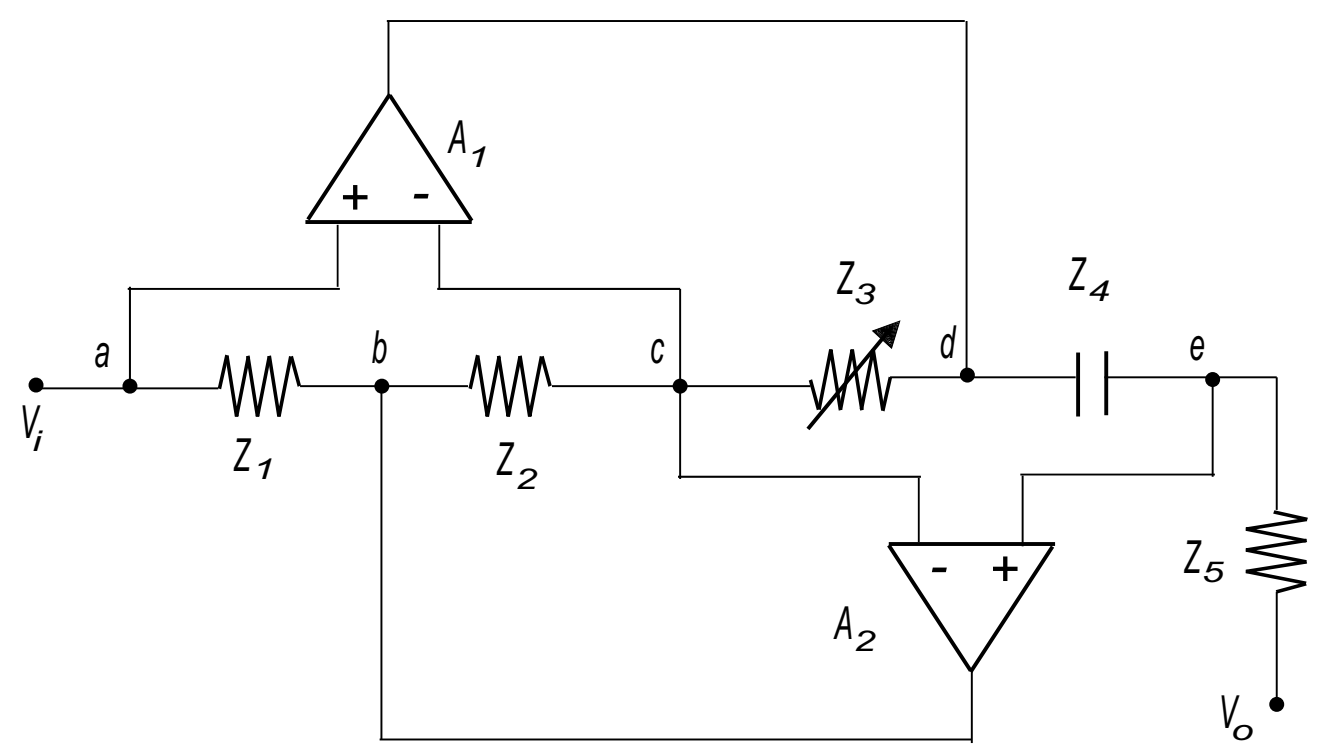

Figura 3.9: Circuito para um indutor sintético (modificado de Viana e Steffen (2006))

do amplificador 2 é nula), obtém-se a expressão:

$$
I_{5}=\frac{V_{i}}{Z_{5}}=I_{4}
$$

Usando a lei de Ohm nas impedâncias $Z_{4}$ e $Z_{3}$ são obtidas as equações:

$$
V_{d}-V_{i}=I_{4} Z_{4}, \quad V_{i}-V_{d}=-I_{3} Z_{3}
$$

Arranjando os termos da eq. 3.84, usando a lei de Kirchhoff no nó $c$ (as correntes nas entradas negativas dos amplificadores são nulas), e substituindo a eq. 3.83, obtém-se a relação:

$$
I_{3}=\frac{Z_{4}}{Z_{3}} I_{4}=\frac{Z_{4}}{Z_{3} Z_{5}} V_{i}=I_{2}
$$

Novamente aplicando a lei de Ohm nas impedâncias $Z_{2}$ e $Z_{1}$ são obtidas as equações:

$$
V_{b}-V_{i}=I_{2} Z_{2}, \quad V_{i}-V_{b}=-I_{1} Z_{1}
$$

Arranjando os termos da eq. 3.86, aplicando a lei de Kirchhoff no nó a (a corrente na entrada positiva do amplificador 1 é nula), e substituindo a eq. 3.85, obtém-se a relação:

$$
I_{1}=\frac{Z_{2}}{Z_{1}} I_{2}=\frac{Z_{4} Z_{2}}{Z_{1} Z_{3} Z_{5}} V_{i}=I_{i}
$$

Colocando um capacitor na impedância $Z_{4}=\frac{1}{C_{4} s}$, e os demais componentes resistores, a relação entre a tensão a corrente de entrada no domínio de Laplace seria:

$$
\frac{V_{i}}{I_{i}}=\frac{R_{1} R_{3} C_{4} R_{5}}{R_{2}} s
$$


mostrando um comportamento similar a um indutor $\left(V_{i}=I_{i} L_{e q} s\right)$. Portanto a indutância equivalente seria:

$$
L_{e q}=\frac{R_{1} R_{3} C_{4} R_{5}}{R_{2}}
$$

O comportamento da indutância equivalente $L_{e q}$ pode diferir da realidade numa certa faixa de frequências, dependendo da influencia da resistências e capacitâncias internas dos amplificadores operacionais usados. Uma análise simulando o comportamento real é descrita na seção de resultados.

\subsection{Solução Ativa}

Com o fim de aumentar o amortecimento do sistema de maneira ativa, é considerado o controle de realimentação de posição e velocidade usando uma camada piezelétrica como sensor e outra como atuador, como é mostrado na figura 1.3 (b). Para obter o modelo, assume-se que ambas camadas piezelétricas cobrem todo o comprimento da viga como é mostrado na figura 3.1 .

A quantidade de carga elétrica gerada na camada piezelétrica é proporcional ao promédio de curvatura da seção mostrada na fig. 3.1 (b), assim a saída do sensor é proporcional à diferença da rotação nos extremos da camada piezelétrica. Usando a equação constitutiva da eq. 3.32 escrita em termos da constante piezelétrica de polarização $e_{31}$ e forçando um campo elétrico nulo $\left(E_{3}=0\right)$ com um amplificador de carga elétrica, o deslocamento elétrico é obtido (PREUMONT, 2006):

$$
D_{3}=e_{31} S_{1}
$$

Assumindo que a espessura do sensor piezelétrico é fina com respeito à espessura total da viga, a deformação $S_{1}$ está definida na equação 3.35. Substituindo na eq. 3.90:

$$
D_{3}=e_{31} \frac{h_{t}+h_{s}}{2} \frac{\partial^{2} w(x, t)}{\partial x^{2}}
$$

A tensão de saída do sensor distribuído $v^{s e}(t)$ pode se descrever em função da capacitância da camada piezelétrica da equação 3.40, e carga elétrica definida na equação 3.37 :

$$
v^{s e}(t)=\frac{1}{C_{p}} q(t)=\frac{h_{t}-h_{s}}{2 \epsilon_{33}^{S} b L_{b}} \int_{0}^{L_{b}} D_{3} b d x
$$

Substituindo o termo do deslocamento elétrico da eq. 3.91 na eq. 3.92, e completando a integração obtém-se:

$$
v^{s e}(t)=\left.\frac{e_{31}}{\epsilon_{33}^{S}} \frac{\left(h_{t}-h_{s}\right)\left(h_{t}+h_{s}\right)}{4 L_{b}} \frac{\partial w(x, t)}{\partial x}\right|_{0} ^{L_{b}}
$$


Sabendo que a constante piezelétrica do sensor é definida como (IEEE, 1988):

$$
h_{31}=\frac{e_{31}}{\epsilon_{33}^{s}},
$$

a tensão de saída do sensor é descrita como:

$$
v^{s e}(t)=\left.\frac{\left(h_{t}+h_{s}\right)\left(h_{t}-h_{s}\right)}{4 L_{b}} h_{31} \frac{\partial w(x, t)}{\partial x}\right|_{0} ^{L_{b}}
$$

No controle de realimentação de deslocamento a tensão aplicada no atuador é proporcional á tensão de saída do sensor e no controle de velocidade a tensão aplicada é proporcional à primeira derivada da tensão de saída do sensor. Assim a tensão aplicada na camada piezelétrica do atuador é descrita como:

$$
v^{a c}(t)=G_{d} v^{s e}(t)+G_{v} \frac{d v^{s e}(t)}{d t}
$$

onde $G_{d}$ e $G_{v}$ são os ganhos de realimentação de deslocamento e velocidade, respectivamente. Esta ação de controle produz um momento distribuído uniformemente ao longo do comprimento da viga e que pode ser calculado como (KAYACIK et al., 2008):

$$
M^{a}(x, t)=\frac{h_{t}+h_{s}}{2} d_{31} Y_{p} v^{a c}(t)
$$

Substituindo a equações 3.95 e 3.96 na equação 3.97 o momento é expressado como:

$$
M^{a}(x, t)=\left.\left(\xi_{d}+\xi_{v} \frac{d}{d t}\right) \frac{\partial w(x, t)}{\partial x}\right|_{0} ^{L_{b}},
$$

onde os termos $\xi_{d}$ e $\xi_{v}$ estão definidos como:

$$
\begin{aligned}
& \xi_{d}=-\frac{G_{d}\left(h_{t}-h_{s}\right)\left(h_{t}+h_{s}\right)^{2} d_{31} Y_{p} h_{31}}{8 L_{b}}, \\
& \xi_{v}=-\frac{G_{v}\left(h_{t}-h_{s}\right)\left(h_{t}+h_{s}\right)^{2} d_{31} Y_{p} h_{31}}{8 L_{b}}
\end{aligned}
$$

Devido a que as camadas piezelétricas do sensor e atuador cobrem todo o comprimento da viga, pode se obter assim a seguinte equação de movimento com uma força pontual $f(t)$ no extremo livre da viga engastada (KAYACIK et al., 2008):

$$
Y I \frac{\partial^{4} w(x, t)}{\partial x^{4}}+\rho A \frac{\partial^{2} w(x, t)}{\partial t^{2}}=f\left(L_{b}, t\right)
$$

Desde que existe uma derivada parcial de quarta ordem com respeito á posição $x$ na eq. 3.101, é necessário definir quatro condições de contorno para sua solução: 


$$
\begin{gathered}
w(0, t)=0 \\
\frac{\partial w(0, t)}{\partial x}=0 \\
Y I \frac{\partial^{2} w\left(L_{b}, t\right)}{\partial x^{2}}=-b\left(\xi_{d}+\xi_{v} \frac{d}{d t}\right) \frac{\partial w\left(L_{b}, t\right)}{\partial x} \\
Y I \frac{\partial^{3} w\left(L_{b}, t\right)}{\partial x^{3}}=0
\end{gathered}
$$

As condições de contorno das equações 3.102 e 3.103 indicam que no extremo fixo da viga engastada-livre o deslocamento e a rotação do eixo são nulas. A equação 3.104 indica que no extremo livre da viga engastada é aplicado o momento de controle correspondente ao atuador. A equação 3.105 indica que a força cortante é nula no extremo livre da viga. Usando a transformação modal da eq. 3.4, e considerando a coordenada temporal como harmônica $\eta_{r}=$ $H_{r} e^{\lambda_{r} t}$ a resposta á vibração livre e sem amortecimento viscoso pode ser escrita como:

$$
w(x, t)=\phi_{r}(x) H_{r} e^{\lambda_{r} t}
$$

Assim a condição de contorno da eq. 3.104 pode ser escrita como:

$$
\frac{d \phi_{r}^{2}(x)}{d x^{2}}+\beta(\lambda) \frac{d \phi_{r}(x)}{d x}=0
$$

onde:

$$
\beta(\lambda)=b \frac{\xi_{d}+\xi_{v} \lambda}{Y I}
$$

Quando $f(t)=0$ e substituindo a eq. 3.106, a equação 3.101 pode ser escrita como:

$$
\frac{d \phi_{r}^{4}(x)}{d x^{4}}-\alpha^{4} \phi_{r}(x)=0
$$

onde:

$$
\alpha^{4}=-\frac{\rho A \lambda^{2}}{Y I}
$$

Substituindo a solução da 3.109 nas condições de contorno, e solucionando o sistema de equações para encontrar as constantes de integração é possível obter a seguinte equação transcendental:

$$
\begin{array}{r}
\alpha_{r}\left(1+\cos \left(\alpha_{r} L_{b}\right) \cosh \left(\alpha_{r} L_{b}\right)\right)+ \\
+\beta\left(\alpha_{r}\right)\left(\cos \left(\alpha_{r} L_{b}\right) \sinh \left(\alpha_{r} L_{b}\right)+\cosh \left(\alpha_{r} L_{b}\right) \sin \left(\alpha_{r} L_{b}\right)\right)=0
\end{array}
$$


onde combinando as equações 3.108 e 3.110 podem se obter os autovalores do problema:

$$
\lambda_{r}= \pm i \alpha_{r}^{2} \sqrt{\frac{Y I}{\rho A}}
$$

assim como:

$$
\beta\left(\alpha_{r}\right)=\frac{b}{Y I}\left(\xi_{d} \pm \xi_{v} i \alpha_{r}^{2} \sqrt{\frac{Y I}{\rho A}}\right)
$$

A equação 3.111 pode ser resolvida para um conjunto de valores $\alpha_{r}$ para $r=1 \ldots \infty$, modificando as soluções preliminares e fazendo um processo iterativo. Se não existir nenhuma ação de controle o valor $\beta\left(\lambda_{r}\right)=0$, e a equação transcendental se reduz a equação característica de vibração livre de uma viga engastada com as condições de contorno fixo-livre da Eq. 3.24, considerada na análise da solução passiva.

Os autovalores calculados na eq. 3.112 são reais quando é aplicado controle de realimentação de deslocamento numa viga não amortecida. Se for aplicado controle de realimentação de velocidade, os autovalores obtidos serão números complexos da forma $\lambda_{r}=\lambda_{r e, r} \pm i \lambda_{i m, r}$. A resposta temporal da eq. 3.106 pode ser escrita como (KAYACIK et al., 2008):

$$
e^{\lambda_{r} t}=e^{\lambda_{r e, r} t}\left(\cos \left(\lambda_{i m, r} t\right) \pm i \sin \left(\lambda_{i m, r} t\right)\right)
$$

A condição de estabilidade para um modo depende de que a parte real do autovalor $\lambda_{r e, r}$ seja negativa, assim a resposta diminui com o tempo. Por essa razão são utilizadas os valores negativos do conjunto de soluções da eq. 3.112. A relação das frequências naturais não amortecidas com os autovalores complexos pode ser descrita como (CRAIG; KURDILA, 2006):

$$
\omega_{r}=\sqrt{\lambda_{r e, r}^{2}+\lambda_{i m, r}^{2}}
$$

De igual maneira os valores das relações de amortecimento:

$$
\zeta_{r}=-\frac{\lambda_{r e, r}}{\omega_{r}}
$$

As formas modais normalizadas $\phi_{r}(x)$ podem ser calculadas substituindo as soluções da eq. 3.111 na eq. 3.23 .

$$
\begin{array}{r}
\phi_{r}(x)=\sqrt{\frac{1}{\rho A L_{b}}}\left[\cosh \left(\alpha_{r} x\right)-\cos \left(\alpha_{r} x\right)-\right. \\
\left.-\frac{\sinh \left(\alpha_{r} L_{b}\right)-\sin \left(\alpha_{r} L_{b}\right)}{\cosh \left(\alpha_{r} L_{b}\right)+\cos \left(\alpha_{r} L_{b}\right)}\left(\sinh \left(\alpha_{r} x\right)-\sin \left(\alpha_{r} x\right)\right)\right]
\end{array}
$$

A função de transferência $G(s)$ pode ser calculada com as formas modais $\phi_{r}(x)$ no extremo 
livre da viga engastada calculadas na eq. 3.117 para a solução ativa, e a relação $H_{r} / F(s)$, obtida aplicando a eq. 3.48 quando o termo que contém a impedância do circuito de dissipação é nula $Z=0$ :

$$
\frac{H_{r}}{F}(s)=\frac{\phi_{r}\left(L_{b}\right)-\chi_{r} \frac{s \sum_{r=1}^{\infty} \frac{\phi_{r}\left(L_{b}\right) \chi_{r}}{G_{H}(s)}}{s C_{p}+\frac{1}{0}+s \sum_{r=1}^{\infty} \frac{\chi_{r}^{2}}{G_{H}(s)}}}{G_{H}(s)}
$$

ou usando a resposta da equação 3.9:

$$
G(s)=\frac{W}{F}(s)=\sum_{r=1}^{\infty} \frac{\phi_{r}^{2}\left(L_{b}\right)}{s^{2}+2 \zeta_{r} \omega_{r} s+\omega_{r}^{2}}
$$

\subsubsection{Análise do controle ativo}

Com o objetivo de analisar a influência das ações de controle é importante obter a função de transferência que relaciona a tensão do sensor e a tensão do atuador acoplados no suporte da ferramenta. A Fig. 3.10 ilustra o esquema do sistema de controle do suporte da ferramenta com o controlador $C(S)$, e a função de transferência $G_{t}(s)$ a ser obtida .

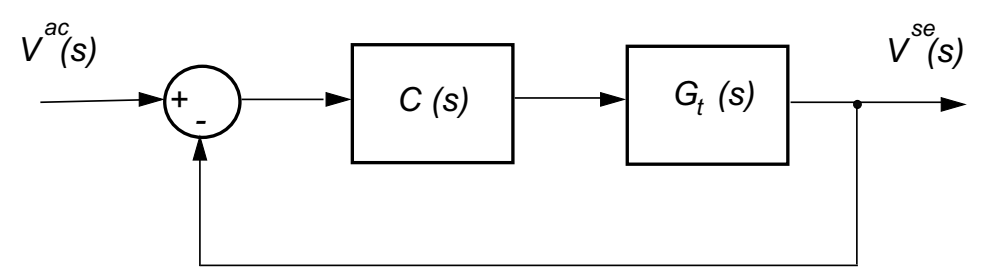

Figura 3.10: Controle de realimentação

Considerando o momento gerado pelo atuador $M^{a}(x, t)$ na equação diferencial de movimento da eq. 3.101, e sem aplicação da força externa, pode se escrever (KAYACIK et al., 2008):

$$
Y I \frac{\partial^{4} w(x, t)}{\partial x^{4}}+\rho A \frac{\partial^{2} w(x, t)}{\partial t^{2}}-b \frac{\partial^{2} M^{a}(x, t)}{\partial x^{2}}=0
$$

Usando a transformação de coordenadas da eq. 3.4 na eq. 3.120, multiplicando por a função normal $\phi_{s}(x)$ e integrando nos limites de 0 a $L_{b}$ obtem-se:

$$
\begin{array}{r}
\eta_{r}(t) \sum_{r=1}^{\infty} \int_{0}^{L_{b}} Y I \frac{d^{4} \phi_{r}(x)}{d x^{4}} \phi_{s}(x) d x+\frac{d^{2} \eta_{r}(t)}{d t^{2}} \sum_{r=1}^{\infty} \int_{0}^{L_{b}} \rho A \phi_{r}(x) \phi_{s}(x) d x+ \\
-b \int_{0}^{L_{b}} \frac{\partial^{2} M^{a}(x, t)}{\partial x^{2}} \phi_{s}(x) d x=0
\end{array}
$$

Usando as condições de ortogonalidade das equações 3.27 e 3.28 quando $r=s$, considerando o momento da eq. 3.97, e incluindo a relação de amortecimento $\zeta$ obtém-se:

$$
\frac{d^{2} \eta_{r}(t)}{d t^{2}}+2 \zeta_{r} \omega_{r} \frac{d \eta_{r}(t)}{d t}+\omega_{r}^{2} \eta_{r}(t)=\left.b \frac{h_{t}+h_{s}}{2} d_{31} Y_{p} v^{a c}(t) \frac{d \phi_{r}(x)}{d x}\right|_{0} ^{L_{b}}
$$


Aplicando transformada de Laplace:

$$
H_{r}(s) s^{2}+2 H_{r}(s) \zeta_{r} \omega_{r} s+H_{r}(s) \omega_{r}^{2}=\left.b \frac{h_{t}+h_{s}}{2} d_{31} Y_{p} \frac{d \phi_{r}(x)}{d x}\right|_{0} ^{L_{b}} V^{a c}(s)
$$

Isolando o termo da coordenada temporal $H_{r}(s)$ :

$$
H_{r}(s)=b \frac{h_{t}+h_{s}}{2} d_{31} Y_{p} \frac{\left.\frac{d \phi_{r}(x)}{d x}\right|_{0} ^{L_{b}}}{s^{2}+s \zeta_{r} \omega_{r} s+\omega_{r}^{2}} V^{a c}(s)
$$

Para definir a função de transferência do sensor é necessário usar a transformação de coordenadas da eq. 3.4 na eq. 3.95 da tensão da saída do sensor:

$$
v^{s e}(t)=\left.\sum_{r=1}^{\infty} \eta_{r}(t) \frac{d \phi_{r}(x)}{d x}\right|_{0} ^{L_{b}}
$$

Aplicando transformada de Laplace obtém-se:

$$
V^{s e}(s)=\left.\frac{\left(h_{t}+h_{s}\right)\left(h_{t}-h_{s}\right)}{4 L_{b}} h_{31} \sum_{r=1}^{\infty} H_{r}(s) \frac{d \phi_{r}(x)}{d x}\right|_{0} ^{L_{b}},
$$

e substituindo a coordenada temporal da eq. 3.124 na eq. 3.126 :

$$
V^{s e}(s)=\frac{b h_{31} d_{31} Y_{p}\left(h_{t}+h_{s}\right)^{2}\left(h_{t}-h_{s}\right)}{8 L_{b}} \sum_{r=1}^{\infty} \frac{\left(\left.\frac{d \phi_{r}(x)}{d x}\right|_{0} ^{L_{b}}\right)^{2}}{s^{2}+2 \zeta_{r} \omega_{r} s+\omega_{r}^{2}} V^{a c}(s)
$$

Finalmente a função de transferência que relaciona a tensão de saída do sensor com a tensão gerada no atuador, está definida por:

$$
G_{t}(s)=\frac{V^{s e}}{V^{a c}}(s)=\frac{b h_{31} d_{31} Y_{p}\left(h_{t}+h_{s}\right)^{2}\left(h_{t}-h_{s}\right)}{8 L_{b}} \sum_{r=1}^{\infty} \frac{\left(\left.\frac{d \phi_{r}(x)}{d x}\right|_{0} ^{L_{b}}\right)^{2}}{s^{2}+2 \zeta_{r} \omega_{r} s+\omega_{r}^{2}}
$$

A eq. 3.128 em termos de controle de realimentação seria definida como a função de transferência em malha aberta. O denominador dessa equação é conhecido como equação característica e sua solução mostra a posição dos pólos do sistema no plano complexo. A posição dos zeros do sistema depende da posição do sensor e atuador, devido a que o termo $\left.\frac{d \phi_{r}(x)}{d x}\right|_{0} ^{L_{b}}$ encontra-se no numerador da eq. 3.128. A posição alternada de pólos e zeros caracteriza a configuração co-localizada do sensor-atuador (GANGULI, 2005).

Preumont (2006) define a configuração co-localizada do sensor-atuador quando o sensor e o atuador estão colocados sobre a mesma extensão ao longo da viga e trabalham na mesma 
direção. $\mathrm{O}$ amortecimento ativo não precisa as características do modelo do sistema, e é robusto se for usada a configuração co-localizada do sensor-atuador (GANGULI, 2005)

Baseado na eq. 3.96, a equação do controlador $C(s)=G_{d}+G_{v} s$ é considerada na função de transferência em malha fechada:

$$
G_{m f}(s)=\frac{G_{t}(s) g_{c} C(s)}{1+G_{t}(s) g_{c} C(s)}
$$

onde $g_{c}$ é o ganho do controlador.

A solução da equação característica do sistema da a localização dos pólos do sistema em malha fechada. Se $g_{c}=0$ os pólos seriam os mesmos da função de transferência da malha aberta da eq. 3.128. Se $g_{c}=\infty$ os pólos correspondem a posição dos zeros do sistema em malha aberta. Num diagrama do lugar das raízes os pólos do sistema se movimentam da sua posição em malha aberta até os zeros enquanto o valor de $g_{c}$ aumenta. A localização dos pólos do sistema em malha fechada dependem da posição relativa de pólos e zeros da função de transferência em malha aberta, e tem um efeito importante na robustez do controle de realimentação o malha fechada (GANGULI, 2005).

Para mostrar o efeito do controlador de modo simples, só é considerado o primeiro termo do somatório da eq. 3.128. Considerando uma constante $K_{p}$ que depende da posição das camadas do sensor e atuador, assim como suas propriedades geométricas e piezelétricas:

$$
K_{p}=\frac{b h_{31} d_{31} Y_{p}\left(h_{t}+h_{s}\right)^{2}\left(h_{t}-h_{s}\right)}{8 L_{b}}\left(\left.\frac{d \phi_{1}(x)}{d x}\right|_{0} ^{L_{b}}\right)^{2}
$$

A função de transferência em malha fechada da eq. 3.129 para o primeiro modo seria:

$$
G_{m f}^{1}=\frac{K_{p}\left(G_{d}+G_{v} s\right)}{s^{2}+\left(2 \zeta_{1} \omega_{1}+K_{p} G_{v}\right) s+\left(\omega_{1}^{2}+K_{p} G_{d}\right)}
$$

Assim pode se observar que o termo do ganho de velocidade $G_{v}$ introduz um aumento no coeficiente de amortecimento no denominador da eq. 3.131, e o termo do ganho de deslocamento $G_{d}$ modifica a rigidez. Além disso, os ganhos do controlador modificam a magnitude da resposta. Devido à configuração co-localizada do sensor e atuador, $K_{p}$ é sempre positiva resultando numa estabilidade incondicional em malha fechada (GANGULI, 2005). 


\section{Capítulo 4}

\section{Metodologia para avaliação experimental}

O presente capítulo descreve a metodologia usada para avaliar experimentalmente o uso de material piezelétrico acoplado ao suporte da ferramenta, no qual serão aplicadas soluções de controle passivo e ativo. A seção 4.1 detalha os materiais e equipes utilizados nos experimentos, assim como algumas características importantes a considerar. Na seção 3.2 são descritos os experimentos preliminares para definir circuitos de condicionamento de sinal e a obtenção das FRFs . Finalmente nas seções 4.3 e 4.4 são propostos os esquemas de aquisição de dados para as soluções passivas e ativas.

\subsection{Materiais e equipamentos}

\subsubsection{Máquina e materiais para usinagem}

O torno utilizado para as medições e usinagem de eixos é o INDEX GU 600 CNC ilustrado na Fig. 4.1 (a). No fuso principal podem ser montados eixos de até $65 \mathrm{~mm}$ de diâmetro, com um comprimento máximo de torneamento de $600 \mathrm{~mm}$.

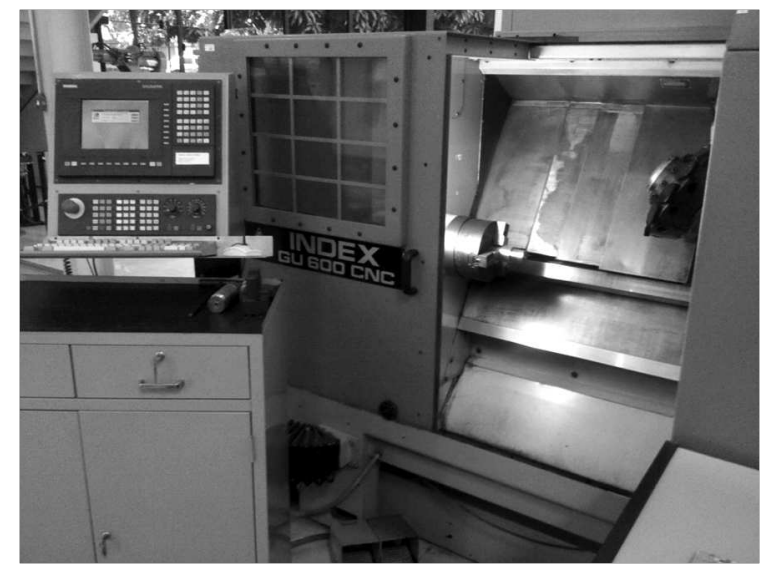

(a)

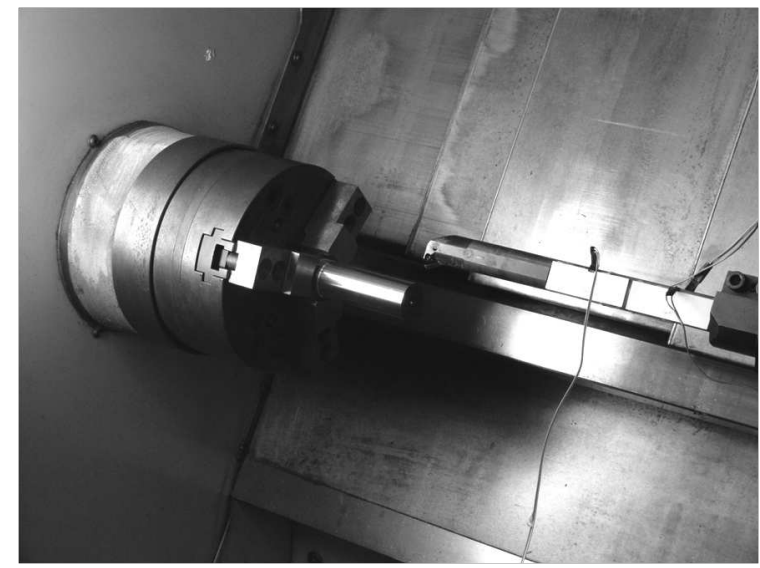

(b)

Figura 4.1: Torno INDEX GU 600 CNC: (a) Vista geral da máquina (b) Vista do eixo de aço no fuso principal e do suporte de ferramenta com as pastilhas piezelétricas coladas

Na Fig. 4.1 (b) é mostrado o suporte de ferramentado montado no cabeçote revólver do torno. O suporte da ferramenta é o CoroTurn ${ }^{\circledR} 111$ para torneamento interno, da Sandvik- 
Coromant ${ }^{\circledR}$. Foram usinadas duas superfícies planas opostas no suporte da ferramenta, para colar as pastilhas de material piezelétrico PZT-5A de $4 \mathrm{~mm}$ de espessura, e eletrodos de saída. Devido ao comprimento do suporte da ferramenta, é necessário colar duas pastilhas piezelétricas para cobrir a maiora do comprimento do suporte. As barras usinadas são de aço 1020 de $40 \mathrm{~mm}$ de diâmetro. As dimensões e materiais foram escolhidos para conseguir uma diferenciação do efeito das soluções passivas e ativas no acabamento das pecas, e no ruído gerado durante a usinagem.

\subsubsection{Equipamento de medição}

Os seguintes equipamentos são utilizados tanto para aquisição de sinais, como para medição da resposta em frequência (Alguns componentes são mostrados na Fig. 4.2):

- Osciloscópio Minipa MO-2200 200 MHz (2 canais)

- Martelo de Impacto PCB 086C03 (Constante 2,25m $/ \mathrm{N}$ )

- Acelerômetro magnético PCB080A30 (Constante 10,28 $\mathrm{mV} / \mathrm{N}$ )

- Condicionador de sinais ICP PCB 482A16 (4 canais)

- Placa de Aquisição NI USB9162

- Fonte $\pm 500 \mathrm{VAC}$

- Amplificador de potência PI E-462 10-1000 V (controle ativo)

- Conector PZT LEMO EGG.0B.701.CJL1173 (controle ativo)

- Placa de Aquisição e Controle (DSpace 1103)

- Cabos UTP

- Cabos coaxiais

\subsubsection{Características da placa de aquisição}

A placa de aquisição e geração de sinais é a DS1103 PPC Controller Board (ilustrada na Fig. 4.3), algumas das características técnicas para serem consideradas são descritas a continuação:

- Conversor A/D 16 canais

- Resolução 16-bit

- Faixa de tensão de entrada $\pm 10 \mathrm{~V}$

- Faixa de proteção para sobre tensão $\pm 15 \mathrm{~V}$

- Erro de offset $\pm 5 \mathrm{~V}$

- Erro de ganho $\pm 0.25 \%$ 


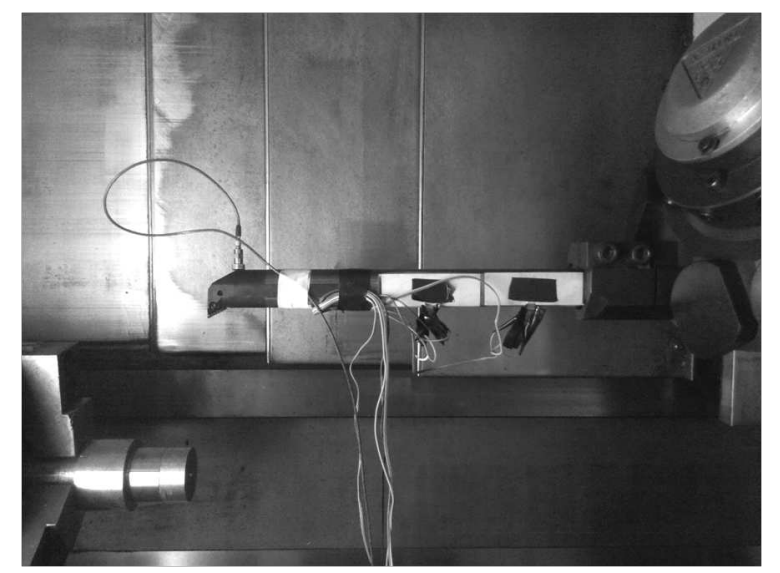

(a)

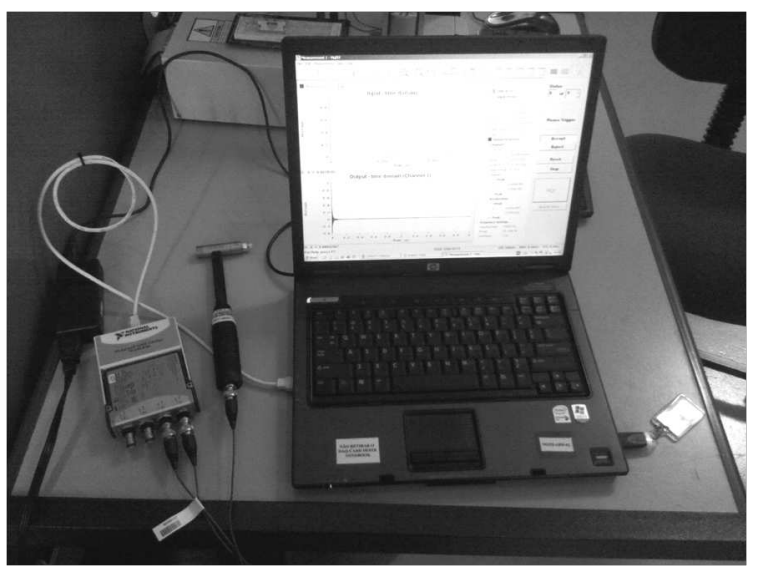

(b)

Figura 4.2: Equipamento para medição da FRF

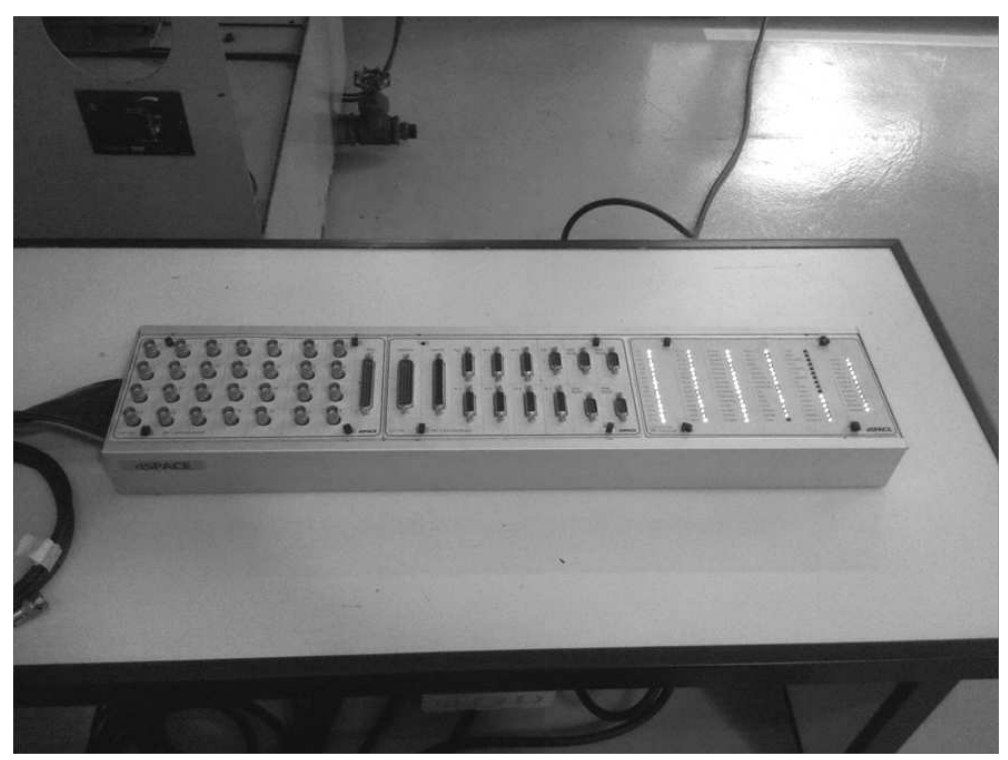

Figura 4.3: Placa de aquisição DS1103

\subsection{Descrição do experimento}

Como foi tratado anteriormente, o projeto propõe uma avaliação experimental de soluções passivas e ativas para o chatter em processos de torneamento. Isto é conseguido acoplando pastilhas piezelétricas no suporte da ferramenta. As pastilhas piezelétricas estão coladas na superfície do suporte da ferramenta e tem eletrodos para medir a diferença de tensão causada pela deformação da pastilha, usando o efeito piezelétrico de geração de tensão.

O experimento é realizado nas seguintes etapas:

- Medição preliminar das tensões de saída durante a usinagem de um eixo de aço 1020 de diâmetro aproximado $40 \mathrm{~mm}$, para definir o circuito de condicionamento de sinal que é conectado antes da placa de aquisição.

- Medição da função de resposta em frequência (FRF) do suporte da ferramenta montado 
no cabeçote do torno. Os valores de frequência de ressonância são usados como referência nas simulações numéricas, para obter valores ótimos de circuito de dissipação ótimo na solução passiva (Como indica a eq. 3.68).

- Montagem dos circuitos de dissipação para a solução passiva, e medição da FRF para fins comparativos e de ajustagem.

- Aplicação das leis de controle para a solução passiva, e medição da FRF para fins comparativos.

- Usando uma pastilha piezelétrica como sensor, medir a resposta do sistema ante as cargas de usinagem e comparar a aplicação das diferentes soluções.

Os resultados das últimas duas etapas não são apresentadas nesse trabalho devido a falta de disponibilidade dos equipamentos ou dificuldades no ajuste dos valores ótimos. No entanto estas atividades são propostas na seção de sugestões para trabalhos futuros.

\subsubsection{Circuito de condicionamento}

Uma vez que o sistema de aquisição trabalha com uma faixa máxima de $\pm 10 \mathrm{~V}$, é necessário colocar um circuito de condicionamento na saída do sensor (pastilha piezelétrica). Para definir os valores de tensão da saída do sensor foram feitos experimentos preliminares de torneamento num eixo de aço de $40 \mathrm{~mm}$ de diâmetro com os seguintes parâmetros:

- Avanço da ferramenta $40 \mathrm{~mm} / \mathrm{min}$ ou $0.04 \mathrm{~mm} /$ volta

- Velocidade de rotação da peça 1000 RPM

- Profundidade $0.5 \mathrm{~mm}$ no raio

Os valores máximos da tensão de saída do sensor foram observados no osciloscópio, como é mostrado na Fig. 4.4:

Um esquema da medição do circuito de condicionamento é mostrado na fig. 4.5. A tensão de saída $V_{1}$ é medida diretamente no osciloscópio obtendo um valor máximo de $500 \mathrm{~V}$, razão pela qual foi escolhido um divisor de tensão para obter uma redução de pelo menos 100 vezes a tensão de saída. Assim a tensão $V_{2}$ a ser medida depois do circuito de condicionamento com o divisor de tensão seria:

$$
V_{2}=\frac{V_{1} R_{1}}{R_{1}+R_{2}}
$$

Uma vez selecionados os valores dos componentes, que foram de $R_{1}=1 K \Omega$ e $R_{2}=$ $4(1 K \Omega)+5 K \Omega+4(10 K \Omega)+50 K \Omega=99 K \Omega$, é obtida uma tensão dentro da faixa do sitema de aquisição. $\mathrm{O}$ funcionamento do circuito de condicionamento é conferido com a medição no osciloscópio das magnitudes da entrada e saída como indica a Fig. 4.5. 


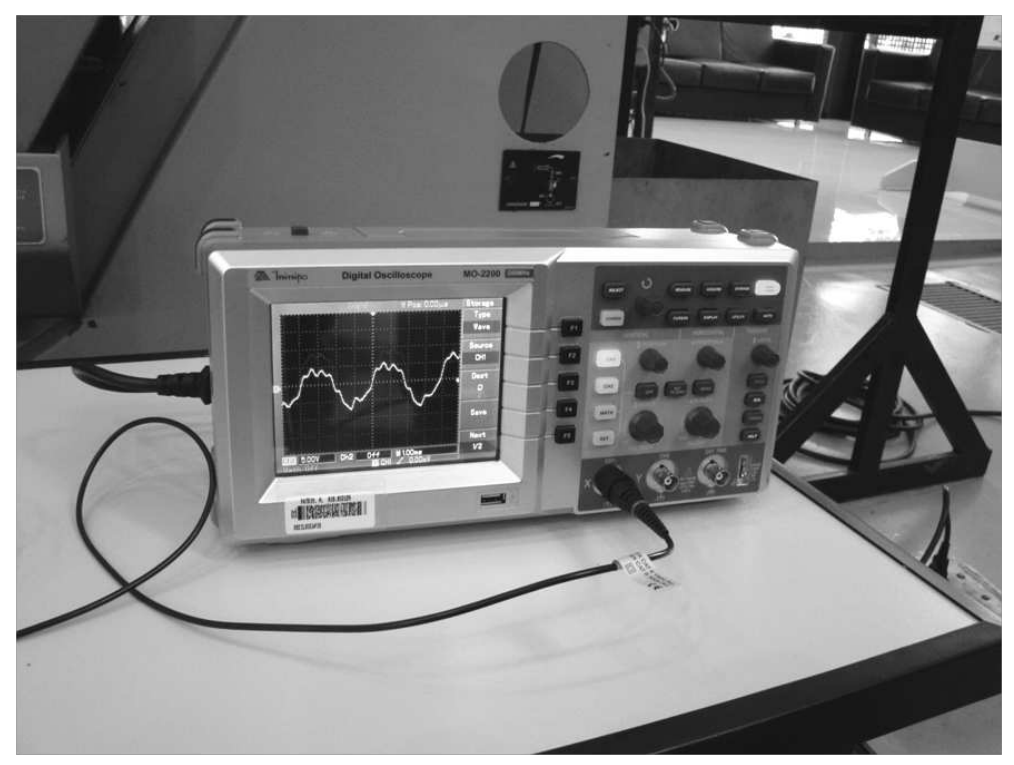

Figura 4.4: Osciloscópio usado para a medição das tensões de saída durante a usinagem

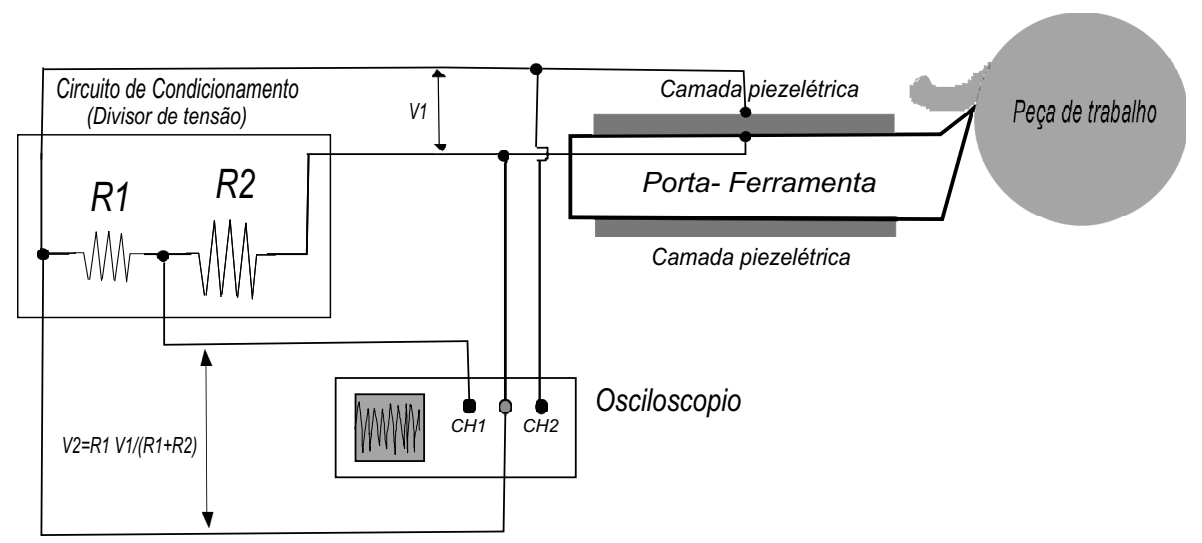

Figura 4.5: Medição de tensões de saída com o circuito de condicionamento de sinal

\subsubsection{Medição da FRF}

A obtenção das FRF do sistema do suporte da ferramenta montado no torno tem como objetivos principais obter as frequências de ressonância (para definir e ajustar os circuitos de dissipação na solução passiva), e fazer uma comparação das magnitudes de resposta identificando, observando a atenuação obtida com as estratégias aplicadas. Para realizar esta medição podem ser aplicados dois métodos. No primeiro método é usada a pastilha piezelétrica colada no suporte da ferramenta como sensor, e o martelo modal como atuador num teste de impacto como indica a Fig. 4.6.

A tensão gerada no impacto do martelo modal passa por um amplificador de sinal e de acordo as constantes de calibração é lida pela placa de aquisição. A tensão gerada pela deformação da pastilha piezelétrica, devido ao efeito efeito piezelétrico direto, passa previamente pelo circuito de condicionamento e é lida também pela placa de aquisição de acordo aos parâmetros de amostragem. Os dados são coletados para obter a resposta do sistema a um impulso, 


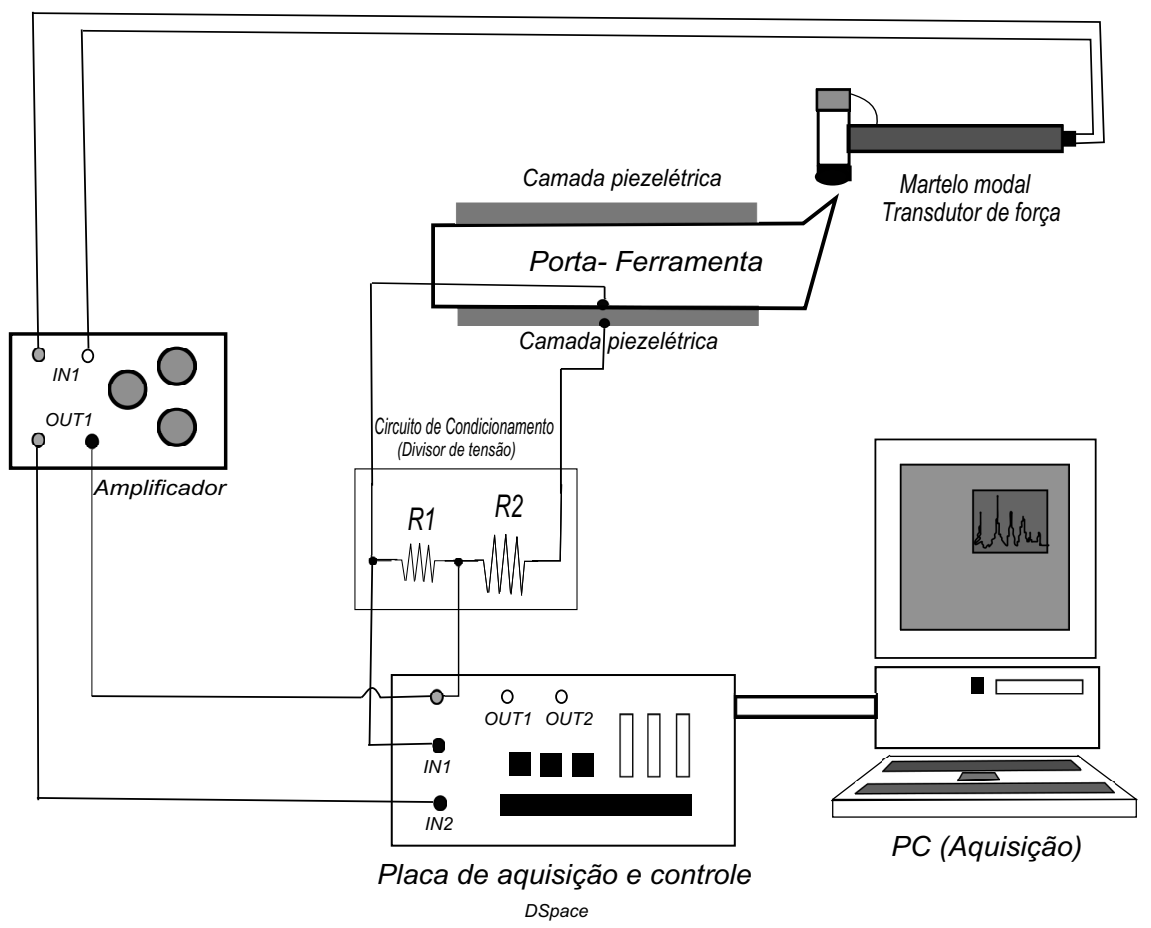

Figura 4.6: Medição da FRF usando uma pastilha piezelétrica como sensor e o martelo modal como atuador

tentando excitar todas as frequências de ressonância na direção perpendicular à direção de corte. Os dados coletados são tratados posteriormente no software ControlDesk ${ }^{\circledR}$ 3.7.1, ilustrado na Fig. 4.7, o qual trabalha junto com a ferramenta Simulink do Matlab ${ }^{\circledR}$, assim podem se incluir filtros de rejeita faixa para desconsiderar a frequência da rede presente nos equipes $(60 \mathrm{~Hz})$. Também pode se incluir filtros para desconsiderar o ruído do cabeamento. Esse método é mais qualitativo já que as magnitudes da resposta dependem das constantes piezelétricas do sensor, as quais não seriam consideradas imediatamente no cálculo.

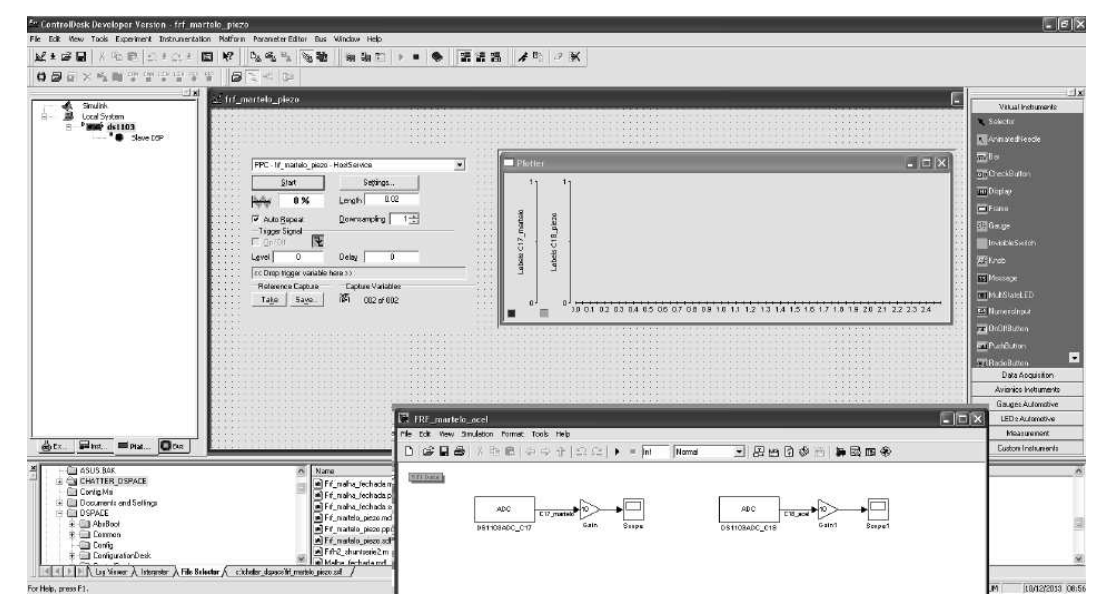

Figura 4.7: Esquema do software ControlDesk ${ }^{\circledR}$ 3.7.1 para aquisição de dados na placa DSpace

O segundo método usa um acelerômetro colocado no extremo livre do suporte da ferramenta como sensor, e o martelo modal como atuador, de igual maneira num teste de impacto como 
indica a Fig. 4.8.

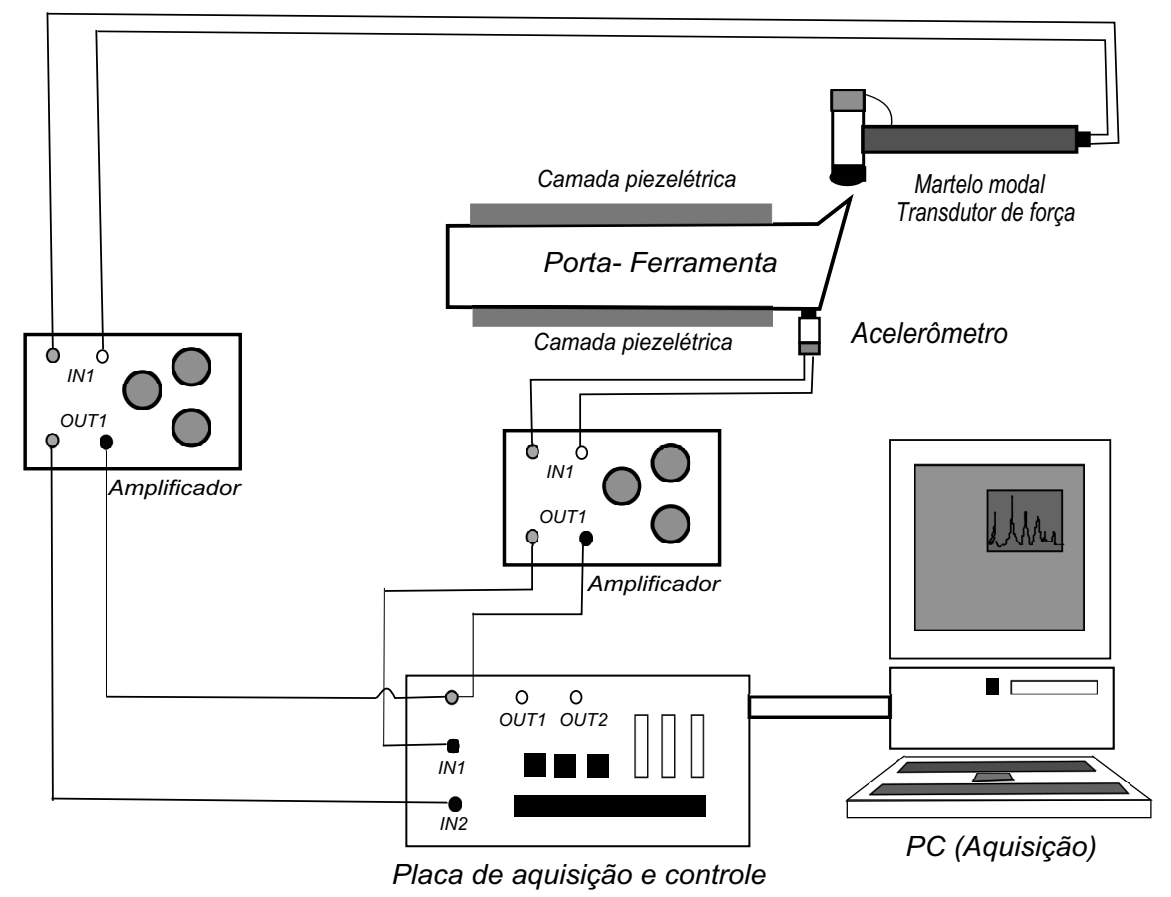

Figura 4.8: Medição da FRF usando um acelerômetro como sensor e o martelo modal como atuador

Os dados passam por condicionadores de sinal e amplificadores antes de ser coletados pela placa de aquisição, conectada com o computador. Aqui é utilizado o software CutPro ${ }^{\circledR}$ mostrado na Fig. 4.9 o qual já obtém as FRF.

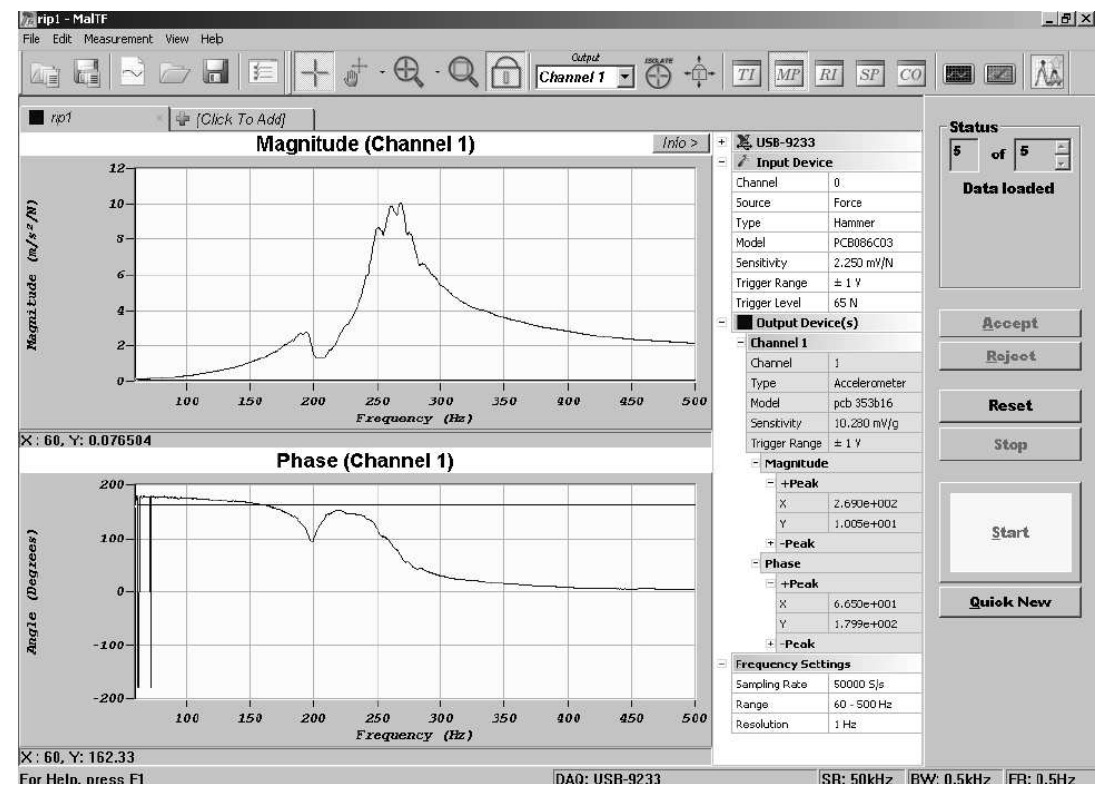

Figura 4.9: Software CutPro ${ }^{\circledR}$ para medição de FRF em equipamentos de usinagem 


\subsection{Aquisição de dados solução passiva}

A solução passiva propõe conectar os eletrodos da pastilha piezelétrica a um circuito de dissipação de impedância $Z$. Como foi indicado anteriormente o primeiro passo é comparar as magnitudes de resposta medindo as FRF com um teste de impacto. Podem ser usados qualquer dos métodos propostos na seção anterior (Figs. 4.6 e 4.8, considerando que pelo menos uma das pastilhas tem que estar conectada ao circuito de dissipação. Os circuitos testados no experimento são resistivo-indutivos, e foram conectados como indica a Fig. 4.10. O circuito com indutor sintético ilustrado na Fig. 4.10 (b) precisa usar uma fonte de alimentação com retificadores para alimentar os amplificadores operacionais que fazem parte do circuito.

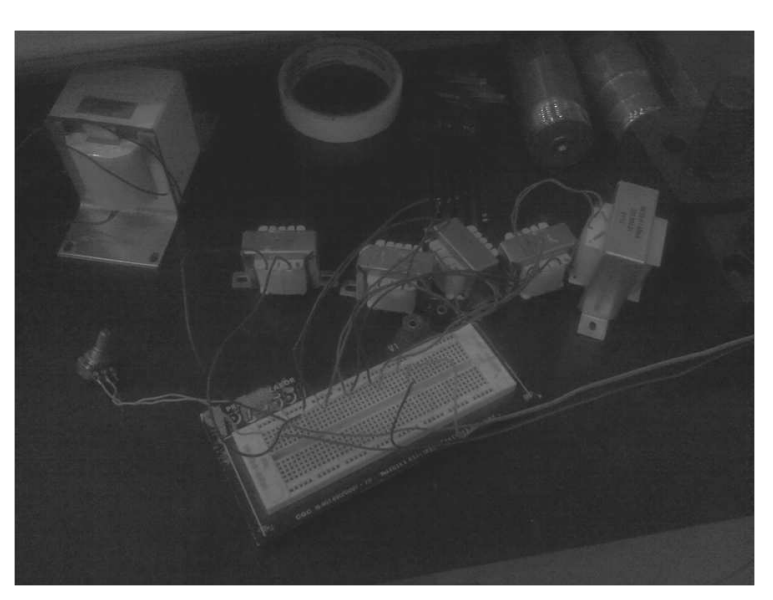

(a)

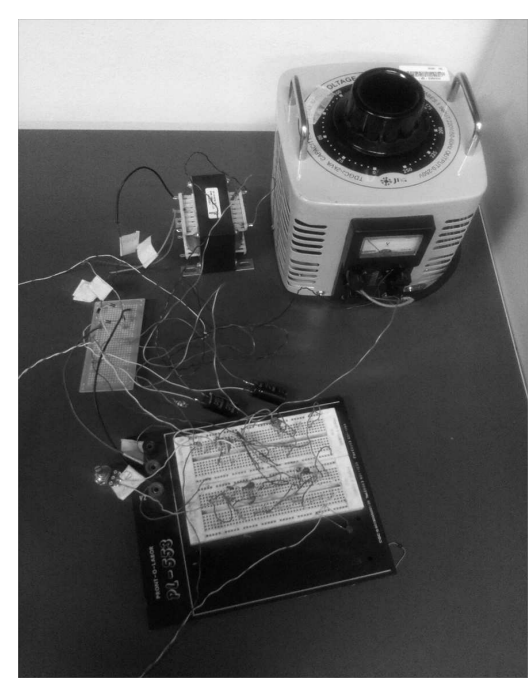

(b)

Figura 4.10: Circuitos de dissipação: (a) Com indutores de bobina (b) Com indutores sintéticos

Para realizar a aquisição de dados durante a usinagem é proposto o esquema da Fig. 4.11. Assim os eletrodos de uma das pastilhas piezelétricas é conectado ao circuito de dissipação, e outra é usada como sensor para a aquisição dos dados, seu tratamento e avaliação do desempenho da solução passiva durante a usinagem. Podem ser usados os parâmetros de torneamento propostos para medir as tensões do circuito de condicionamento. 


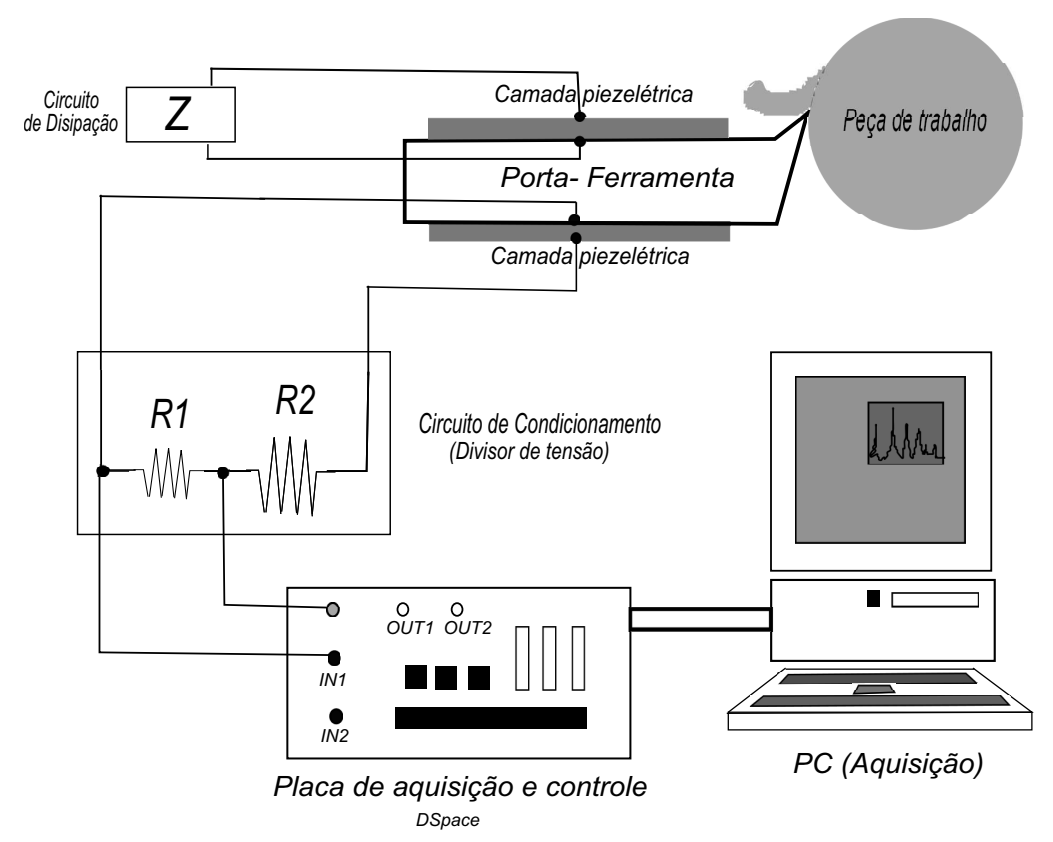

Figura 4.11: Aquisição de dados na solução passiva

\subsection{Aquisição de dados solução ativa}

A solução ativa consiste na aplicação de leis de controle de realimentação usando uma pastilha como sensor e outra como atuador. Uma vez que as duas pastilhas serão usadas no experimento, As FRF podem ser obtidas unicamente com o esquema da Fig. 4.8. Para que a pastilha piezelétrica que funciona como atuador possa ter o efeito requerido sobre o suporte da ferramenta (efeito piezelétrico inverso) é necessário utilizar o amplificador de tensão mostrado na Fig. 4.12 o qual aplicará o ganho de tensão na mesma proporção que foi diminuído no circuito de condicionamento (1 a 100).

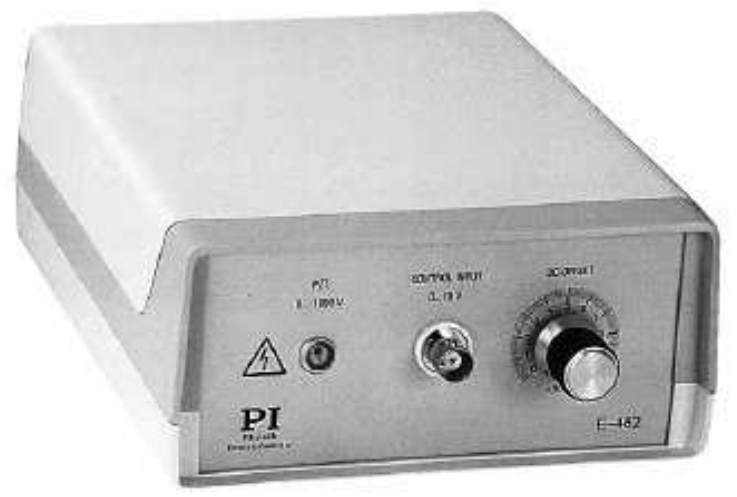

Figura 4.12: Aquisição de dados na solução ativa 
Para os testes de torneamento uma pastilha piezelétrica é mantida como sensor que passa pelo circuito de condicionamento e envia os sinais à placa de aquisição como indica a Fig. 4.13. Esses dados são tratados e usados como entrada no algoritmo de controle (ganhos de deslocamento e velocidade), montado na ferramenta Simulink, e transferido novamente como saída de tensão à placa. A saída gerada precisa ser amplificada para poder atuar na outra pastilha piezelétrica, gerando uma resposta do sistema e completando o circuito de realimentação. Os dados do sensor e do atuador são coletados para fazer a avaliação do desempenho do controlador ativo.

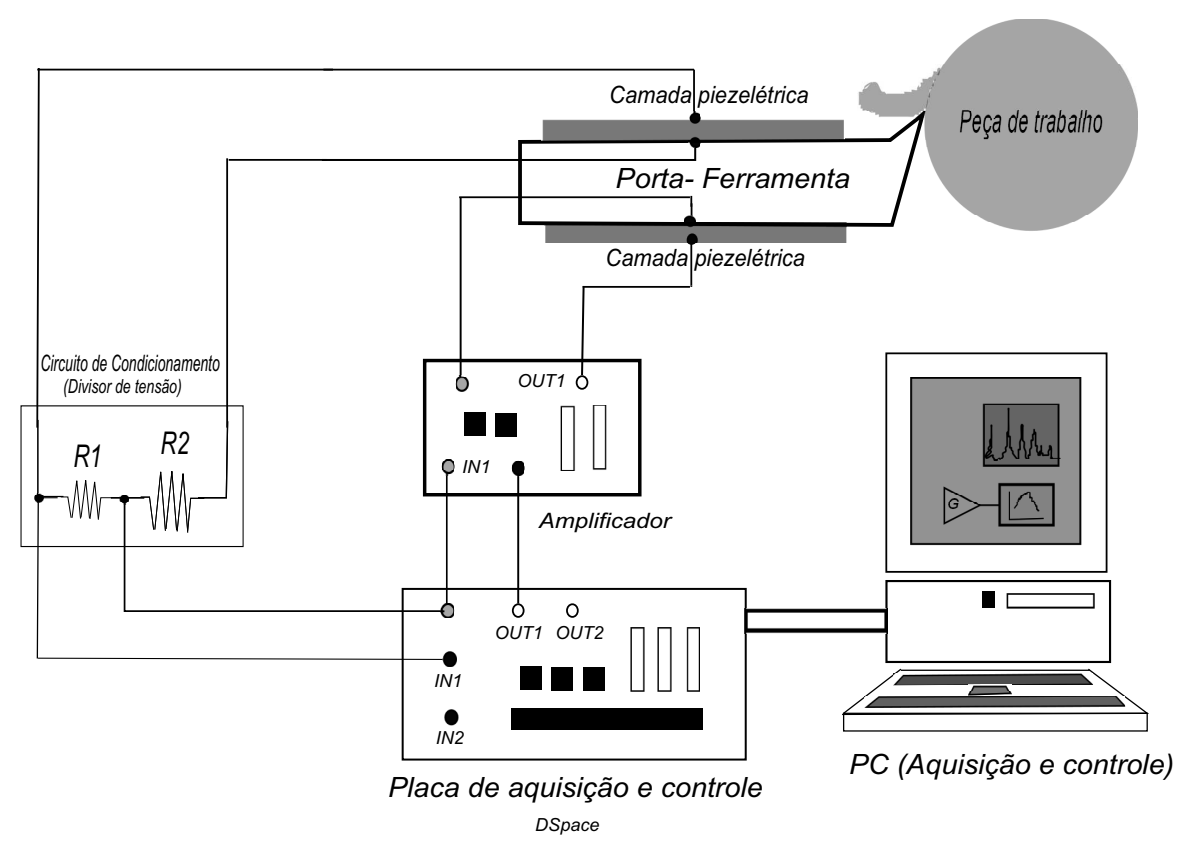

Figura 4.13: Aquisição de dados na solução ativo 


\section{Capítulo 5}

\section{Análise de Resultados}

Neste capítulo serão apresentados e analisados os resultados tanto da simulação numérica como da parte experimental. A seção da avaliação numérica apresentará as propriedades do suporte da ferramenta com camadas piezelétricas acopladas, utilizados para a simulação numérica, as funções de resposta em frequência (FRF) para a solução ativa e passiva obtidas usando a metodologia do Capítulo 3, e a plotagem dos diagramas de lóbulos de estabilidade para comparar a melhora do processo com as estratégias usadas. A análise de resultados experimentais terá a comparação das respostas obtidas com o sistema de aquisição de dados durante os experimentos de torneamento de peças usando a metodologia do Capítulo 4, usando circuitos de dissipação para a solução passiva e uma comparação visual das peças usinadas.

\subsection{Resultados Simulação Numérica}

\subsubsection{Propriedades do suporte da ferramenta com camadas piezelétricas}

Com o objetivo de simular a flexibilidade da ferramenta e permitir a simulação numérica, usando o modelo de parâmetros distribuídos analisado na seção de metodologia, é necessário selecionar uma geometria comum para um suporte da ferramenta. Usando o esquema da figura 3.1, as dimensões da viga engastada assim como as propriedades são descritas na tabela 5.1. Usualmente este dispositivo é fabricado de aço.

\begin{tabular}{|c||c||c|}
\hline Dimensão/Propriedade & Símbolo & Valor \\
\hline \hline Comprimento & $L_{b}$ & $0.383[\mathrm{~m}]$ \\
\hline Largura & $b$ & $0.020[\mathrm{~m}]$ \\
\hline Espessura total & $h_{t}$ & $0.028[\mathrm{~m}]$ \\
\hline Espessura subestrutura aço & $h_{s}$ & $0.020[\mathrm{~m}]$ \\
\hline Módulo de Rigidez (Young) & $Y_{s}$ & $2.1 \cdot 10^{11}[\mathrm{~Pa}]$ \\
\hline Densidade & $\rho$ & $7750\left[\mathrm{Kg} / \mathrm{m}^{3}\right]$ \\
\hline
\end{tabular}

Tabela 5.1: Dimensões e propriedades do suporte de ferramenta

As camadas piezelétricas são acopladas à estrutura, como se mostra na figura 3.1. O material piezelétrico escolhido é o PZT-5A (Titano-zirconato de chumbo) (SINOCERA, ), o qual é o mais comumente usado das cerâmicas piezelétricas. As propriedades do material usadas na simulação 
são descritas na tabela 5.2.

\begin{tabular}{|c||c||c|}
\hline Dimensão/Propriedade & Símbolo & Valor \\
\hline \hline Comprimento & $L_{b}$ & $0.383[\mathrm{~m}]$ \\
\hline Espessura camada & $h_{p}$ & $0.004[\mathrm{~m}]$ \\
\hline Módulo de Rigidez (Young) & $Y_{p}$ & $7.4 \cdot 10^{10}[\mathrm{~Pa}]$ \\
\hline Acoplamento Piezelétrico & $d_{31}$ & $-175 \cdot 10^{-12}[\mathrm{C} / \mathrm{N}]$ \\
\hline Constante Piezelétrica & $h_{31}$ & $-7.3 \cdot 10^{8}[\mathrm{~N} / \mathrm{C}]$ \\
\hline Permissividade relativa & $\epsilon_{33}^{T} / \epsilon_{0}$ & 1800 \\
\hline
\end{tabular}

Tabela 5.2: Propriedades do PZT-5A (modificado de Sinocera ())

A constante de permissividade no vácuo está definida como $\epsilon_{0}=8.85418782 \cdot 10^{-12}$ $\left[\mathrm{m}^{-3} \mathrm{~kg}^{-1} \mathrm{~s}^{4} \mathrm{~A}^{2}\right]$. Os eletrodos da camada piezelétrica cobrem todo o comprimento da viga e são conectados de acordo com a estratégia adotada.

\subsubsection{Avaliação da solução passiva}

Nesta seção, são avaliadas diferentes estratégias passivas modificando a impedância do circuito de dissipação conectado às camadas de material piezelétrico, analisando as FRFs do sistema no primeiro modo, e os diagramas de lóbulos de estabilidade. Primeiramente são obtidos os seis primeiros valores $\lambda$, da equação 3.24 e descritos na tabela 5.3:

\begin{tabular}{|c|c|c|c|c|c|}
\hline$\lambda_{1}$ & $\lambda_{2}$ & $\lambda_{3}$ & $\lambda_{4}$ & $\lambda_{5}$ & $\lambda_{6}$ \\
\hline \hline 1.8751 & 4.6941 & 7.8547 & 10.9955 & 14.1372 & 17.2788 \\
\hline
\end{tabular}

Tabela 5.3: Valores $\lambda$ solução passiva

Para cada valor $\lambda$ é obtida uma forma modal usando a eq. 3.23. A Fig. 5.1 ilustra as formas modais calculadas para cada modo.

Para analisar a influência do circuito de dissipação na resposta do sistema são plotadas as magnitudes da FRF da eq. $3.49(|G(s)|)$ no extremo livre do porta-ferramenta, substituindo a impedância correspondente ao circuito usado na eq. $3.48 \mathrm{O}$ valor da relação de amortecimento $\zeta_{r}$ adotado é de 0.01.

\section{Circuito resistivo}

A Fig. 5.2 ilustra a magnitude da FRF $(|G(s)|)$ usando circuitos puramente resistivos $(Z(s)=$ $R$ ). Primeiramente é observado que pode se obter a mesma resposta usando a eq. 3.48 para um circuito com $R=0$, que a eq. 3.119 sem considerar o circuito. Também é possível observar que o circuito puramente resistivo não afeta significativamente as características dinâmicas do sistema como rigidez e amortecimento, já que unicamente existe um pequeno deslocamento da frequência entre o circuito curto $R=0$ e um circuito aberto $R=\infty$, que seria um efeito direto do acoplamento piezelétrico (ERTURK; INMAN, 2009). Este comportamento confirma o discutido no trabalho de Da Silva et al. (2010) sobre circuitos puramente resistivos. 

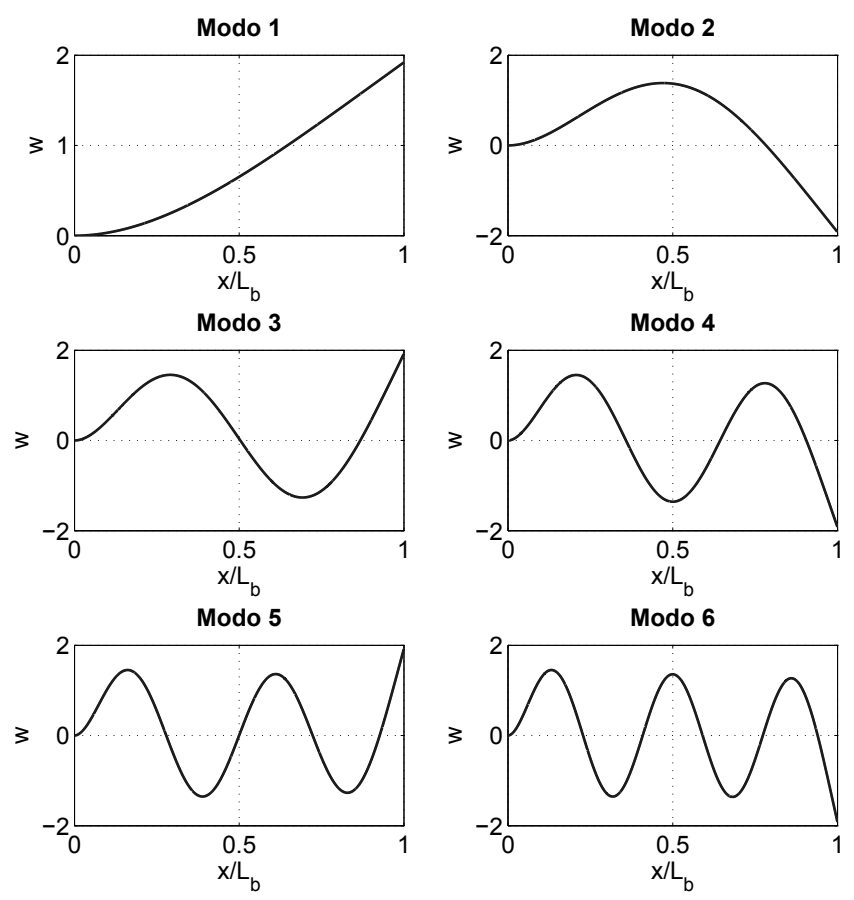

Figura 5.1: Formas modais solução passiva

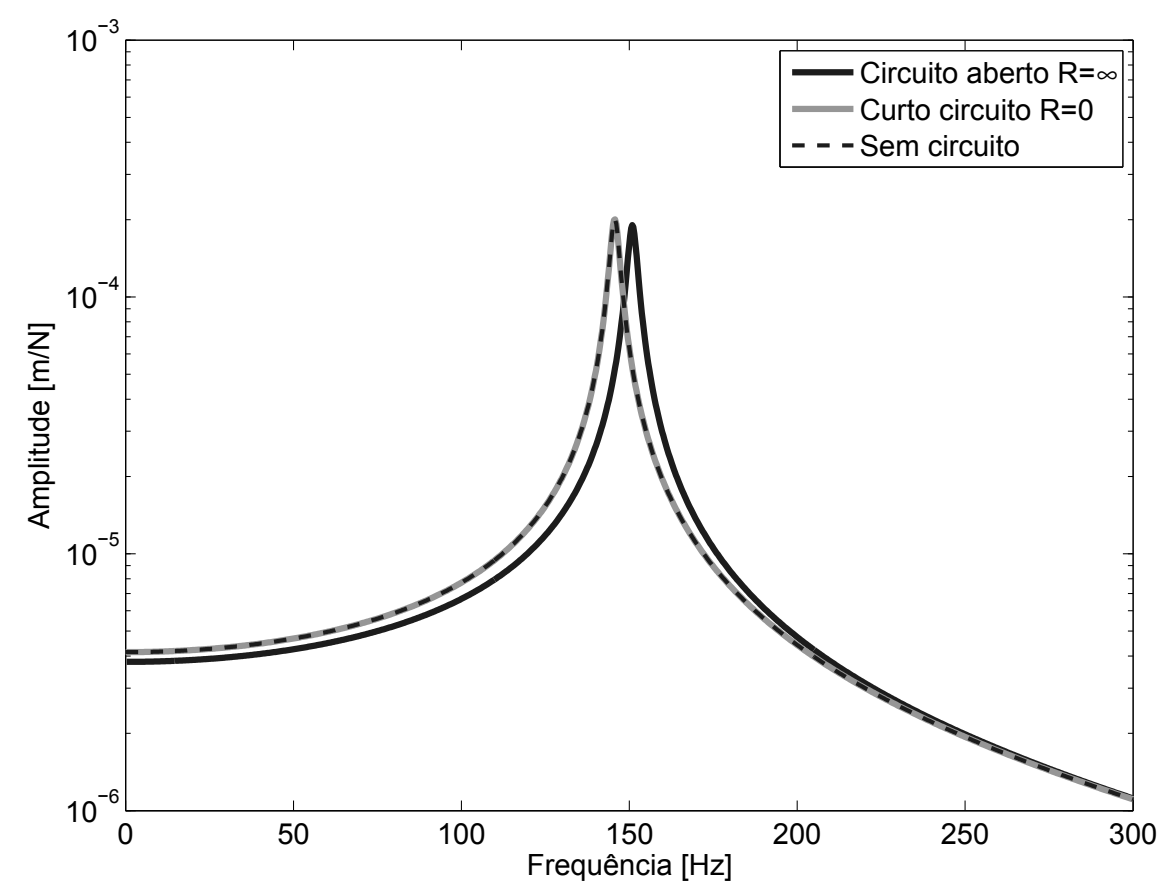

Figura 5.2: FRF com circuito de dissipação resistivo

\section{Circuito capacitivo}

O efeito de usar circuitos puramente capacitivos $\left(Z(s)=\frac{1}{C s}\right)$ na FRF do sistema, é ilustrado na Fig. 5.3. Pode se observar que o circuito capacitivo modifica levemente a rigidez do sistema, 
comparando com a resposta do sistema sem circuito. De igual maneira é observado um pequeno deslocamento das frequências de ressonância sem afetar consideravelmente a magnitude da resposta. Esses dois efeitos também são analisados no trabalho de Erturk e Inman (2009).

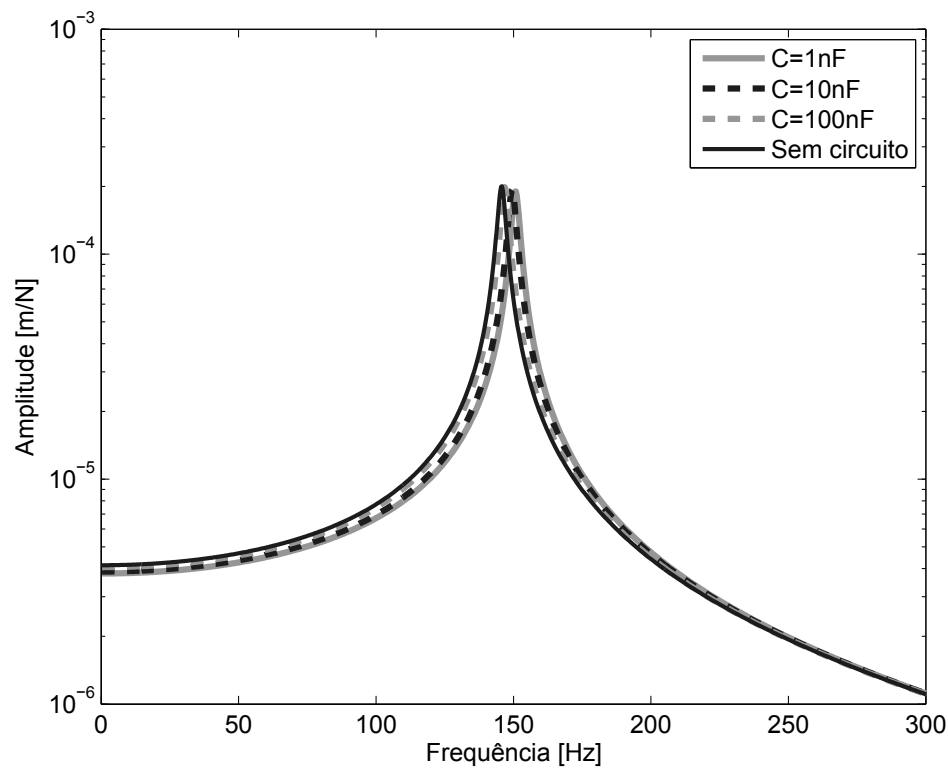

Figura 5.3: FRF com circuito de dissipação capacitivo

\section{Circuito indutivo}

Usando circuitos puramente indutivos $(Z(s)=L s)$ são obtidas a FRFs da Fig. 5.4. É possível ver que o circuito indutivo se comporta como um absorvedor dinâmico não amortecido, presentado a forma de filtro notch (DA SILVA et al., 2010), e com picos de ressonância e antiressonância afiados, o que indica que nenhum amortecimento foi adicionado (ERTURK; INMAN, 2009). O valor da indutância que cancela a capacitância interna da camada piezelétrica pode se aproximar usando a eq. 3.50, assim a anti-ressonância atinge a frequência de ressonância da resposta quando nenhum circuito é usado.

\section{Circuito resistivo-indutivo}

Foi observado que a utilização de circuitos puramente resistivos ou indutivos não adicionam amortecimento ao sistema, portanto uma alternativa para analisar são os circuitos resistivosindutivos em serie e paralelo.

Na Fig. 5.5 são plotadas as magnitudes da FRFs considerando vários circuitos com a resistência e indutância conetados em série como indica a Fig. 3.5, onde a impedância equivalente usada no cálculo de FRF é definida na eq. 3.57. Os valores ótimos da indutância e resistência dependem das características dinâmicas do sistema e coeficientes de acoplamento eletromecânico (ERTURK; INMAN, 2009), e são calculados com as equações 3.72 e 3.73 respetivamente. O coeficiente $K_{31}^{2}$ foi calculado considerando a aproximação teórica da eq. 3.67 


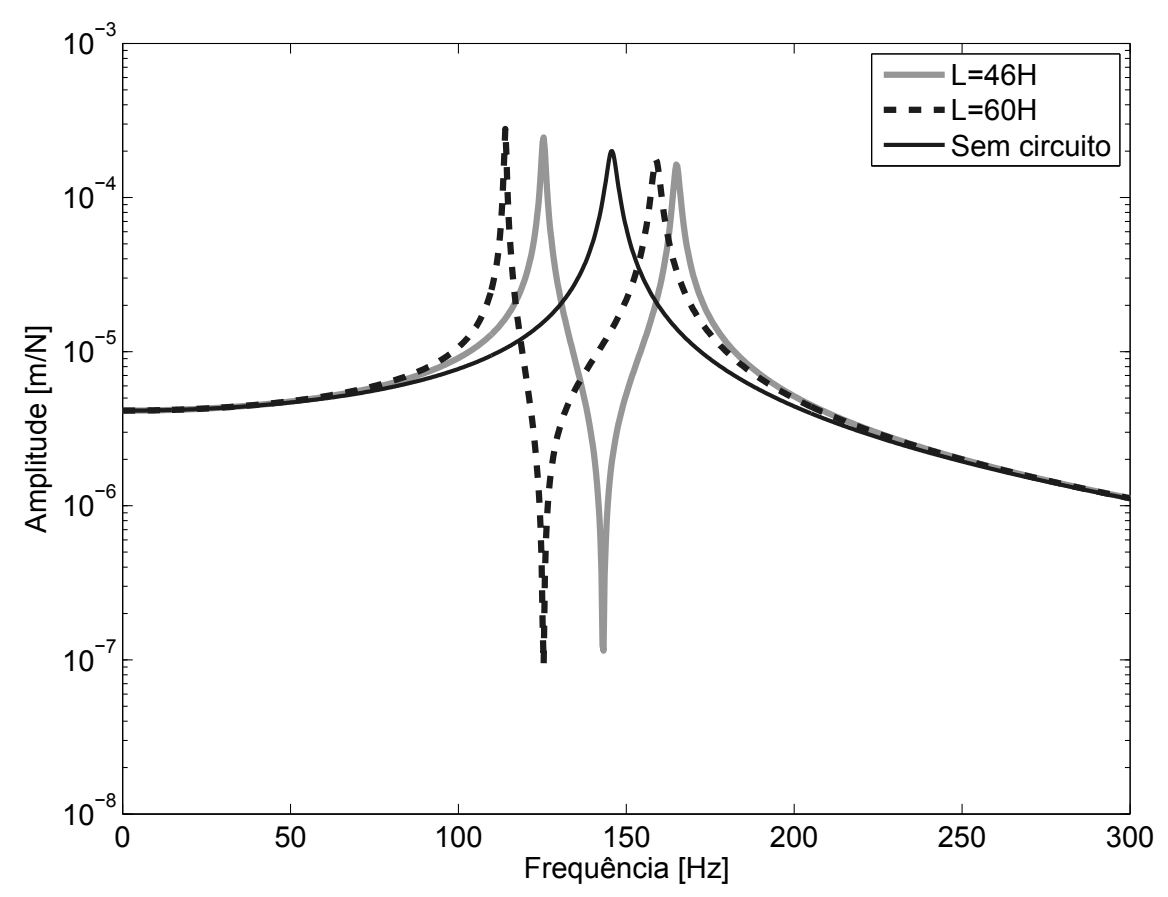

Figura 5.4: FRF com circuito de dissipação indutivo

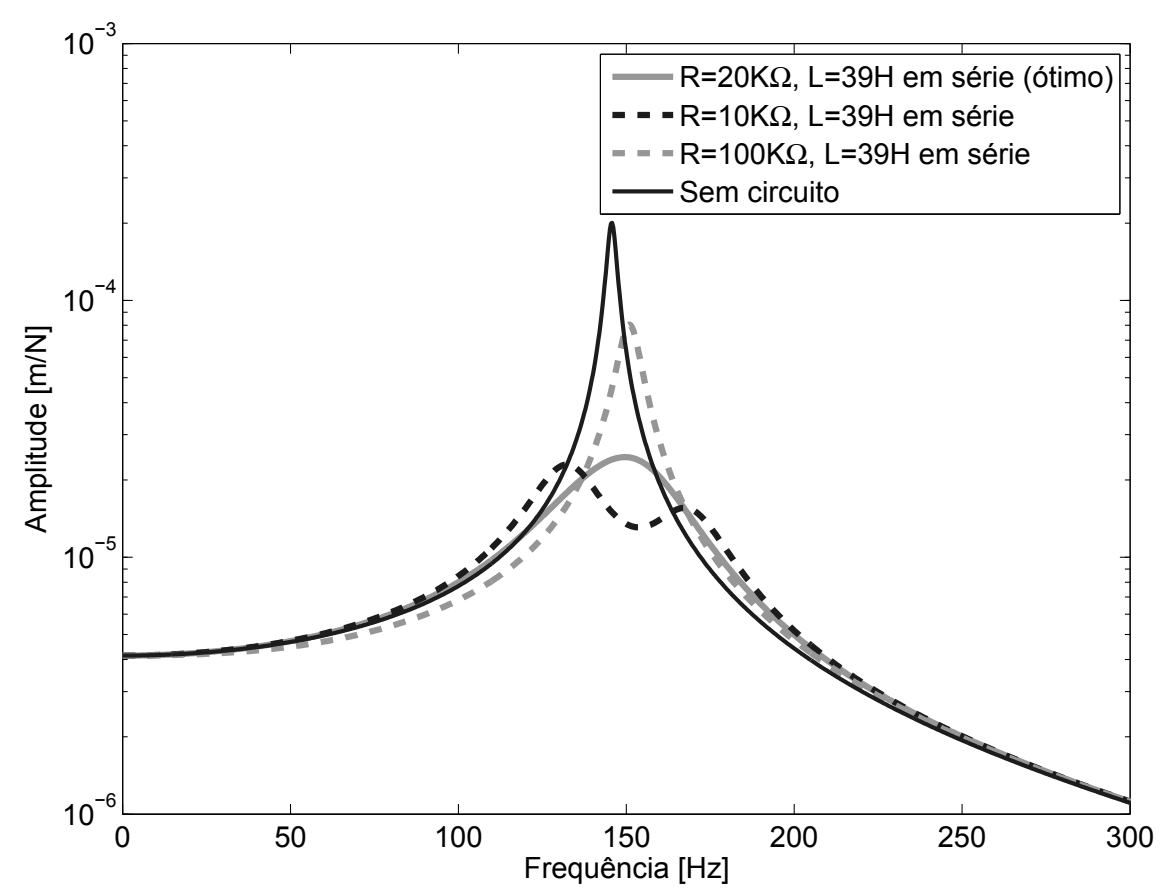

Figura 5.5: FRF com circuito resistivo-indutivo em série

Pode se observar que o efeito de amortecimento depende do valor da resistência: se for maior do que o ótimo, a curva se aproxima ao caso de curto circuito, se for menor tem mais similitude com o caso do circuito puramente indutivo formando uma anti-ressonância.

A Fig. 5.6 ilustra as FRFs considerando vários valores de resistência e indutância conetados 
em paralelo como indica a Fig. 3.7, onde a impedância equivalente usada no cálculo da FRF é definida na eq. 3.74. Os valores ótimos da indutância e resistência são calculados com as equações 3.80 e 3.81 respetivamente. $O$ coeficiente $K_{31}^{2}$ também foi calculado considerando a aproximação teórica da eq. 3.67.

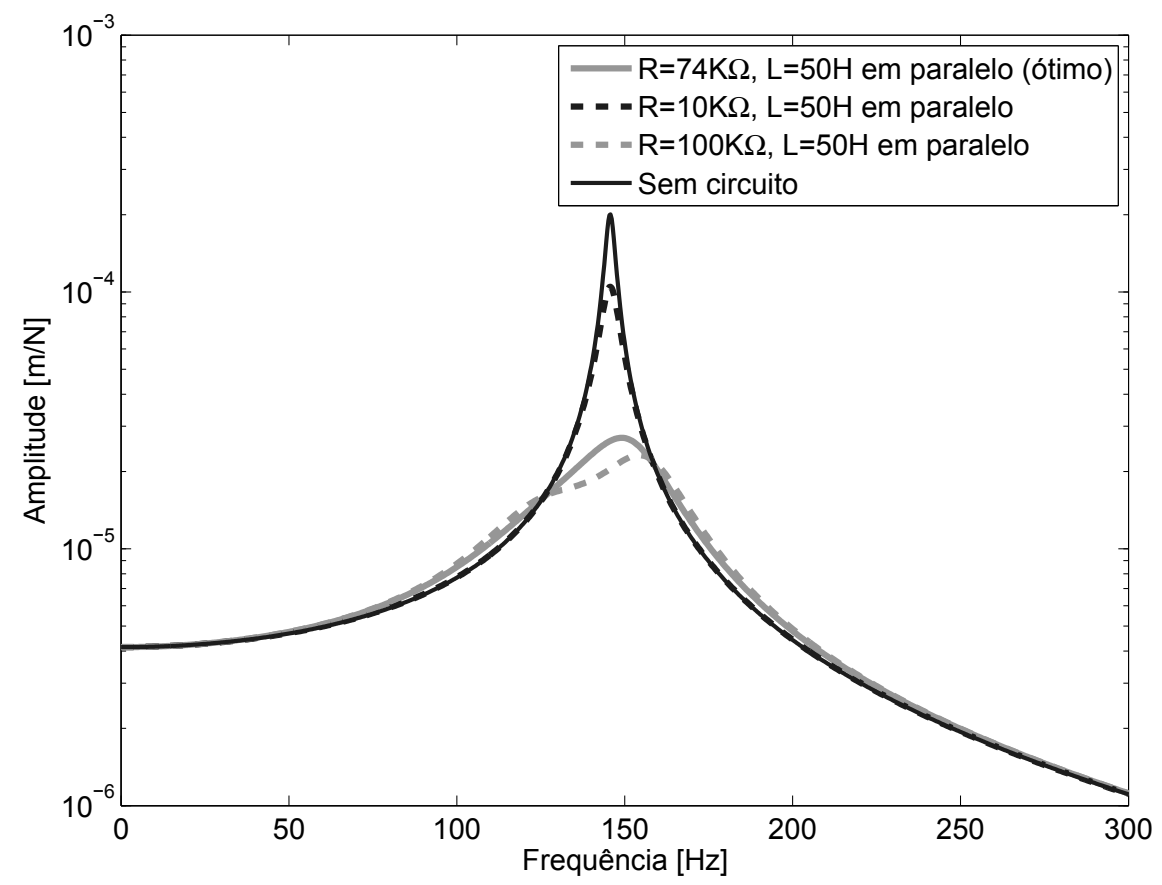

Figura 5.6: FRF com circuito resistivo-indutivo em paralelo

O efeito de amortecimento devido à resistência tem uma tendência contrária do que no circuito em série: com uma resistência maior do que o ótimo se aproxima ao circuito puramente indutivo, e com uma resistência maior tende a se comportar como o caso de curto circuito.

A Fig. 5.7 compara os circuitos com valores ótimos para os circuitos em série e paralelo. Pode se observar uma atenuação do pico de ressonância, indicando um aumento no amortecimento do sistema similar para os dois tipos de circuitos. Portanto as duas alternativas podem ser efetivas para a redução do chatter.

\section{Análise do indutor sintético}

A seção 3.2.2 da metodologia indica que os valores de indutâncias requeridos para os circuitos de dissipação podem ser relativamente altos, e propõe como alternativa a utilização de indutores sintéticos baseados na utilização de amplificadores operacionais. A configuração usada para a análise é ilustrada na Fig. 3.9. Com o objetivo de determinar como as propriedades reais do amplificador operacional afetam o desempenho do indutor sintético, o circuito foi simulado no software de análise de circuitos elétricos NI Multisim ${ }^{\mathrm{TM}} 11.0$.

A Fig. 5.8 ilustra o esquema da simulação no software para um circuito com uma resistência $R_{f}=10 \mathrm{k} \Omega$ e um indutor $L_{f}=50 \mathrm{H}$ conectados em série, também conhecido como circuito RL 


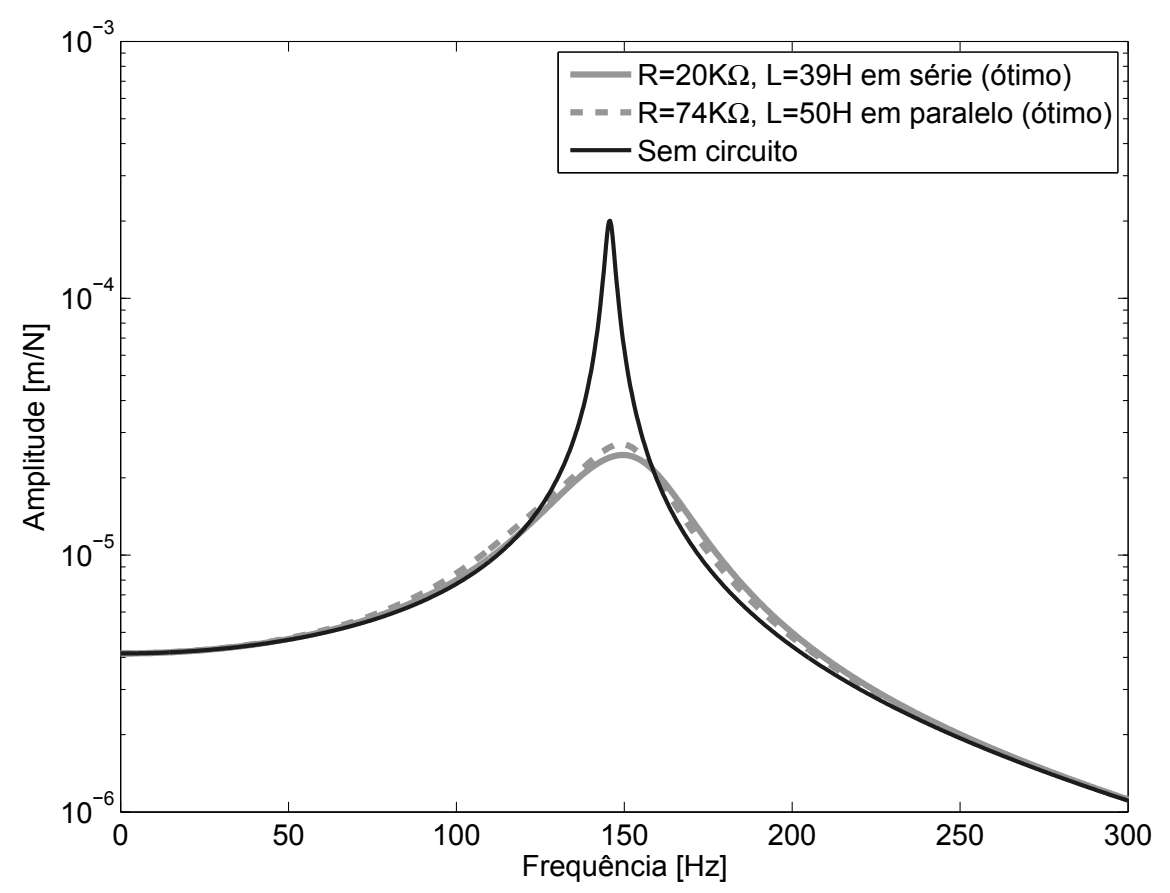

Figura 5.7: Comparação de FRFs com circuitos resistivo-indutivos ótimos

ou filtro passa-alta de primeira ordem. A simulação inclui dois circuitos com fins comparativos: um primeiro (a) usando o indutor sintético e outro (b) usando um indutor real. Em cada circuito foi conectado um instrumento de medição do diagrama de Bode (na Fig. 5.8 XBP1 para o indutor sintético e XBP2 para o indutor ideal), para encontrar diferenças no comportamento como circuito. O modelo de amplificador operacional utilizado na simulação usado é o APEX PA94, o qual foi considerado no trabalho devido a sua capacidade de trabalhar com altas tensões, e cujas propriedades reais já são consideradas no software para a simulação.

Os valores dos elementos que formam parte do circuito são descritos na tabela 5.4, e são encontrados comercialmente. O valor da resistência variável $R_{3}$ é calculado usando a eq. 3.89:

$$
R_{3}=\frac{R_{2} L_{f}}{R_{1} C_{4} R_{5}}
$$

\begin{tabular}{|c|c|c|c|c|c|}
\hline Indutância $[H]$ & $R_{1}[k \Omega]$ & $R_{2}[k \Omega]$ & $R_{5}[k \Omega]$ & $C_{4}[n F]$ & $R_{3}[k \Omega]$ (aprox.) \\
\hline \hline 5 & 22 & 22 & 1 & 220 & 22 \\
\hline 50 & 220 & 220 & 1 & 220 & 220 \\
\hline 100 & 470 & 470 & 1 & 220 & 470 \\
\hline
\end{tabular}

Tabela 5.4: Valores de resistência e capacitância usados no indutor sintético

A Fig. 5.9 compara os diagramas de bode do circuito RL considerando o indutor sintético (instrumento XBP1) e o indutor ideal (instrumento XBP2). É possível observar que não existe uma diferença considerável na resposta de um circuito e do outro, inclusive a frequência de corte é a mesma. 


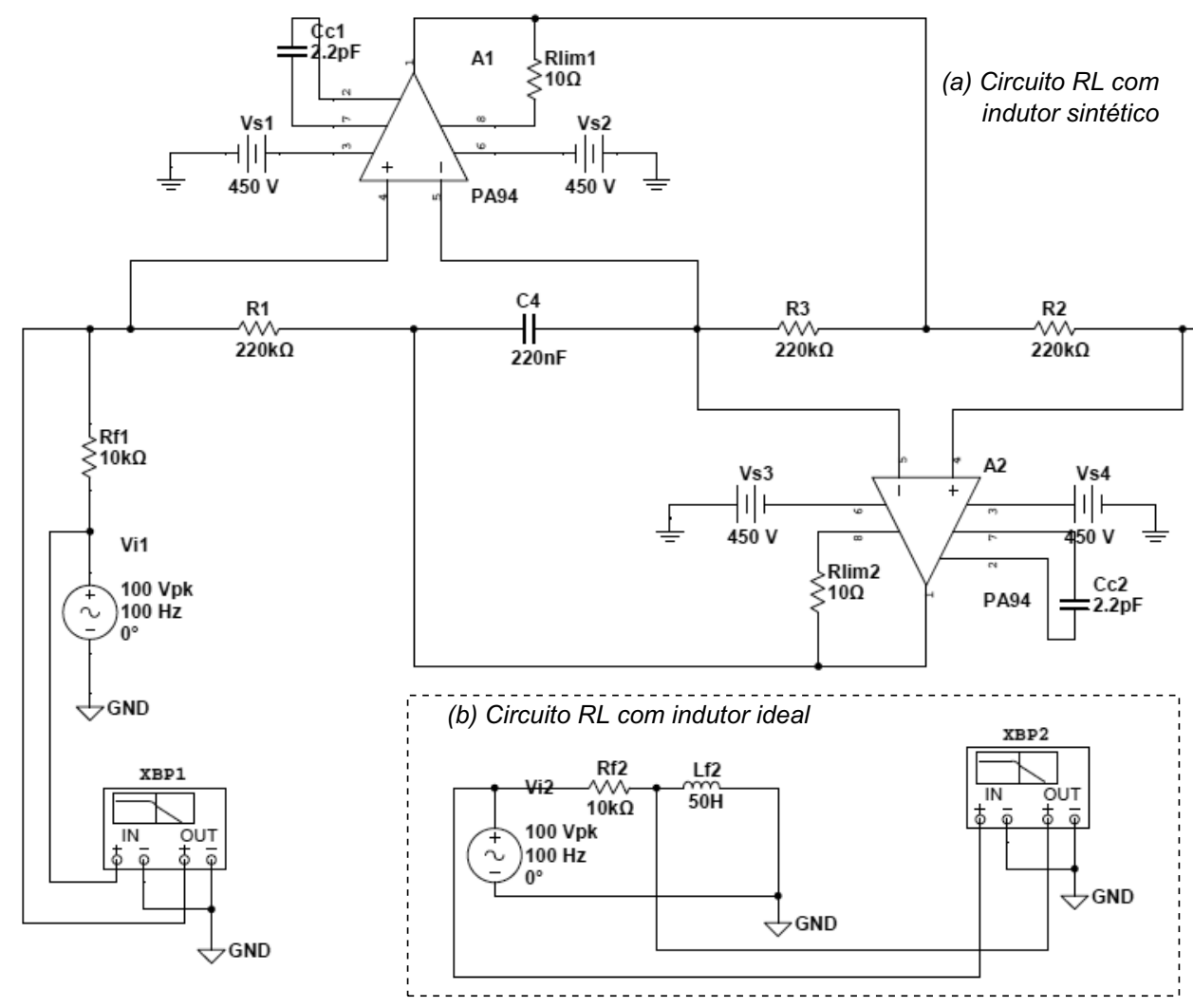

Figura 5.8: Esquema dos circuitos RL simulados no software NI Multisim ${ }^{\mathrm{TM}} 11.0$ (a) com indutor sintético (b) com indutor ideal

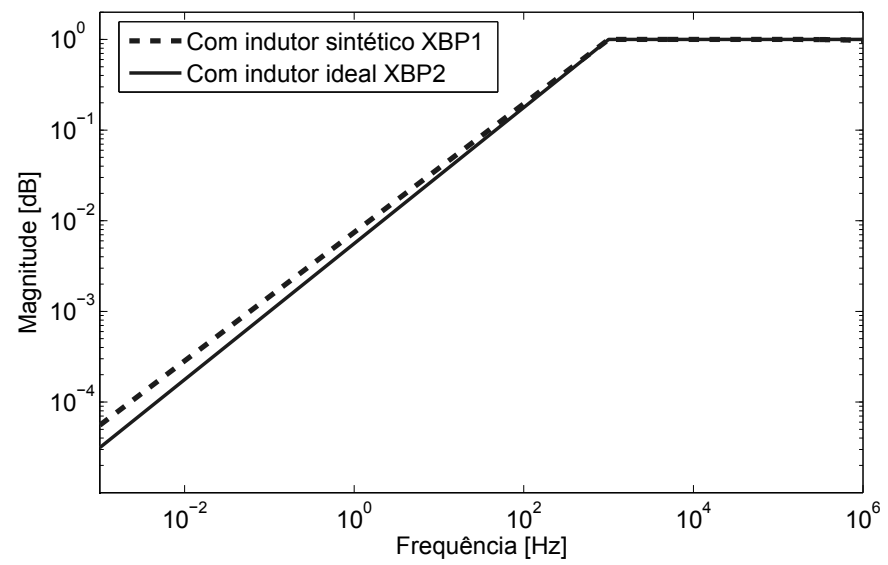

Figura 5.9: Diagrama de bode circuito RL com indutores sintéticos e ideal

Na Fig. 5.10 ilustra a comparação entre as impedâncias de um indutor ideal e um indutor sintético em função da frequência para diversos valores de indutância. Pode se observar que existe uma faixa de frequência (aproximadamente entre $1 \mathrm{~Hz}$ e $10000 \mathrm{~Hz}$ ) para a qual o indutor sintético age como um indutor ideal, o qual indica que poderia ser usado para o presente trabalho. Fora de esta faixa de frequência, as propriedades reais do amplificadores e demais elementos do indutor sintético afetam seu comportamento. O uso do indutor sintético também oferece flexibilidade na variação dos valores de indutância já que requer unicamente da mudança do valor 
da resistência variável $R_{3}$ (potenciômetro). Devido a que os amplificadores operacionais requerem de alimentação externa, o uso de indutores sintéticos num circuito de dissipação, torna essa solução como semi-ativa.

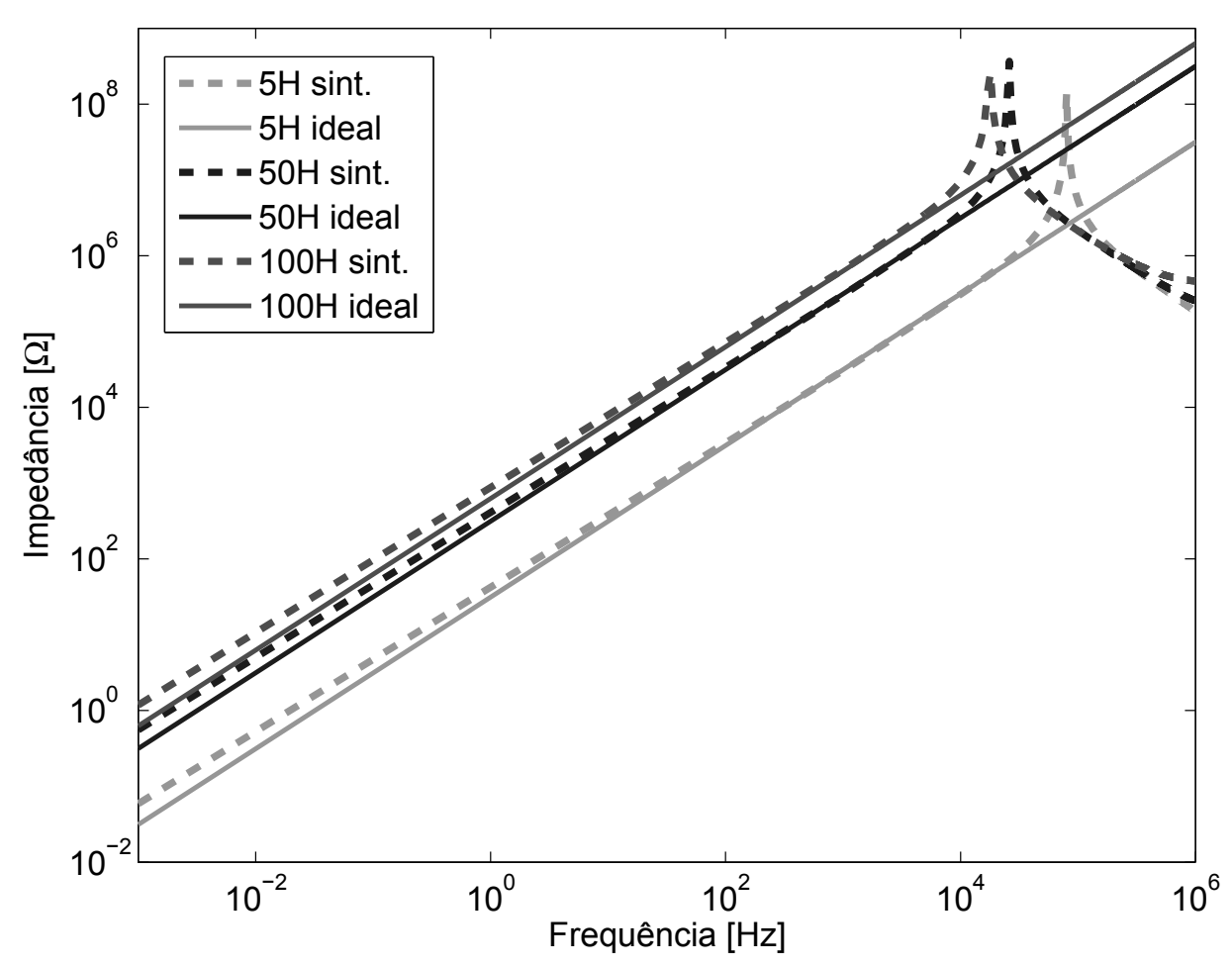

Figura 5.10: Comparação de impedâncias do indutor real e do indutor sintético em função da frequência

\section{Análise da estabilidade das estrategias passivas}

Para fazer a análise de estabilidade das estratégias passivas no processo de torneamento, é necessário obter as características dinâmicas dos sistemas. Graficamente é possível estimar a rigidezes e as frequências de ressonâncias das FRFs da Fig. 5.7. Mas para poder obter o amortecimento é usado o método inverso de identificação modal (MAIA; SILVA, 1998). Esse método é baseado no fato de que a parte real e imaginária da FRF de receptância são linhas retas quando são função do $\omega^{2}$, de modo que:

$$
\begin{aligned}
& \operatorname{Re}\left(\frac{1}{G(s)}\right)=m_{R}+n_{R} \omega^{2} \\
& \operatorname{Im}\left(\frac{1}{G(s)}\right)=m_{I}+n_{I} \omega^{2}
\end{aligned}
$$

Depois de fazer um ajuste das curvas obtidas de $\operatorname{Re}(1 / G(s))$ e $\operatorname{Im}(1 / G(s))$ à linhas retas são obtidos os valores de $m_{R}, m_{I}, n_{R}, n_{I}$ das eqs. 5.2 e 5.3. Assim a frequência de ressonância 
pode ser descrita como:

$$
\omega_{r}=\sqrt{\frac{-m_{R} n_{R}-m_{I} n_{I}}{n_{R}^{2}+n_{I}^{2}}},
$$

e a relação de amortecimento:

$$
\zeta_{r}=\frac{m_{R} n_{I}-m_{I} n_{R}}{-m_{R} n_{R}-m_{I} n_{I}}
$$

A tabela 5.5 apresenta os valores das características dinâmicas obtidas graficamente e com o método inverso de identificação modal para as estrategias passivas.

\begin{tabular}{|c||c|c|c|}
\hline Propriedade & Sem Circuito & Série & Paralelo \\
\hline \hline Rigidez $K_{r}[N / m]$ & $4.142 \cdot 10^{-6}$ & $4.142 \cdot 10^{-6}$ & $4.142 \cdot 10^{-6}$ \\
\hline Amortecimento $\zeta_{r}$ & 0.0100 & 0.0649 & 0.0604 \\
\hline Frequência natural $\omega_{r}[H z]$ & 145.6792 & 144.8932 & 143.6878 \\
\hline
\end{tabular}

Tabela 5.5: Características dinâmicas soluções passivas

Usando as relações de estabilidade descritas nas equações 2.10 e 2.11 é possível obter os diagramas de lóbulos de estabilidade da figura 5.11. Pode se observar um aumento de estabilidade de aproximadamente 3 vezes com relação ao valor para um sistema sem circuito de dissipação. Isto significa que para uma determinada velocidade de rotação, num processo de torneamento, pode ser escolhida uma profundidade de corte 3 vezes maior sem apresentar problemas de instabilidade ou chatter. O efeito é muito similar para o caso do uso do circuito resistivo-indutivo em série e em paralelo. Este aumento da estabilidade é produto do aumento do amortecimento no sistema.

\subsubsection{Avaliação da solução ativa}

Nesta seção são avaliadas numericamente as diferentes estrategias ativas para controle de chatter, mediante a aplicação de ganhos de deslocamento e velocidade no controle de realimentação. Os valores das propriedades geométricas do suporte da ferramenta e das propriedades piezelétricas das pastilhas são as mesmas da solução passiva. Igualmente são analisadas as FRFs do sistema no primeiro modo obtidas da eq. 3.119, assim como a estabilidade do sistema de controle com o lugar das raízes, e no processo de torneamento com o diagrama de lóbulos de estabilidade. Os autovalores $\lambda$ e as formas modais $\phi_{r}(x)$ são calculados com as equações 3.112 e 3.117 respetivamente, e dependem da estrategia adotada.

\section{Controle de deslocamento}

Na Fig. 5.12 são ilustradas várias FRFs com a aplicação de diferentes ganhos de deslocamento $G_{d}$. É possível observar que esse tipo de controle desloca as frequências de ressonância e diminui a magnitude da resposta modificando a rigidez. Com valores de ganho relativamente grandes a magnitude de ressonância se aproxima ao valor quando o sistema está sem controle. A forma dos picos de ressonância é afiada para todos os valores de ganho de deslocamento , 


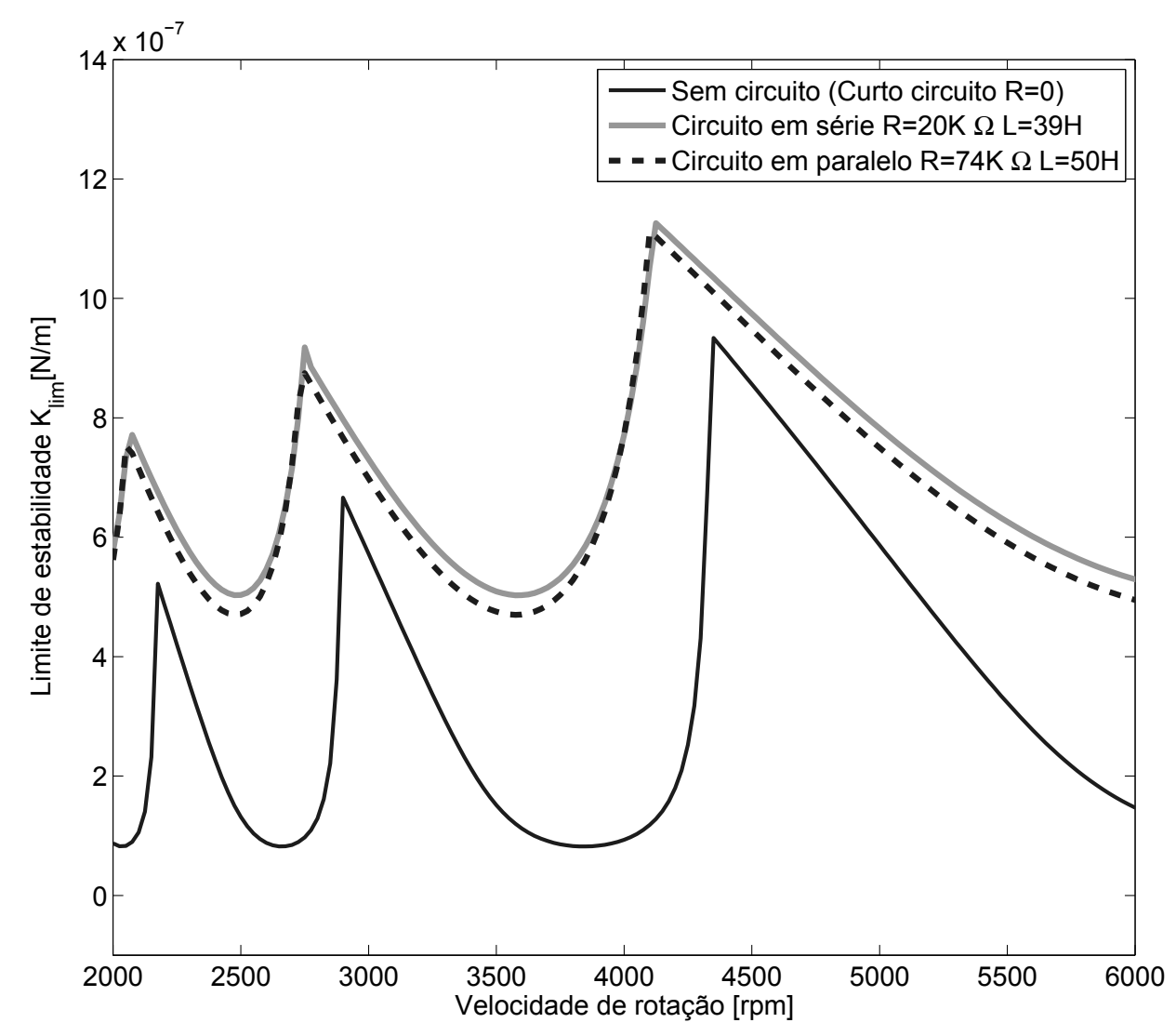

Figura 5.11: Comparação entre diagramas de lóbulos de estabilidade solução passiva

portanto nenhum amortecimento é adicionado ao sistema, razão pela qual não poderia ser uma opção efetiva para redução do chatter.

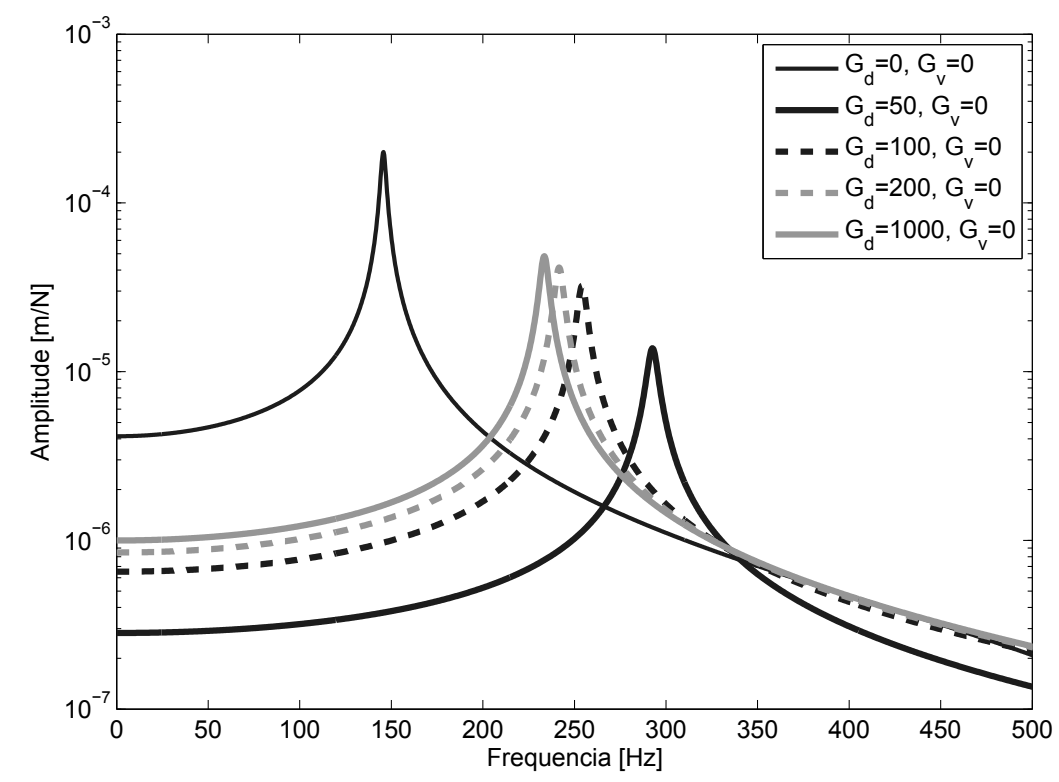

Figura 5.12: FRF com controle de deslocamento 


\section{Controle de velocidade}

As FRFs do sistema também são modificadas com a aplicação de diferentes ganhos de velocidade $G_{v}$ como é ilustrado na figura 5.13. Quando é considerado esse tipo de controle, os valores $\alpha_{r}$ obtidos da eq. 3.111, e portanto os autovalores $\lambda$ da eq. 3.112 são imaginários, o que implica uma modificação no amortecimento do sistema. Pode se observar que existe uma atenuação no pico de ressonância com ganhos relativamente pequenos (menores que 1), e que quanto maior for o ganho, maior o amortecimento adicionado. No entanto esse decremento na magnitude da resposta tem um limite, já que com ganhos maiores a rigidez também é modificada, e as frequências de ressonância são deslocadas consideravelmente.

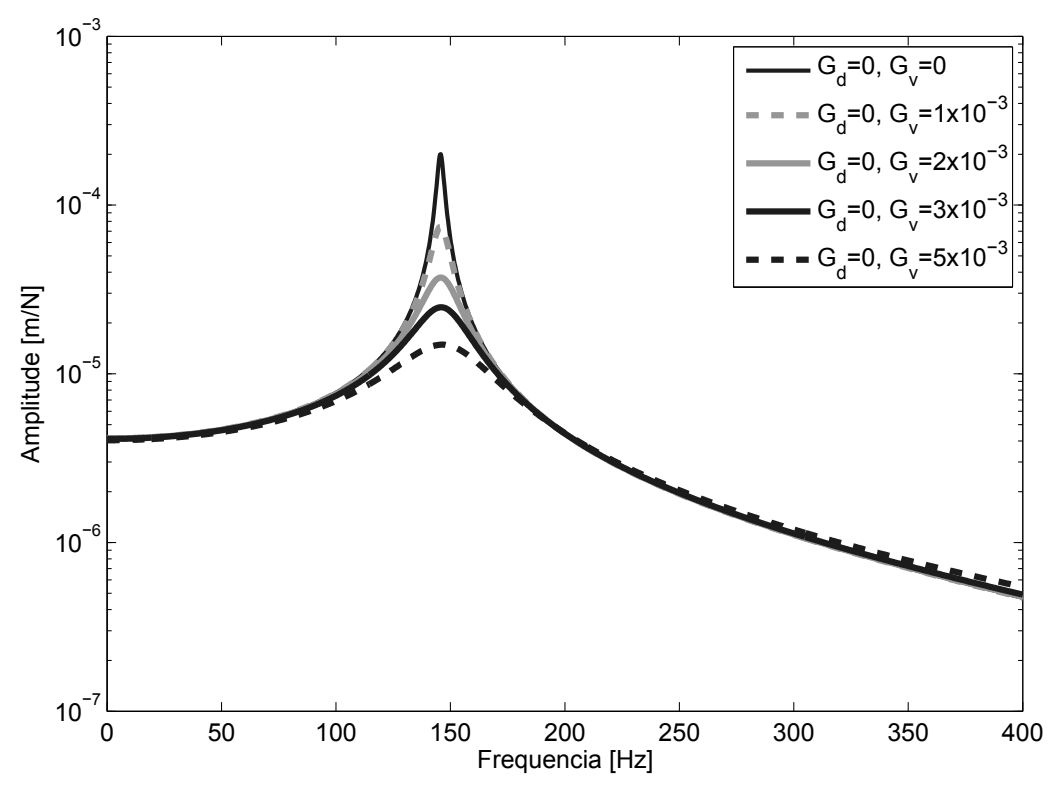

Figura 5.13: FRF com controle de velocidade

Se o interesse for, além de adicionar o amortecimento ao sistema, deslocar as frequências de ressonância e modificar a rigidez com um ganho de velocidade fixo, pode se usar ganhos de deslocamento e velocidade combinados. A Fig. 5.14 ilustra as FRFs considerando ganhos de deslocamento e velocidade $\left(G_{d}\right.$ e $\left.G_{v}\right)$ no controlador. É observado que quanto menor for o ganho de deslocamento , maior é a atenuação do pico de ressonância. No entanto a diminuição na rigidez e o deslocamento das frequências de ressonância, são consideráveis.

\section{Análise da solução ativa pelo lugar das raízes}

Com o objetivo de analisar a estabilidade das estrategias de controle ativo, e determinar limites para os valores dos ganhos de deslocamento e velocidade co controlador, é usada a função de transferência entre as tensões do sensor e atuador $G_{t}$ da eq. 3.128. Para a análise é usado a ferramenta de projeto de sistemas de controle SISOTOOL do Matlab ${ }^{\circledR}$. Esta ferramenta considera a arquitetura de controle mostrado na Fig. 5.15.

Para o cálculo da função de transferência $G_{t}$ no software, são considerados os três primeiros 


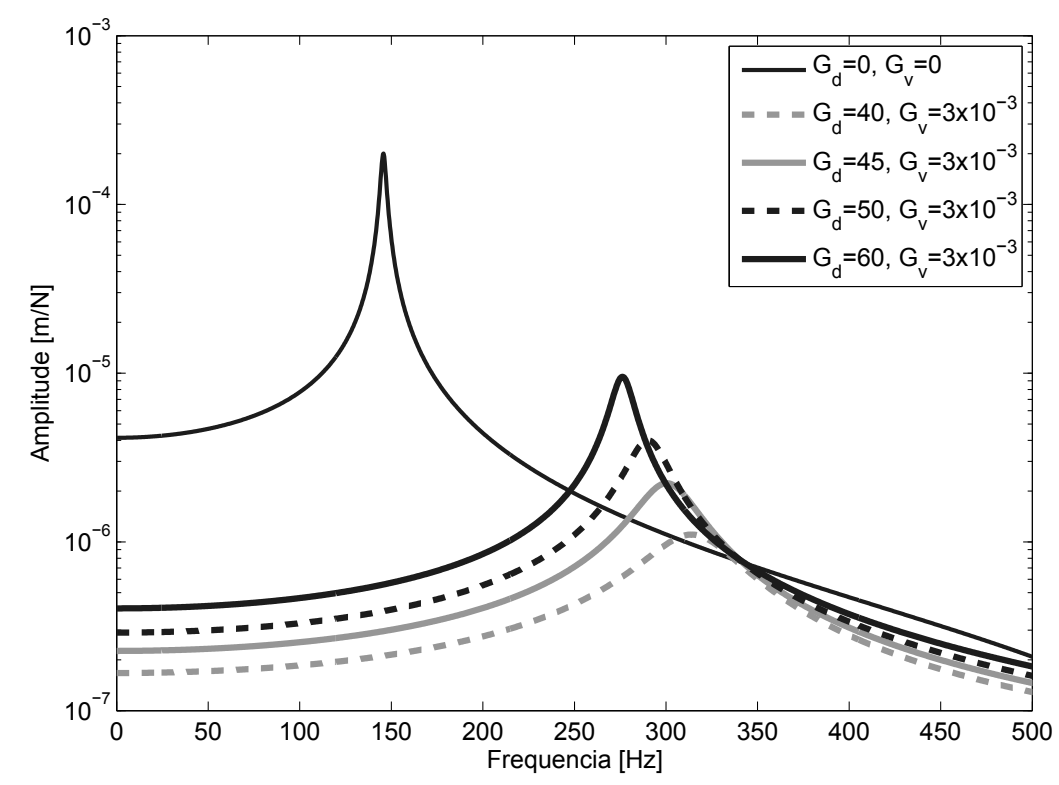

Figura 5.14: FRF com controle de deslocamento e velocidade

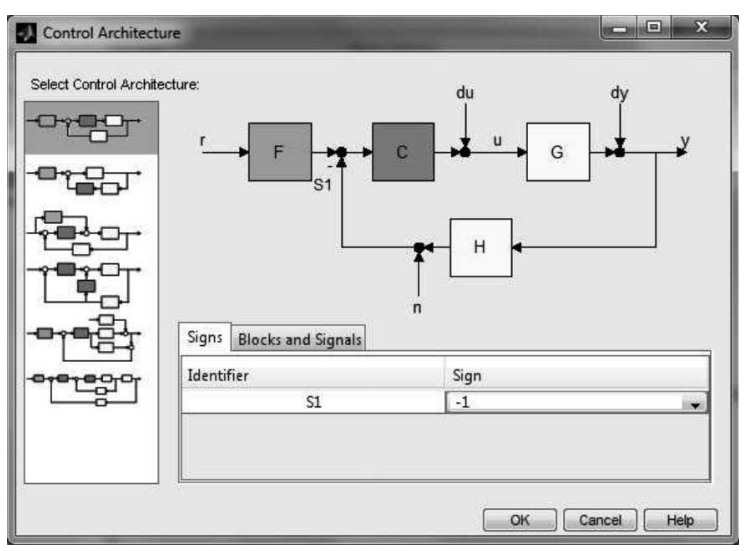

Figura 5.15: Arquitetura básica de controle considerada pela ferramenta SISOTOOL de Matlab ${ }^{\circledR}$

termos do somatório da eq. 3.128 (três primeiros modos). As propriedades geométricas e do material piezelétrico são as mesmas utilizadas nas avaliações numéricas anteriores.

O diagrama de lugar das raízes, sem considerar nenhuma ação de controle, é mostrado na Fig. 5.16 (a). Os seis pólos marcados com $X$ indicam as soluções da equação característica ou denominador da função de transferência $G_{t}$ em malha aberta, e os quatro zeros marcados com $O$ indicam as soluções da equação do numerador. Pode se observar que os pólos e zeros encontram-se de forma alternada indicando as ressonâncias e anti-ressonâncias, e estão levemente deslocados para o lado esquerdo do plano complexo, o que indica a presença do amortecimento considerado para o sistema $(\zeta=0.01)$ (PREUMONT, 2006).

Se na equação de transferência em malha fechada da eq. 3.129 for considerado uma ação de controle com ganho de deslocamento $G_{d}$, este valor seria parte do ganho total do controlador $g_{c}$, obtendo assim o mesmo diagrama da Fig. 5.16. Uma vista detalhada do diagrama do lugar das 


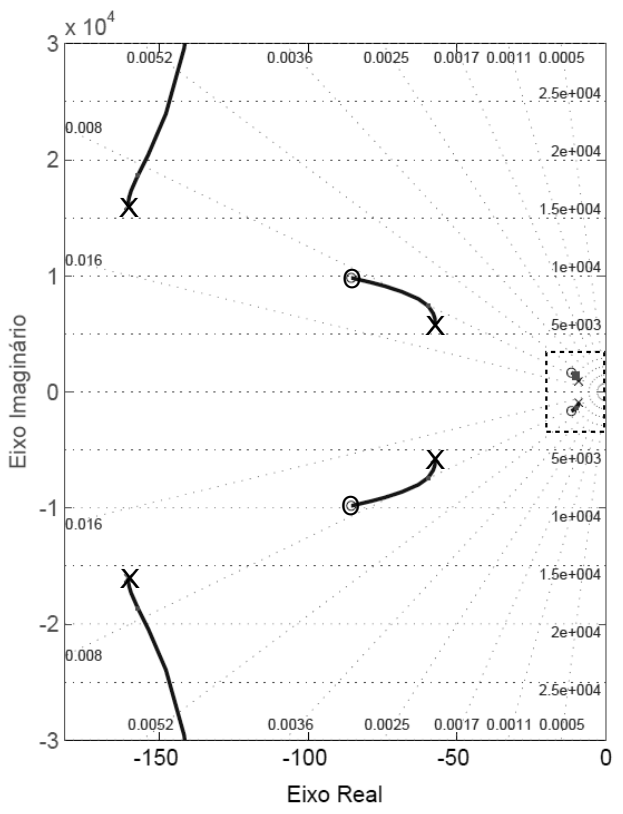

(a)

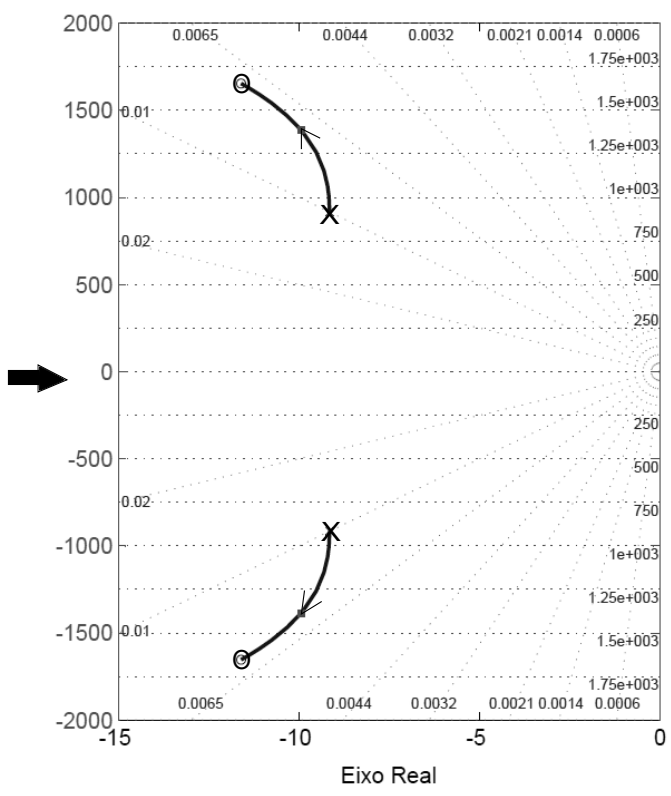

(b)

Figura 5.16: Diagrama do lugar das raízes $G_{t}(s)$ (a) Completo para os três primeiros modos (b) Detalhe para o primeiro modo

raízes para o primeiro modo é ilustrada na Fig. 5.16 (b). Pode se observar que aumentando o ganho de deslocamento (proporcional) o lugar das raízes é deslocado desde os pólos até os zeros, aumentando a frequência de ressonância e modificando levemente a relação de amortecimento.

A Fig. 5.17 (a) ilustra o diagrama do lugar das raízes quando é considerado um ganho de velocidade $G_{v}$ no controlador (derivativo). Esta ação introduz um zero adicional na origem (diferenciador) cujo efeito é puxar o lugar das raízes para o lado esquerdo do plano complexo (OGATA; YANG, 1970). É possível observar que para qualquer valor do ganho de velocidade, as raízes se mantêm no lado direito do plano complexo, razão pela qual o sistema com controle é incondicionalmente estável.

Analisando o detalhe para o primeiro modo na Fig. 5.17 (b), pode se observar que o aumento do ganho de velocidade aumenta consideravelmente a relação de amortecimento até um ponto máximo, depois do qual o valor começa diminuir. Também se encontra o efeito de deslocamento das frequências de ressonância. No entanto, existe uma faixa de valores de ganhos relativamente pequenos que podem aumentar a relação de amortecimento sem uma grande variação da frequência de ressonância.

Utilizando conjuntamente o ganho de deslocamento e velocidade (controlador proporcional - derivativo) é obtido o diagrama do lugar das raízes da Fig. 5.18 (a). É possível observar o efeito da colocação do zero adicional que, quanto mais afastado da origem estiver, puxa o lugar das raízes para o lado esquerdo do terceiro modo, para o lado direito o lugar das raízes dos dois primeiros modos. Igualmente mantêm a estabilidade com o aumento do ganho do controlador.

O detalhe na Fig. 5.18 (b) mostra que, comparado com o controlador com unicamente um ganho de velocidade, o aumento do ganho deste controlador aumenta em menor proporção a 


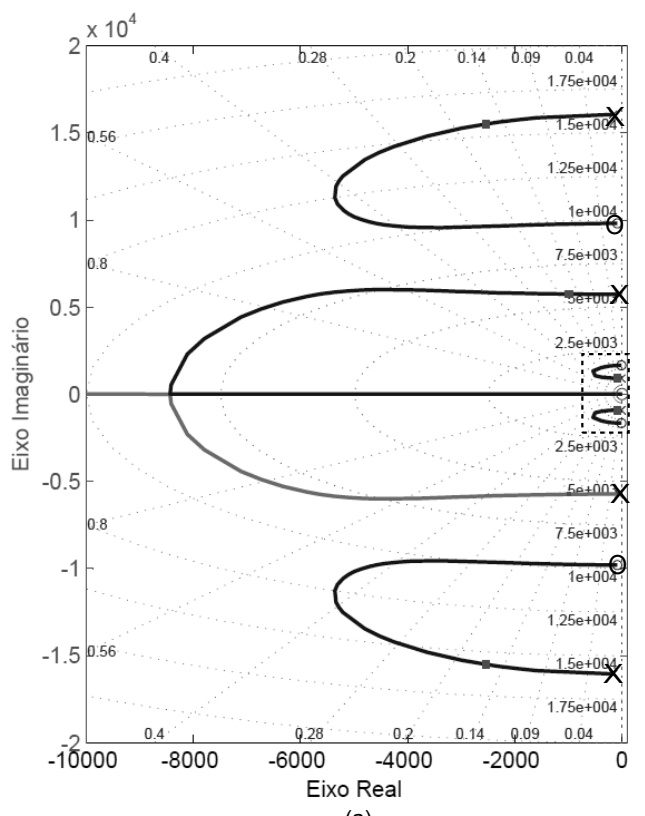

(a)

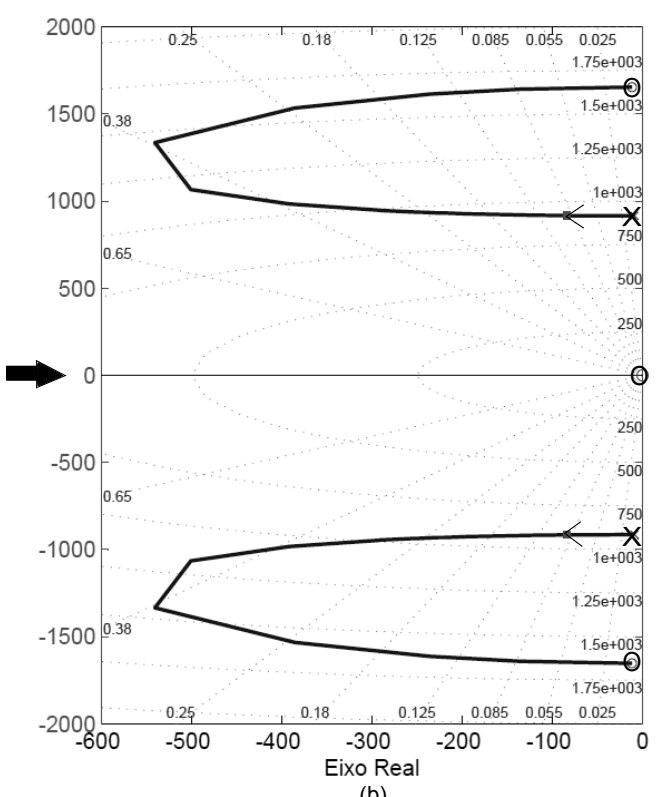

(b)

Figura 5.17: Diagrama do lugar das raízes $G_{t}(s)$ com controle de realimentação de velocidade (a) Completo para os três primeiros modos (b) Detalhe para o primeiro modo

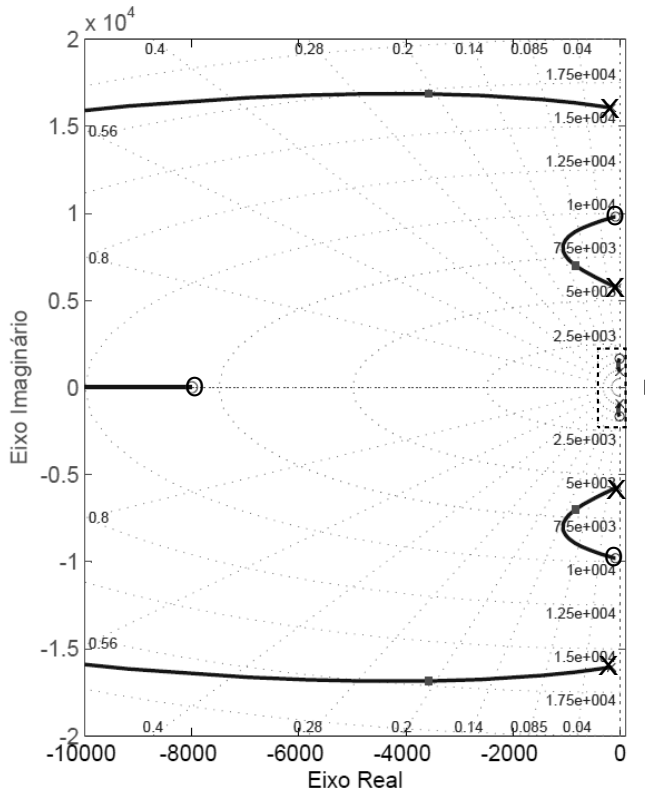

(a)

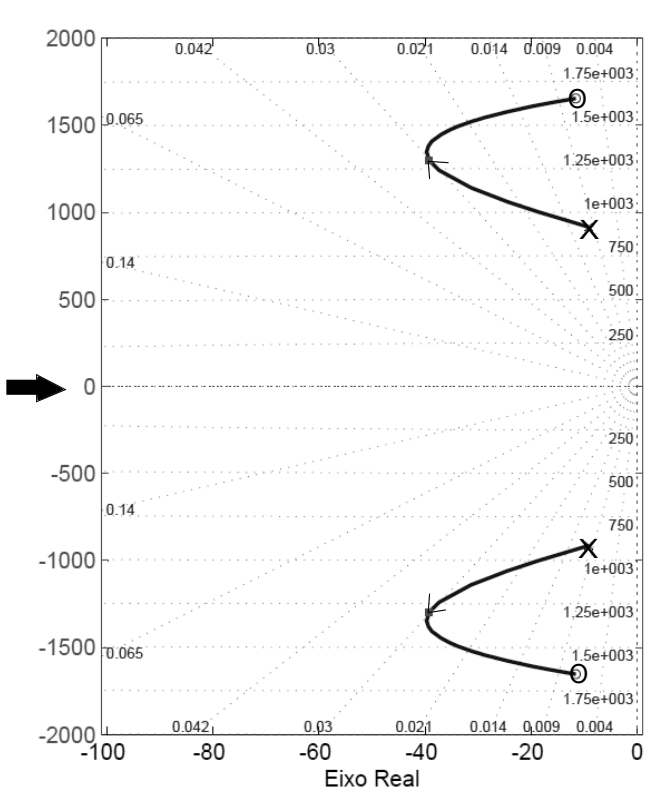

(b)

Figura 5.18: Diagrama do lugar das raízes $G_{t}(s)$ com controle de realimentação de deslocamento e velocidade (a) Completo para os três primeiros modos (b) Detalhe para o primeiro modo

relação de amortecimento, no entanto desloca as frequências de ressonância de maneira mais sensível.

A Fig. 5.19 ilustra o diagrama de bode da função de transferência das tensões do sensor e o atuador, comparando as soluções ativas propostas dentro da faixa de frequência que inclui os três primeiros modos. Pode se observar que o controle de realimentação com ganho de velocidade é a estratégia mais efetiva já que existe uma atenuação dentro da faixa de ressonância para os 
três modos. As soluções que incluem ganho de deslocamento tendem a diminuir a resposta, mas deslocando as frequência de ressonância.

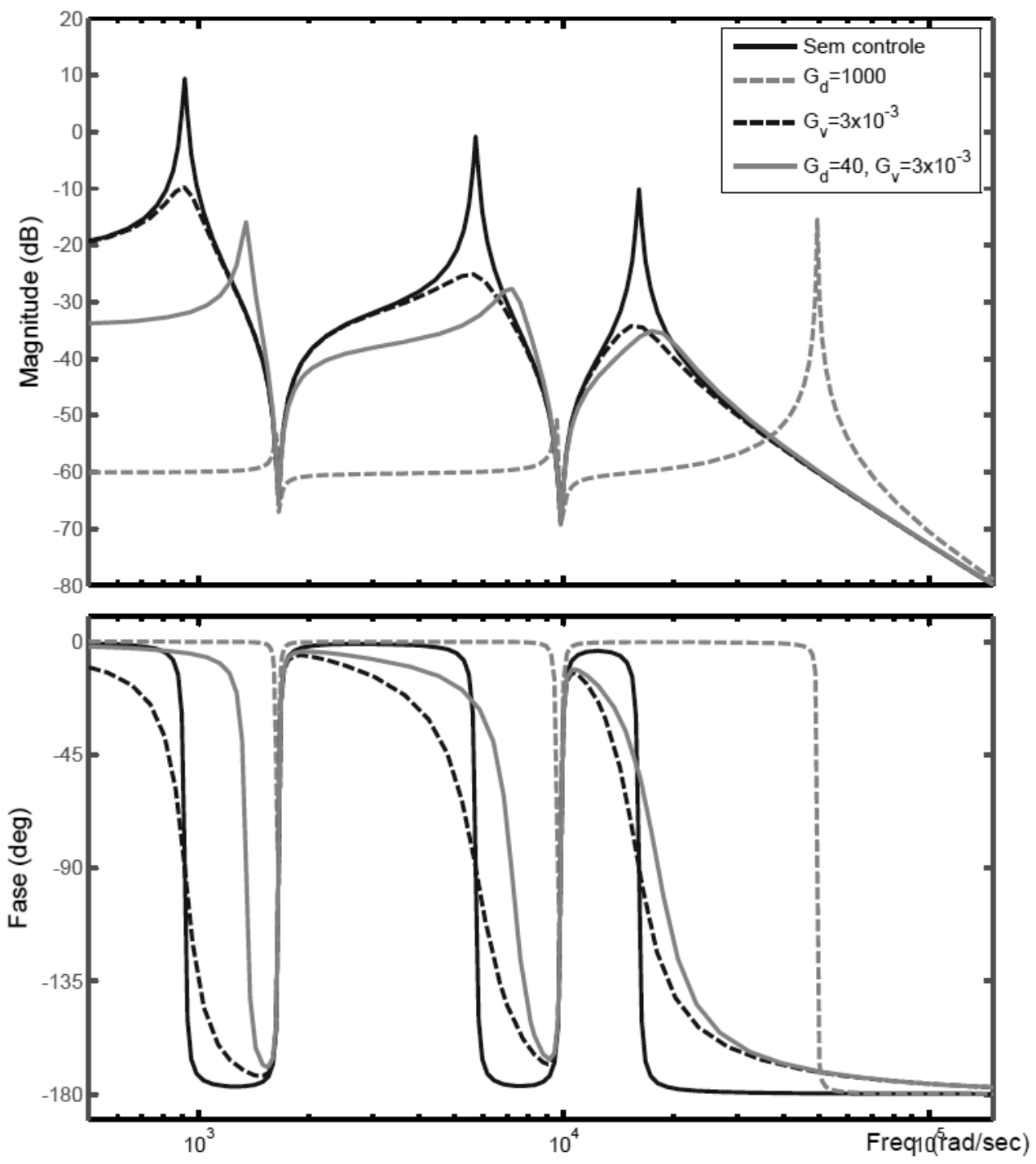

Figura 5.19: Diagrama de bode $G_{t}(s)$ com estrategias de controle ativo

A Fig. 5.20 ilustra a resposta ao impulso unitário para as estratégias de controle ativo, confirmando que o controlador com ganho de velocidade adiciona amortecimento na resposta, diminuindo o tempo de estabelecimento sem afetar o valor final, como acontece com as estratégias de controle que incluem ganho de deslocamento.

\section{Análise da estabilidade das estrategias ativas}

Para analisar a estabilidade do processo de torneamento com estratégias ativas, são obtidas as características dinâmicas detalhadas na tabela 5.6. Os valores de rigidez foram obtidos graficamente das FRF de receptância das Figs. 5.12, 5.13 e 5.14. Os valores das frequências naturais não amortecidas e relações de amortecimento foram obtidos das equações 3.115 e 3.116 .

Os diagramas de lóbulos de estabilidade para as estratégias ativas são plotados na Fig. 5.21, 


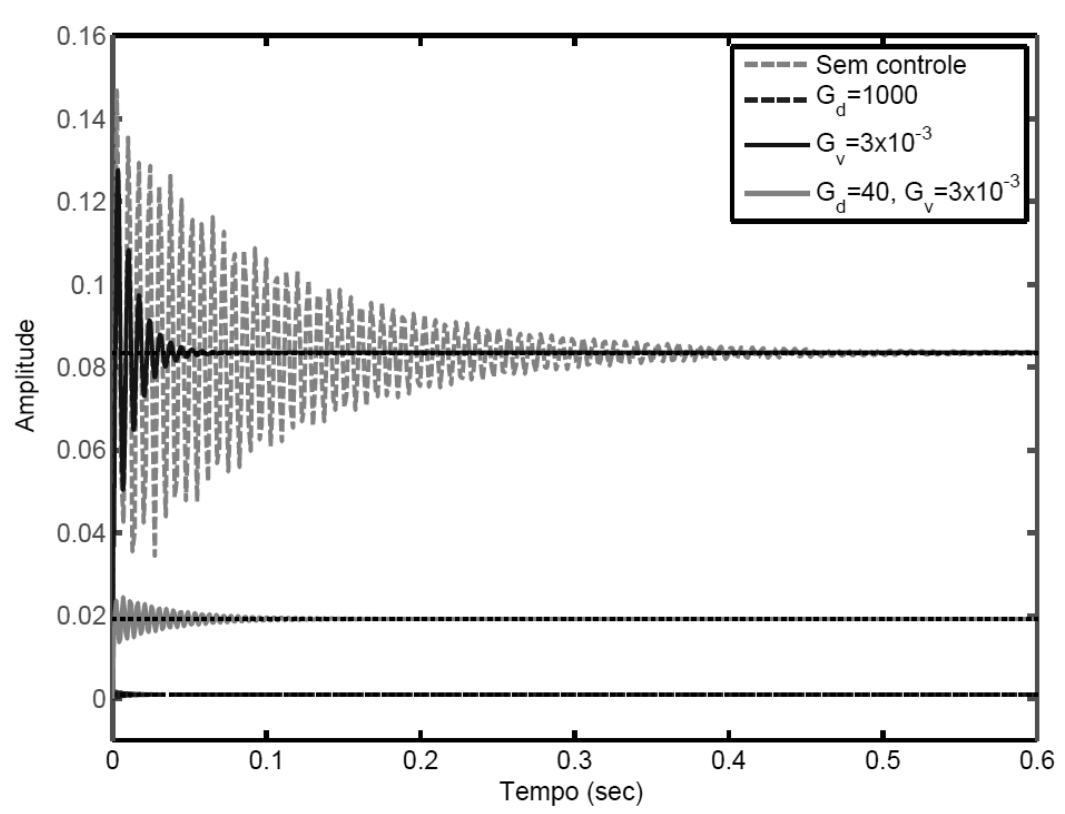

Figura 5.20: Resposta ao impulso unitário para as estratégias de controle ativo

\begin{tabular}{|c||c|c|}
\hline Propriedade & Sem Controle & $G_{v}=3 \cdot 10^{-3}$ \\
\hline \hline Rigidez $K_{r}[N / m]$ & $4.141 \cdot 10^{-6}$ & $4.113 \cdot 10^{-6}$ \\
\hline Amortecimento $\zeta_{r}$ & 0.0100 & 0.0809 \\
\hline Frequência natural $\omega_{r}[H z]$ & 145.6772 & 146.4498 \\
\hline \hline Propriedade & $G_{d}=1000$ & $G_{d}=40, G_{v}=3 \cdot 10^{-3}$ \\
\hline \hline Rigidez $K_{r}[N / m]$ & $9.987 \cdot 10^{-7}$ & $1.1670 \cdot 10^{-7}$ \\
\hline Amortecimento $\zeta_{r}$ & 0.0100 & 0.0772 \\
\hline Frequência natural $\omega_{r}[H z]$ & 233.5617 & 314.6976 \\
\hline
\end{tabular}

Tabela 5.6: Características dinâmicas soluções ativas

usando as equações 2.10 e 2.11. Pode se observar um aumento de estabilidade de aproximadamente 4 vezes o valor para o sistema que usa controle de velocidade com relação ao sistema sem controle. Esse aumento de estabilidade permite escolher, num processo de torneamento, uma profundidade de corte 4 vezes maior para uma determinada velocidade de rotação. Também pode se ver que as estratégias que usam controle de deslocamento, além de reduzir a rigidez do sistema, não melhoram a estabilidade do processo. A estratégia que usa controle de deslocamento e velocidade aumenta o amortecimento, mas a redução na rigidez diminui consideravelmente seu desempenho dentro da estabilidade do processo de usinagem.

\section{Comparação da estabilidade das estratégias passivas e ativas}

O diagrama de lóbulos de estabilidade da Fig. 5.22 compara a estabilidade no processo de torneamento para as soluções passivas e ativas. Pode se observar que as duas estratégias podem ser efetivas para melhorar a estabilidade do processo, no entanto existe um maior aumento do limite de estabilidade para a solução ativa com controle de velocidade. Aliás o ajuste do controlador na solução ativa não depende das características dinâmicas do sistema. Para a so- 


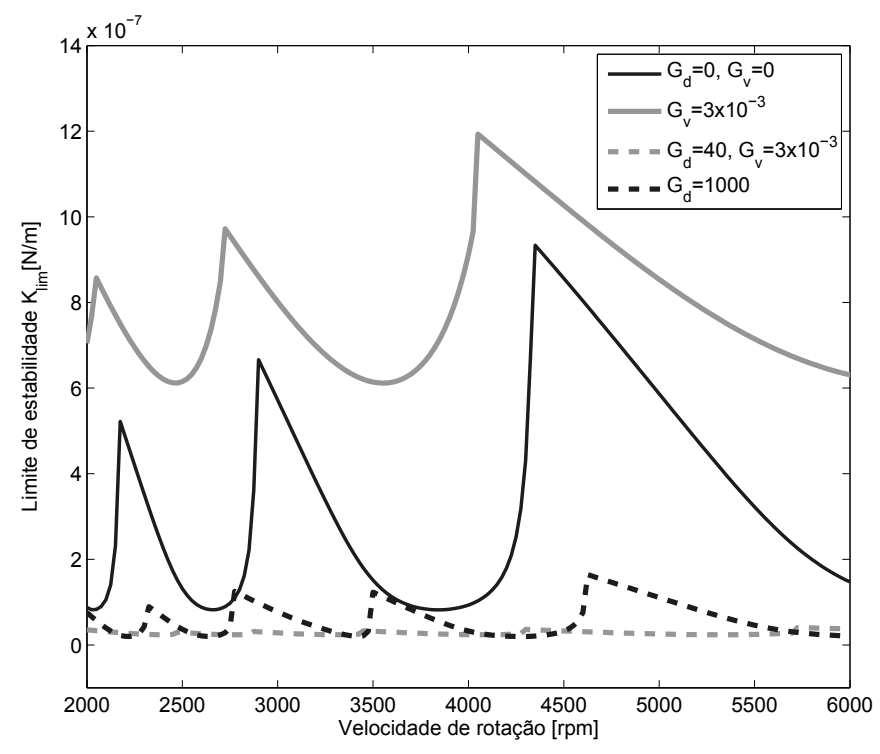

Figura 5.21: Comparação entre diagramas de lóbulos de estabilidade solução ativa

lução passiva isso é uma limitante, já que os valores dos elementos do circuito de dissipação dependem das frequências naturais do sistema (como foi visto na equação 3.68).

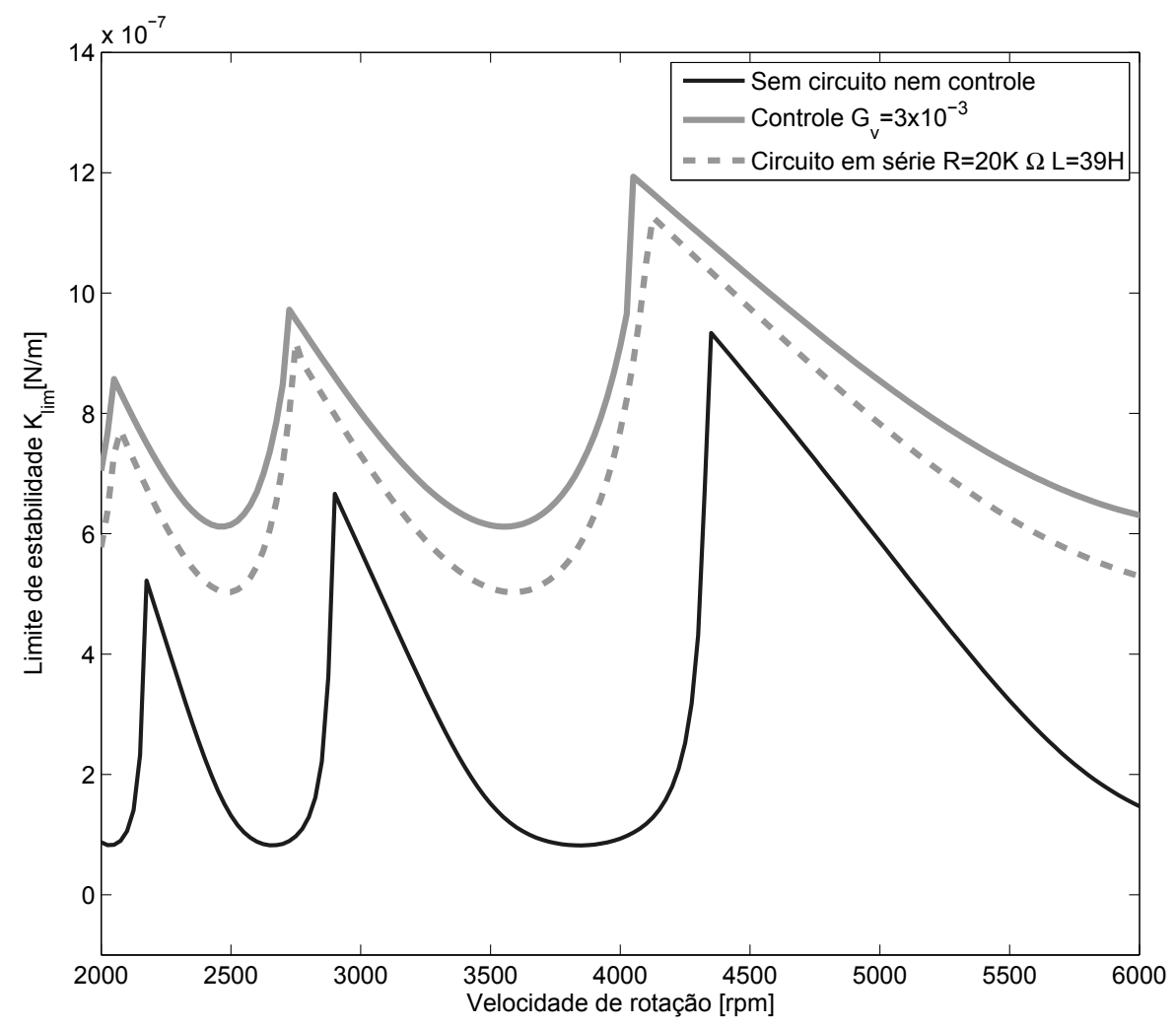

Figura 5.22: Comparação entre diagramas de lóbulos de estabilidade soluções passiva e ativa 


\subsection{Resultados experimentais}

\subsubsection{Resultados medição FRFs}

Nesta seção são comparadas as FRFs do suporte da ferramenta quando são conectados circuitos de dissipação resistivos-indutivos à uma pastilha piezelétrica. Como foi visto na seção de metodologia experimental, são usadas duas pastilhas piezelétricas tentando cobrir a maioria da superfície do suporte da ferramenta. Assim o valor da capacitância da pastilha piezelétrica calculado na eq. 3.40 é modificado pelo comprimento e o número de pastilhas piezelétricas conectadas. Essa modificação afeta o cálculo dos valores ótimos de resistência e indutância do circuito de dissipação.

Outro fator que afeta consideravelmente o cálculo dos valores ótimos, é a variação do coeficiente de acoplamento eletromecânico $K_{31}^{2}$ calculado com a eq. 3.68, devido a variação das frequências de ressonância com diferentes condições de medição e pela resolução do sistema de aquisição. Por essa razão foi proposta a utilização de indutores sintéticos para facilitar o ajuste dos valores ótimos de indutância.

Os valores das frequências de ressonância $\omega_{r}^{D}$ e $\omega_{r}^{E}$ da eq. 3.68, foram obtidas com testes de impacto no software CutPro ${ }^{\circledR}$ registrando os valores de $143.50 \mathrm{~Hz}$ e $144.00 \mathrm{~Hz}$. Assim os valores de resistências e indutâncias usados nos testes de impacto estão descritos na tabela 5.7:

\begin{tabular}{|c|c|c|c|c|}
\hline & \multicolumn{2}{|c|}{ Com 1 pastilha } & \multicolumn{2}{c|}{ Com 2 pastilhas } \\
\cline { 2 - 5 } & série & paralelo & série & paralelo \\
\hline Indutância $[H]$ & 177 & 177 & 88 & 88 \\
\hline Resistência $[k \Omega]$ & 21 & 1200 & 10 & 750 \\
\hline
\end{tabular}

Tabela 5.7: Valores de indutância e resistência dos circuitos de dissipação usados no experimento

Uma vez coletados os valores da resposta no domínio do tempo com uma taxa de amostragem de $50000 \mathrm{~Hz}$ e um tempo de $2 \mathrm{~s}$, é necessário obter as funções de resposta em frequência (FRF) a partir dos dados experimentais com o uso de estimadores. Os estimadores de FRF usam a densidade espectral de força (CPSD pelas siglas em inglês) das sinais de entrada $x$ (a resposta do martelo no domínio do tempo), e da saída y (a resposta do acelerômetro no domínio do tempo). Com o objetivo de desconsiderar o ruído na entrada e diferenciar a magnitude na ressonância, foi selecionado o estimador $H_{2}(\omega)$, o qual relaciona a densidade espectral de força da saída $G_{y y}$ e a densidade espectral da força entre a entrada e a saída $G_{x y}$ (MAIA; SILVA, 1998):

$$
H_{2}(\omega)=\frac{G_{y y}(\omega)}{G_{x y}(\omega)}
$$

A função de densidade espectral de força está definida no software Matlab ${ }^{\circledR}$. Para poder obter os resultados da magnitude da resposta em $d B$ é necessário multiplicar a resposta por 10 vezes o logaritmo da magnitude de $H_{2}(\omega)$.

Na Fig. 5.23 são comparadas as magnitudes das FRFs do sistema suporte ferramenta-pastilhas 
piezelétricas, em circuito aberto e conectadas com os circuitos resistivos-indutivos em série, detalhados anteriormente para uma pastilha e duas pastilhas. É possível observar que a magnitude de resposta máxima é menor para um sistema conectado em série com uma única pastilha piezelétrica.

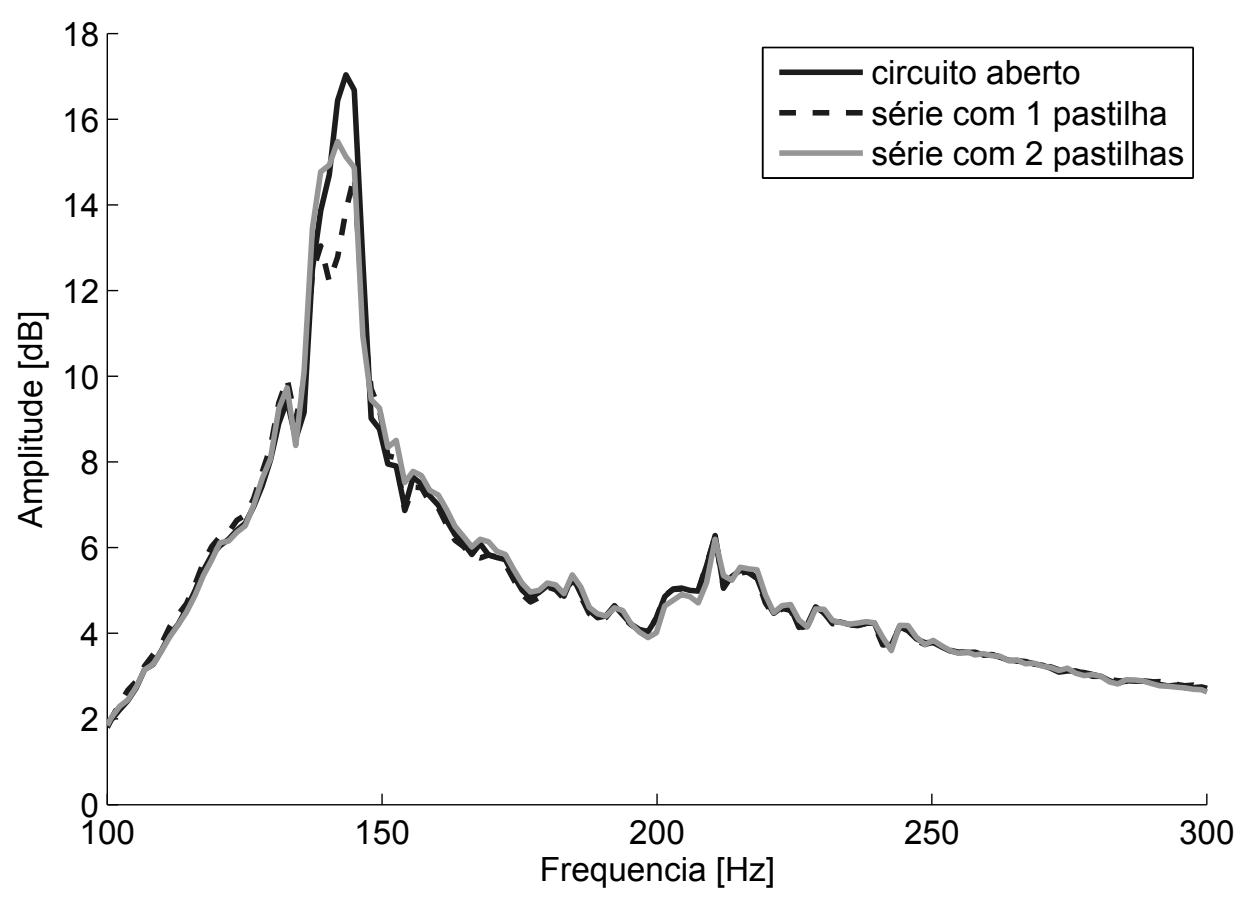

Figura 5.23: Comparação FRF circuitos em série

A Fig. 5.24 mostra a comparação das FRFs dos sistemas com uma e duas pastilhas conectados com circuitos resistivos-indutivos em paralelo. De igual maneira que com os circuitos em série da Fig. 5.23, a resposta é menor para o sistema que trabalha unicamente com uma pastilha. Pode se observar para os dois casos que o comprimento da pastilha piezelétrica, além de afetar os valores ótimos calculados, também afeta a resposta do sistema do suporte da ferramenta.

Na Fig. 5.25 são comparadas as respostas do sistema com uma pastilha conectada a o circuito em série e paralelo. Uma maior diminuição na resposta é conseguida com o circuito de dissipação em série. Além disso o circuito requer uma menor resistência. As respostas estão afetadas pelo ruído no sinal e a resolução na aquisição de dados.

\subsubsection{Resultados torneamento}

A Fig. 5.26 mostra o resultado da usinagem da peça com os parâmetros de torneamento detalhados na seção de metodologia experimental. O suporte da ferramenta foi conectado com o circuito em série, trabalhando com uma única pastilha piezelétrica. Fazendo uma comparação visual é possível diferenciar uma melhora no acabamento superficial da superfície usinada, possivelmente devida à atenuação da resposta com o circuito-resistivo indutivo em série. Essa resposta pode indicar que a solução passiva pode ser efetiva para redução do chatter nessas 


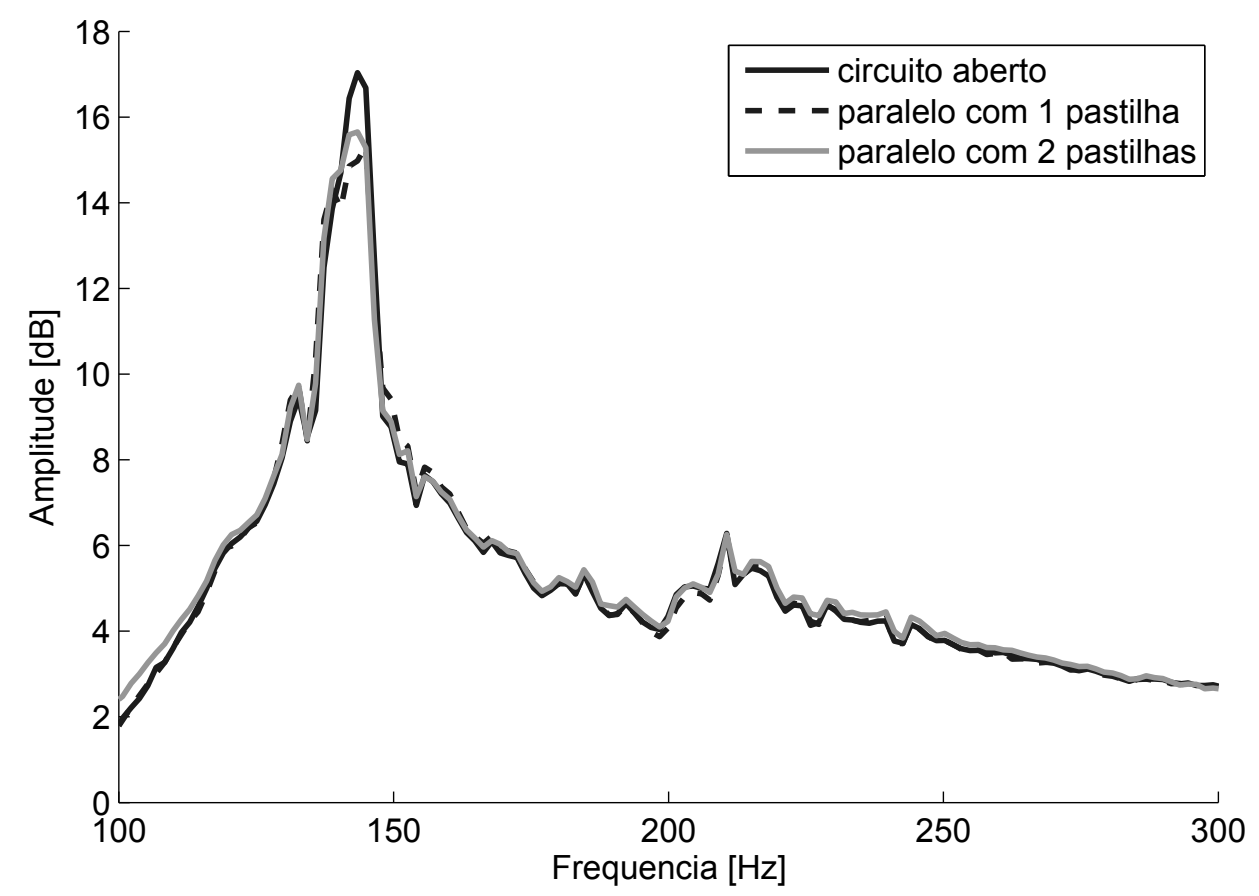

Figura 5.24: Comparação FRF circuitos em paralelo

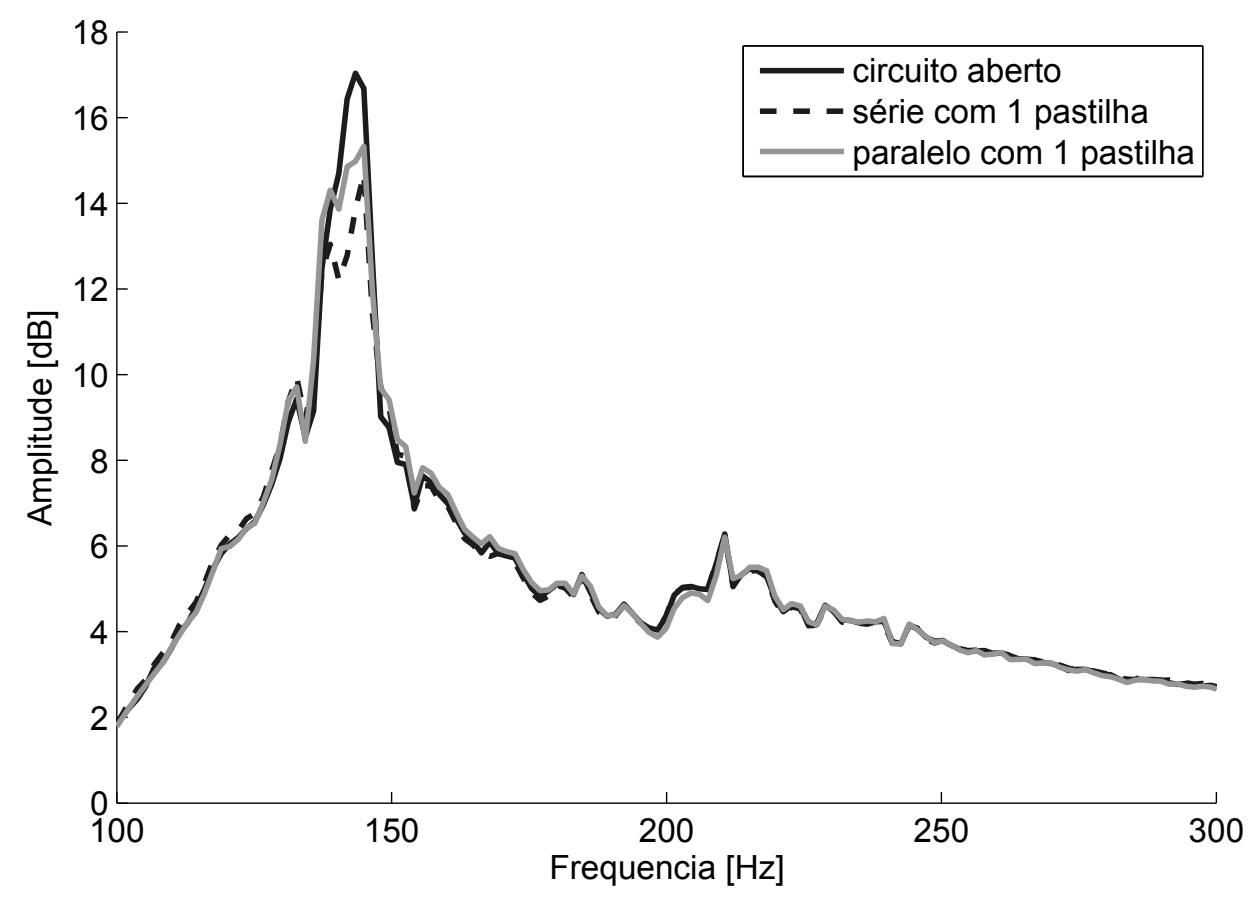

Figura 5.25: Comparação FRF circuitos em série e paralelo

condições de usinagem. 


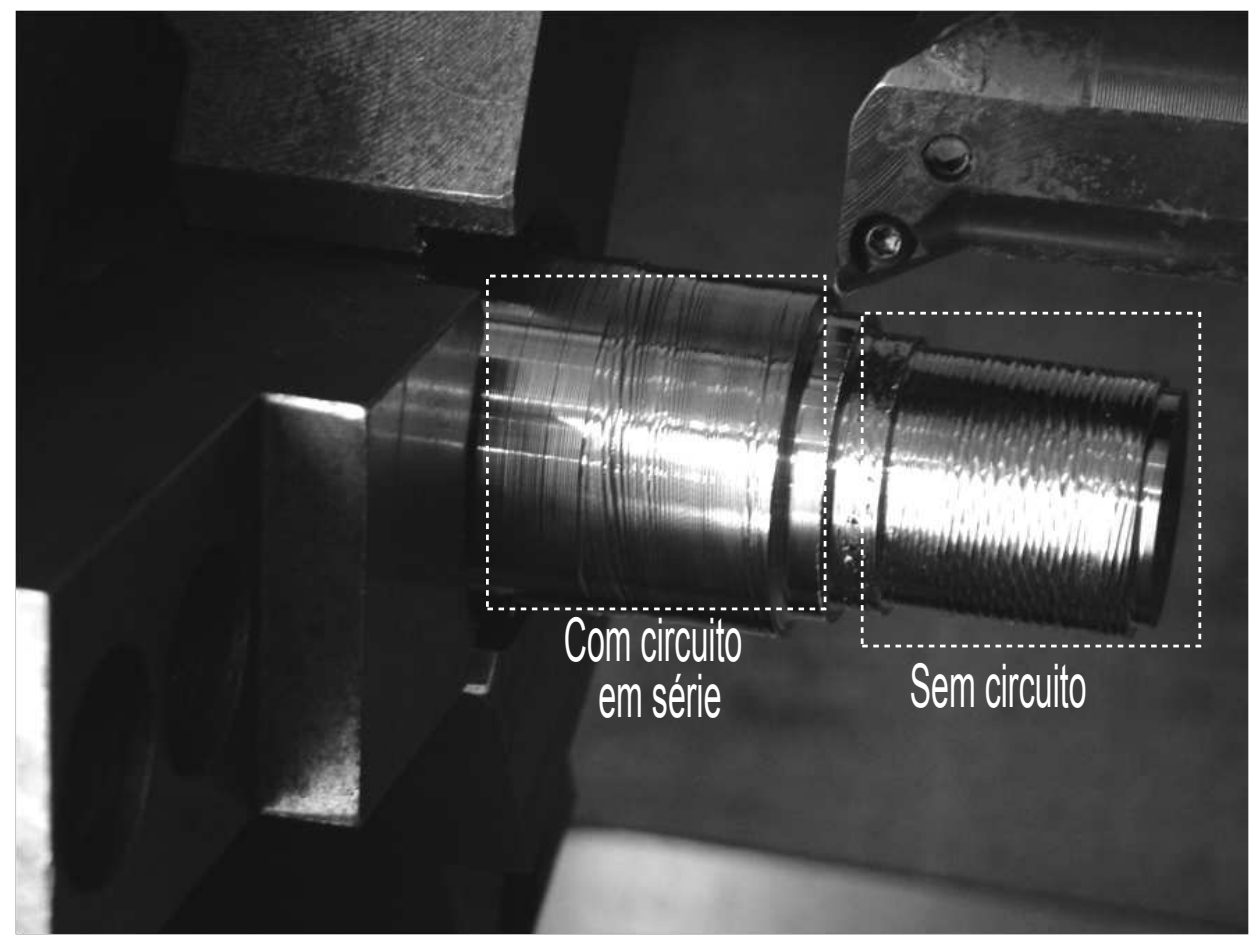

Figura 5.26: Comparação visual acabamento superficial peça usinada 


\section{Capítulo 6}

\section{Conclusões e Sugestões para Trabalhos Futuros}

O presente capítulo apresenta primeiramente as conclusões do trabalho de pesquisa, revisando os conceitos teóricos e analisando a metodologia usada e os resultados obtidos com relação aos objetivos iniciais. A continuação são descritas sugestões para trabalhos futuros, baseadas nas limitações e avanços encontrados nas metodologias propostas, e encontrando oportunidades de pesquisa relacionadas ao trabalho realizado.

\subsection{Conclusões}

- As estratégias passivas mudam as características dinâmicas do sistema melhorando o projeto da máquina-ferramenta ou usando dispositivos adicionais para dissipar a energia. As estratégias ativas precisam de energia externa para o funcionamento de sensores e atuadores que também modificam as características dinâmicas do sistema.

- O modelo eletro-mecânico suporte da ferramenta com as pastilhas piezelétricas acopladas foi baseado na teoria de Euler Bernoulli, sendo considerado como uma viga engastada de seção retangular, e que as pastilhas piezelétricas cobrem todo o comprimento do suporte. Esse modelo facilita a obtenção da função de transferência e o cálculo da resposta ante as cargas de usinagem que serão aplicadas no extremo livre do suporte.

- A solução passiva propõe o uso de um circuito de dissipação de energia conectado às pastilhas piezelétricas. Esses circuitos podem ser resistivos-indutivos conectados em série ou paralelo. Os valores ótimos do circuito de dissipação podem ser calculados considerando as frequências de ressonância do sistema e a capacitância da camada piezelétrica.

- A relativamente baixa frequência de ressonância do suporte da ferramenta influi no cálculo do indutor ótimo que é parte do circuito resistivo-indutivo, devido a que é inversamente proporcional à frequência de ressonância do sistema suporte da ferramenta, portanto são necessários valores de indutância relativamente altos e difíceis de encontrar comercialmente.

- Esses valores de indutância podem ser obtidos utilizando indutores sintéticos, os quais são circuitos formados por resistores, capacitores e amplificadores operacionais cuja res- 
posta ante uma entrada de tensão pode ser comparada com um indutor real numa certa faixa de frequência dependendo das propriedades e valores dos elementos do circuito, principalmente dos amplificadores operacionais. O uso dos indutores sintéticos também oferece uma certa flexibilidade para mudar o valor da indutância equivalente já que requer unicamente a modificação do valor de uma resistência variável dentro do circuito (potenciômetro). Devido a que os amplificadores operacionais requerem de alimentação externa, o uso de indutores sintéticos num circuito de dissipação, torna essa solução como semi-ativa.

- As FRFs obtidas numericamente indicam que o circuito puramente resistivo não modifica consideravelmente as características dinâmicas do sistema, devido a que não existe diferença entre a resposta de um sistema conectado a um circuito aberto, e a resposta de um sistema conectado em curto circuito.

- A resposta para um sistema com um circuito puramente indutivo é semelhante a um absorvedor dinâmico não amortecido, com picos de ressonância e anti-ressonância afiados, indicando que não adiciona amortecimento ao sistema.

- Os sistemas conectados aos circuitos resistivos-indutivos em série ou em paralelo adicionam amortecimento ao sistema na medida que os valores de resistência e indutância possam se aproximar aos valores ótimos. $\mathrm{O}$ valor da indutância influi na aproximação à frequência de ressonância do sistema, e a resistência modifica o amortecimento.

- Observando a resposta do sistema com circuito resistivo -indutivo num diagrama de lóbulos de estabilidade pode se concluir que, teoricamente, a estratégia passiva que usa esse tipo de circuitos pode ser uma solução para a redução do chatter.

- A solução ativa propõe usar uma das pastilhas piezelétricas acopladas no suporte da ferramenta como sensor, e a outra como atuador, e assim aplicar leis de controle de realimentação que modifiquem as características dinâmicas e a resposta dos sistema.

- As FRFs obtidas da avaliação numérica da solução ativa indicam que o controle de realimentação de velocidade adiciona amortecimento no sistema. No entanto existe uma faixa de ganhos de velocidade, na qual as frequências de ressonância e a rigidez do sistema não são modificadas, o qual é requerido para manter a estabilidade do sistema.

- As leis de controle que incluem o ganho de deslocamento reduzem a magnitude da resposta do sistema, mas diminuem a rigidez e deslocam as frequências de ressonância, o qual é um efeito não desejado como estratégia de redução do chatter.

- A análise de lugar das raízes das soluções ativas usa a função de transferência entre a tensão de entrada do sensor e a tensão de saída do atuador. Assim pode se confirmar 
o efeito dos controles de deslocamento (proporcional) e de velocidade (derivativo) nas características do sistema. Com o controle de realimentação de velocidade é possível adicionar amortecimento com ganhos relativamente pequenos, sem diminuir a rigidez e deslocar as frequências de ressonância.

- O limite de estabilidade pode ser melhorado aplicando a estratégia ativa de controle de velocidade. Dessa maneira pode se concluir que, teoricamente esta estratégia é uma solução para a redução do chatter.

- Comparando a estabilidade no processo de torneamento para a solução passiva com circuitos resistivos-indutivos, e a solução ativa com controle de velocidade, pode se concluir que a estratégia ativa aumenta mais a estabilidade, e sua aplicação é mais efetiva e robusta devido a que seu ajuste não seria afetado com a variação das características dinâmicas do sistema.

- Para a avaliação experimental a seleção do circuito de dissipação na estratégia passiva está limitada pela variação das frequências de ressonância medidas e os valores da capacitância da pastilha piezelétrica que variam dependo do seu comprimento real.

- Devido as tensões geradas nos eletrodos das pastilhas piezelétricas pelo efeito piezelétrico direto, é necessário usar um circuito de condicionamento com um divisor de tensão que permita o funcionamento do equipamento de aquisição de dados. Assim também a pastilha piezelétrica que funciona como atuador precisa de um amplificador de tensão.

- A medição das FRFs dos sistemas com circuitos de dissipação indicou atenuação da resposta maior para o sistema com circuito em série e conectado a uma única pastilha piezelétrica. Esta estratégia foi avaliada em testes de torneamento, onde uma inspeção visual da peça mostrou uma melhora no acabamento superficial indicando que baixo essas condições de usinagem a solução passiva reduz as vibrações no processo.

\subsection{Sugestões para trabalhos futuros}

- Obter um modelo eletro-mecânico do suporte da ferramenta que considere sua montagem no cabeçote do torno e assim comparar as características dinâmicas do sistema com o modelo apresentado neste trabalho. Essa modelagem pode ser feita com uma análise de elementos finitos.

- O modelo eletro-mecânico proposto também pode incluir os comprimentos reais da pastilha piezelétrica acoplada, e considerar o efeito da cola, ou o tamanho do eletrodo na obtenção do modelo.

- Obter a resposta quando for aplicado o controle ativo para os demais modos do suporte de ferramenta. $\mathrm{O}$ acoplamento de modos de vibração também pode ter um efeito que pode ser considerado na modelagem teórica, e pode ser identificado mediante testes experimentais. 
- Como alternativa para a solução ativa, podem ser aplicados outros tipos de leis de controle ativo. Um exemplo encontrado na revisão bibliográfica é controle de realimentação de posição positivo (Positive Position Feedback ou PPF pelas siglas em inglês) os quais trabalham com a medição da deformação diretamente. De igual maneira pode ser feito um análise lugar das raízes e da resposta em frequência considerando mais modos de vibração.

- É necessário procurar mais flexibilidade na seleção do circuito de dissipação para a aplicação da estratégia passiva pode ser feita com testes com indutores sintéticos, encontrando faixas donde o circuito resistivo-indutivo pode adicionar amortecimento ao sistema. Também pode ser testado um circuito de chaveamento para atingir vários modos de vibração e aumentar a faixa de operação.

- Na parte experimental podem ser testadas várias condições de usinagem que possam ser localizadas num diagrama de lóbulos de estabilidade obtido numericamente, assim poder comparar a correlação com os dados experimentais.

- Pode ser encontrada uma relação entre a estabilidade do processo e o acabamento superficial, mediante a medição da rugosidade das peças usinadas. 


\section{Referências Bibliográficas}

AL-REGIB, E.; NI, J.; LEE, S. Programming spindle speed variation for machine tool chatter suppression. International Journal of Machine Tools and Manufacture, v. 43, p. 12291240, 2003.

ALBERTELLI, P. et al. Spindle speed variation in turning: technological effectiveness and applicability to real industrial cases. International Journal of Advanced Manufacturing Technology, v. 62, p. 59-67, 2012.

ALTINTAS, Y. Manufacturing Automation. [S.1.]: Cambridge University Press, 2000.

ALTINTAS, Y.; EYNIAN, M.; ONOZUKA, H. Identification of dynamic cutting force coefficients and chatter stability with process damping. CIRP Annals, v. 57, p. 371-374, 2008.

ANTONIOU, A. Realisation of gyrators using operational amplifiers, and their use in rc-active-network synthesis. Proceedings of the Institution of Electrical Engineers, v. 116, p. 1838-1850, 1969.

AST, A. et al. Adaptronic vibration damping for machine tools. CIRP Annals, v. 56(1), p. 379-382, 2007.

BAMBERGER, H. et al. Identification of machining chatter marks on surfaces of automotive valve seats. Journal of Manufacturing Science and Engineering, v. 133, p. 041003 1-7, 2011.

BEDIAGA, I. et al. An automatic spindle speed selection strategy to obtain stability in high-speed milling. International Journal of Machine Tools and Manufacture, v. 49, p. 384-394, 2009.

CARUSO, G. A critical analysis of electric shunt circuits employed in piezoelectric passive vibration damping. Smart Materials and Structures, v. 10, p. 1059-1068, 2001.

CHEN, M.; KNOSPE, C. R. Control approaches to the suppression of machining chatter using active magnetic bearings. IEEE Transactions on Control Systems Technology, v. 15, p. 220-232, 2007.

CRAIG, R.; KURDILA, A. Fundamentals of Structural Dynamics. [S.1.]: Wiley, 2006.

DA SILVA, M. M. et al. Regenerative chatter reduction through passive damping: numerical evaluation. Proceedings of the 2010 IEEE/ASME International Conference on Advanced Intelligent Mechatronics Montréal, Canada, , p. 1-6, 2010.

DE SOUZA, A. F.; COELHO, R. T. Experimental investigation of feed rate limitations on high speed milling aimed at industrial applications. International Journal of Advanced Manufacturing Technology, v. 32 (11-12), p. 1104-1114, 2007. 
ERTURK, A.; INMAN, D. J. A distribuited parameter electromechanical model for cantilivered piezoelectric energy harvesters. Journal of Vibration and Acoustics, v. 130, p. 1-15, 2008.

ERTURK, A.; INMAN, D. J. Issues in mathematical modeling of piezoelectric energy harvesters. Smart Materials and Structures, v. 17, p. 1-14, 2008.

ERTURK, A.; INMAN, D. J. Piezoelectric shunt damping for chatter suppression in machining processed. In: Proceedings of the International Conference on Noise and Vibration Engineering (ISMA 2009), Leuven, Bélgica. [S.1.: s.n.], 2009. p. 193-207.

EYNIAN, M.; ALTINTAS, Y. Chatter stability of general turning operations with process damping. Journal of Manufacturing Science and Engineering, v. 131, p. 041005 1-10, 2009.

GANGULI, A. Chatter reduction through active vibration damping. Dissertação (Mestrado) - Université Libre de Bruxelles, Bélgica, 2005.

GANGUli, A.; DERAEMAEKER, A.; A., P. Regenerative chatter reduction by active damping control. Journal of Sound and Vibration, v. 300, p. 847-862, 2007.

GRANIER, J.; HUNDHAUSEN, R.; GAYTAN, G. Passive modal damping with piezoelectric shunts. In: SPIE proceedings series. Society of Photo-Optical Instrumentation Engineers. [S.1.: s.n.], 2002.

HAGOOD, N. W.; VON FLOTOW, A. Damping of structural vibrations with piezoelectric materials and passive electrical networks. Journal of Sound and Vibration, v. 146, p. 243-268, 1991.

HOLLKAMP, J. J. Multimodal passive vibration suppression with piezoelectric materials and resonant shunts. Journal of Intelligent Material Systems and Structures, v. 5, p. 49-57, 1994.

HOUCK, L.; SCHMITZ, T. L.; SMITH, K. S. A tuned holder for increased boring bar dynamic stiffness. Journal of Manufacturing Processes, v. 13, p. 24-29, 2011.

HUO, D.; CHENG, K. Machining Dynamics. [S.1.]: Springer, 2009.

IEEE. IEEE Standard on Piezoelectricity. 1988.

JEMIELNIAK, K.; WIDOTA, A. Suppression of self-excited vibration by the spindle speed variation method. International Journal of Machine Tool Design and Research, v. 24, p. 207-214, 1984.

KAYACIK, O. et al. Integral equation approach for piezo patch vibration control of beams with various types of damping. Computers and Structures, v. 86, p. 357-366, 2008.

KELLY, K.; YOUNG, P.; BYRNE, G. Modelling the influence of machining dynamics on surface topography in turning. International Journal of Mechanical Sciences, v. 41, p. 507-526, 1999.

KIM, H. S.; KIM, J. H.; KIM, J. A review of piezoelectric energy harvesting based on vibration. International Journal of Precision Engeneering and Manufacturing, v. 12, p. 1129-1141, 2011. 
KIM, J. D.; NAM, S. R. Development of a micro-depth control system for an ultra-precision lathe using a piezo-electric actuator. International Journal of Machine Tools and Manufacture, v. 37, p. 495-509, 1997.

LEE, D. G.; HWANG, H. Y.; KIM, J. K. Design and manufacture of a carbon fiber epoxy rotating boring bar. Composite Structures, v. 60, p. 115-124, 2003.

LEO, D. J. Engineering Analysis of Smart Material Systems. [S.1.]: Jhon Wiley and Sons, 2007.

LU, K. et al. Industrial applications of a system for chatter stability prediction and monitoring. In: Proceedings of the ASME 2011 International Mechanical Engineering Congress and Exposition IMECE2011. [S.1.: s.n.], 2011.

MA, C. et al. Analysis of regenerative chatter suppression with adding the ultrasonic elliptical vibration on the cutting tool. Precision Engineering, v. 35, p. 329-338, 2011.

MAIA, N. M.; SILVA, J. M. Theoretical and Experimental Modal Analysis. [S.1.]: Research Studies Press Ltd., 1998.

MAKSOUD, T. M. A.; MAKBEL, A. A. Suppression of chatter in grinding using high-viscosity coolants. Journal of Engineering Manufacture, v. 216, p. 116-123, 2012.

MEI, C. Active regenerative chatter suppression during boring manufacturing process. Robotics and Computer-Integrated Manufacturing, v. 21, p. 153-158, 2005.

MEI, D. et al. Magnetorheological fluid-controlled boring bar for chatter suppression. Journal of Materials Processing Technology, v. 209, p. 1861-1870, 2009.

MEI, D. et al. Parameter optimization of time-varying stiffness method for chatter suppression based on magnetorheological fluid-controlled boring bar. International Journal of Advanced Manufacturing Technology, v. 46, p. 1071-1083, 2010.

MEI, Z. et al. Active chatter suppression by on-line variation of the rake and clearance angles in turning. principles and experimental investigations. International Journal of Machine Tools and Manufacture, v. 34, p. 981-990, 1994.

MERRIT, H. E. Theory of self excited machine tool chatter. ASME Journal of Engineering for Industry, v. 87, p. 447-454, 1965.

MIGUéLEZ, M. H. et al. Improvement of chatter stability in boring operations with passive vibration absorbers. International Journal of Mechanical Sciences, v. 52, p. 1376-1384, 2010.

MORADI, H.; BAKHTIARI-NEJAD, F.; MOVAHHEDY, M. R. Tuneable vibration absorber design to suppress vibrations: An application in boring manufacturing process. Journal of Sound and Vibration, v. 318, p. 93-108, 2008.

NAGANO, S. et al. Development of a composite boring bar. Composite Structures, v. 38, p. 531-539, 1997.

NOVAKOV, T.; JACKSON, M. J. Chatter problems in micro- and macrocutting operations, existing models, and influential parametersa review. International Journal of Advanced Manufacturing Technology, v. 47, p. 597-620, 2010. 
OGATA, K.; YANG, Y. Modern control engineering. [S.1.: s.n.], 1970.

OLGAC, N.; HOLM-HANSEN, B. T. A novel active vibration absorption technique: Delayed resonator. Journal of Sound and Vibration, v. 176, p. 93-104, 1994.

PARK, G. et al. The use of active materials for machining processes: A review. International Journal of Machine Tools and Manufacture, v. 47, p. 2189-2206, 2007.

PARK, S. S.; QIN, Y. M. Robust regenerative chatter stability in machine tools. International Journal of Advanced Manufacturing Technology, v. 33, p. 389-402, 2007.

PARK, S. S.; RAHNAMA, R. Robust chatter stability in micro-milling operations. CIRP Annals, v. 59, p. 391-394, 2010.

PREUMONT, A. Vibration Control of Active Structures An Introduction. [S.1.]: Kluwer Academic Publishers, 2002.

PREUMONT, A. Mechatronics Dynamics of Electromechanical and Piezoelectric Systems. [S.1.]: Springer, 2006.

QUINTANA, G.; CIURANA, J. Chatter in machining processes: A review. International Journal of Machine Tools and Manufacture, v. 51, p. 363-376, 2011.

RADECKI, P. P. et al. Vibration suppression in cutting tools using a collocated piezoelectric sensor/actuator with an adaptive control algorithm. Journal of Vibration and Acoustics, v. 132, p. $0510021-8,2010$.

RADECKI, P. P. et al. Improving a turning process using piezoelectric actuators. In: Proceedings of the IMAC-XXVII. [S.1.: s.n.], 2009.

RAO, S. Mechanical Vibrations. [S.1.]: Addison-Wesley Publishing Company, 1995.

SANDVIK-COROMANT. Silent Tools. [S.1.].

SHETTY, D.; ALI, A.; HILL, J. Optical instrumentation for vibration measurement and monitoring. International Journal of Precision Engineering and Manufacturing, v. 12, p. 405-411, 2011.

SIDDHPURA, M.; PAROUBALLY, R. A review of chatter vibration research in turning. International Journal of Machine Tools and Manufacture, v. 61, p. 27-47, 2012.

SIMS, N. D. Machining Dynamics. [S.1.]: Springer, 2009.

SIMS, N. D.; BAYLY, P. V.; YOUNG, K. A. Piezoelectric sensors and actuators for milling tool stability lobes. Journal of Sound and Vibration, v. 281, p. 743-762, 2005.

SINOCERA. http://www.sinocera.net/en/piezomaterial.asp. [S.1.].

SMIRNOVA, T. Dynamic Analysis and Modeling of Machine Tool Parts. Tese de doutorado. Dissertação (Mestrado) - Blekinge Institute of Technology Licentiate Dissertation Series, Suécia, 2008.

TARNG, Y. S.; KAO, J. Y.; LEE, E. C. Chatter suppression in turning operations with a tuned vibration absorber. Journal of Materials Processing Technology, v. 105, p. 55-60, 2000. 
TAYLOR, C. M.; TURNER, S.; SIMS, N. D. Chatter, process damping, and chip segmentation in turning: A signal processing approach. Journal of Sound And Vibration, v. 329, p. 4922-4935, 2010.

TLUSTY, J.; POLACEK, M. The stability of machine tools against self excited vibrations in machining. International Research in Production Engineering, p. 465-474, 1963.

TOBIAS, S. A.; FISHWICK, W. A theory of regenerative chatter. Engineering, v. 205, 1958.

VIANA, F.; STEFFEN, V. Multimodal vibration damping through piezoelectric patches and optimal resonant shunt circuits. Journal of the Brazilian Society Of Mechanical Sciences and Engineering, v. 28, p. 293-310, 2006.

WANG, M. et al. Design and implementation of nonlinear tmd for chatter suppression: An application in turning processes. International Journal of Machine Tools and Manufacture, v. 50, p. 474-479, 2010.

WU, S. Y. Piezoelectric shunts with parallel r-l circuit for structural damping and vibration control. SPIE Smart Structures and Materials, Passive Damping and Isolation, v. 2720, p. 259-269, 1996.

YANG, Y.; MUñOA, J.; ALTINTAS, Y. Optimization of multiple tuned mass dampers to suppress machine tool chatter. International Journal of Machine Tools and Manufacture, v. 50, p. 834-842, 2010.

YUSOFF, A. R.; SIMS, N. D. Optimisation of variable helix tool geometry for regenerative chatter mitigation. International Journal of Machine Tools and Manufacture, v. 51, p. 133-141, 2011.

ZHANG, Y.; SIMS, N. Milling workpiece chatter avoidance using piezoelectric active damping: a feasibility study. Smart Materials and Structures, v. 14, p. 65-70, 2005. 